\title{
2020 Cost Analysis of Hydropower Options at Non-Powered Dams
}

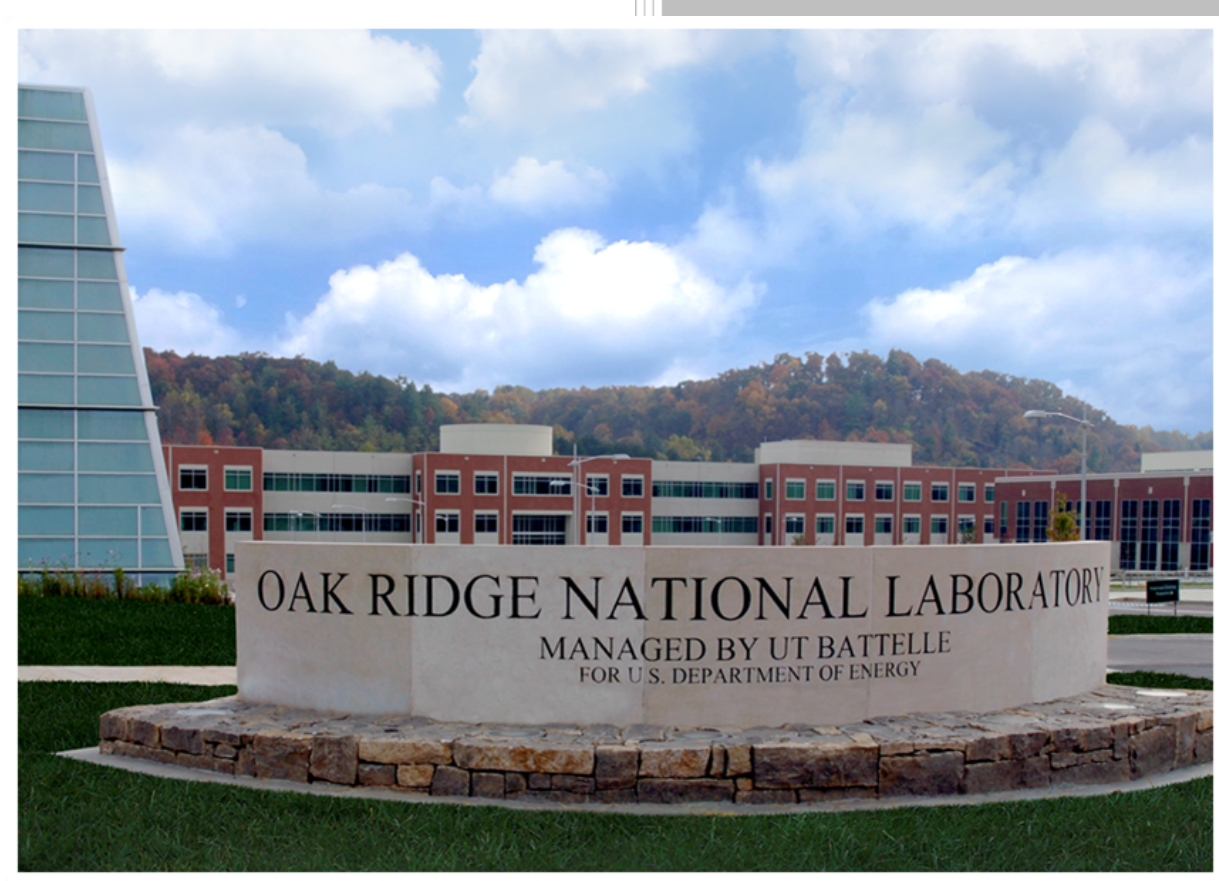

Approved for public release. Distribution is unlimited.

Gbadebo Oladosu

Lindsay George

Jeremy Wells

March 2021 


\title{
DOCUMENT AVAILABILITY
}

Reports produced after January 1, 1996, are generally available free via US Department of Energy (DOE) SciTech Connect.

Website www.osti.gov

Reports produced before January 1, 1996, may be purchased by members of the public from the following source:

\author{
National Technical Information Service \\ 5285 Port Royal Road \\ Springfield, VA 22161 \\ Telephone 703-605-6000 (1-800-553-6847) \\ TDD 703-487-4639 \\ Fax 703-605-6900 \\ E-mail info@ntis.gov \\ Website http://classic.ntis.gov/
}

Reports are available to DOE employees, DOE contractors, Energy Technology Data Exchange representatives, and International Nuclear Information System representatives from the following source:

Office of Scientific and Technical Information

PO Box 62

Oak Ridge, TN 37831

Telephone 865-576-8401

Fax 865-576-5728

E-mail reports@osti.gov

Website http://www.osti.gov/contact.html

This report was prepared as an account of work sponsored by an agency of the United States Government. Neither the United States Government nor any agency thereof, nor any of their employees, makes any warranty, express or implied, or assumes any legal liability or responsibility for the accuracy, completeness, or usefulness of any information, apparatus, product, or process disclosed, or represents that its use would not infringe privately owned rights. Reference herein to any specific commercial product, process, or service by trade name, trademark, manufacturer, or otherwise, does not necessarily constitute or imply its endorsement, recommendation, or favoring by the United States Government or any agency thereof. The views and opinions of authors expressed herein do not necessarily state or reflect those of the United States Government or any agency thereof. 
Environmental Sciences Division

\title{
2020 COST ANALYSIS OF HYDROPOWER OPTIONS AT NON-POWERED DAMS
}

\author{
Gbadebo Oladosu ${ }^{1}$ \\ Lindsay George ${ }^{2}$ \\ Jeremy Wells ${ }^{3}$
}

${ }^{1}$ Oak Ridge National Laboratory

${ }^{2}$ Small Hydro Consultants

${ }^{3}$ Wells Engineering, LLC

March 2021

\author{
Prepared by \\ OAK RIDGE NATIONAL LABORATORY \\ Oak Ridge, TN 37831-6283 \\ managed by \\ UT-BATTELLE, LLC \\ for the \\ US DEPARTMENT OF ENERGY \\ under contract DE-AC05-00OR22725
}





\section{CONTENTS}

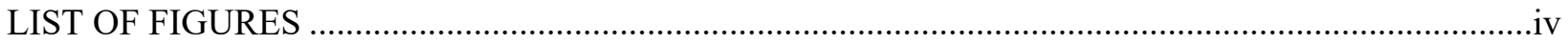

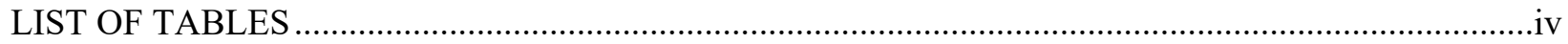

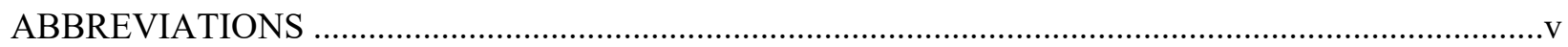

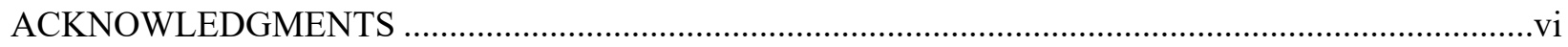

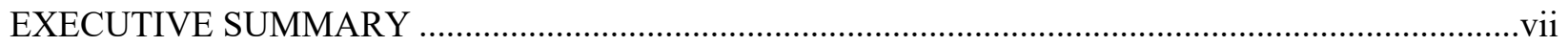

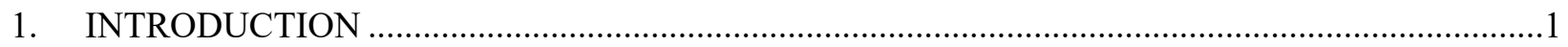

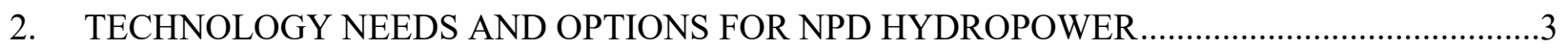

2.1 OVERVIEW OF HYDROPOWER TECHNOLOGY INNOVATIONS ...............................4

2.2 TURBINE-GENERATORS AND CIVIL WORKS INNOVATIONS …................................

2.3 ENVIRONMENTAL IMPACT MITIGATION INNOVATIONS .......................................

3. DATA AND METHODOLOGY FOR NPD COST ANALYSIS .................................................

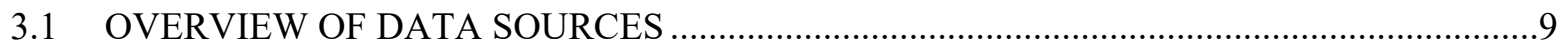

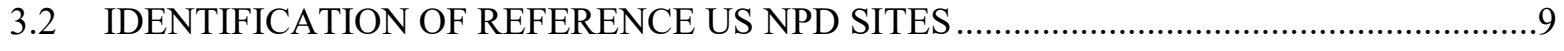

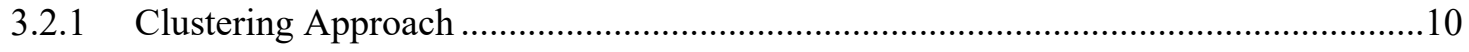

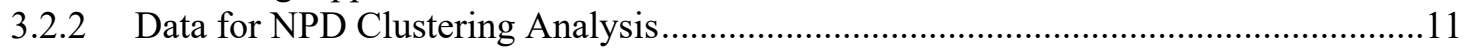

3.3 COST ANALYSIS METHODOLOGY FOR REFERENCE SITES ..................................12

3.3.1 Basic Features of the smHIDEA Model .................................................................13

3.3.2 Updates to smHIDEA Model Capabilities since 2019 ...............................................13

3.3.3 Key Parameters and Assumptions for smHIDEA Simulation .....................................16

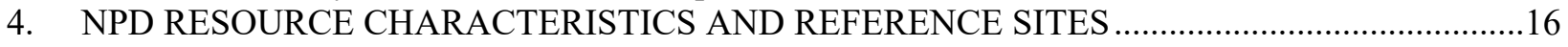

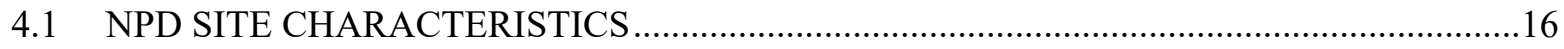

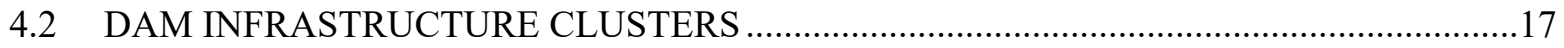

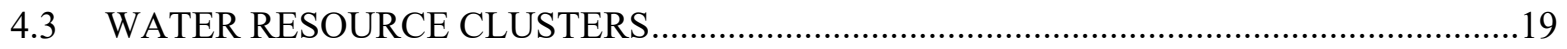

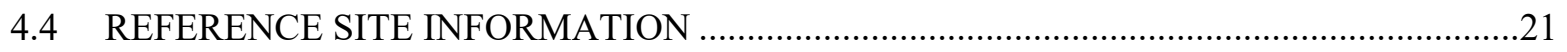

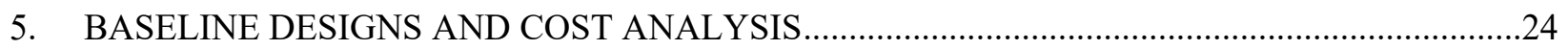

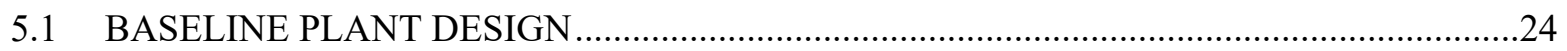

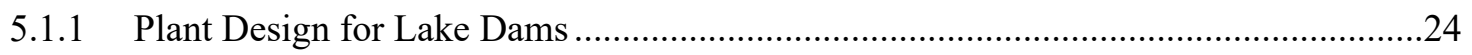

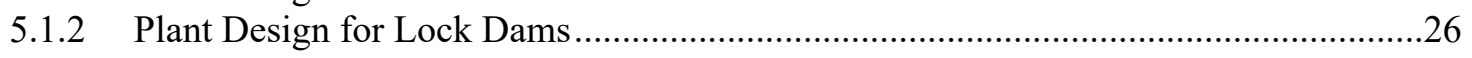

5.2 BASELINE INSTALLATION CAPACITY AND COST ESTIMATES ..............................27

5.3 BASELINE PERFORMANCE SIMULATION RESULTS .....................................................

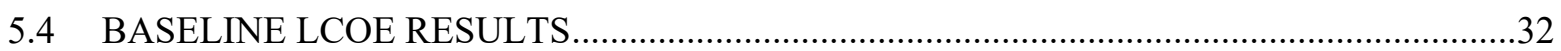

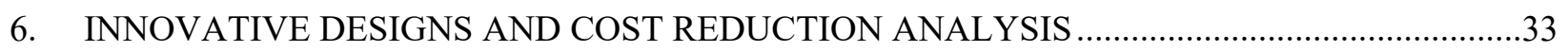

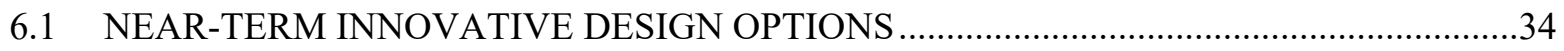

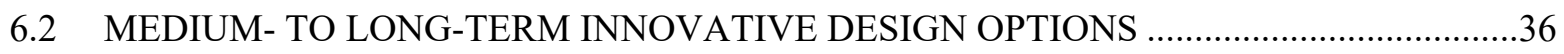

6.3 NEAR-TERM VS. BASELINE CAPACITY AND CAPITAL COSTS ....................................38

6.4 NEAR-TERM VS. BASELINE CAPACITY FACTOR AND LCOE ESTIMATES ...............41

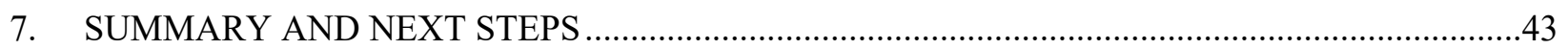

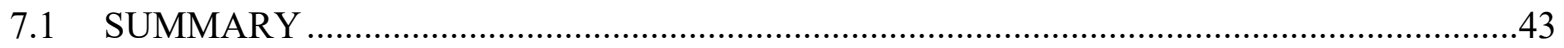

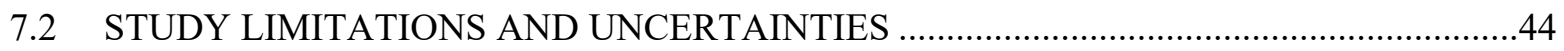

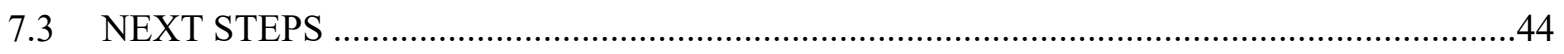

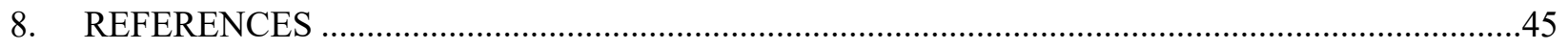

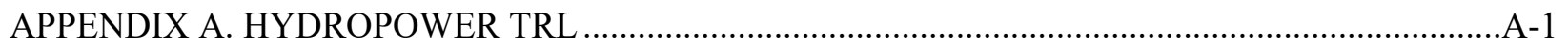

APPENDIX B. NPD INFRASTRUCTURE AND RESOURCE CLUSTERS …...................................

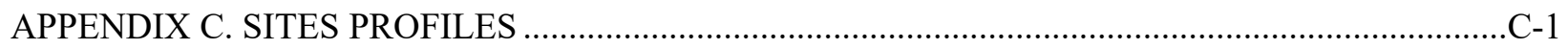

APPENDIX D. BASELINE GENERATION AND EFFICIENCY PROFILES …................................ 


\section{LIST OF FIGURES}

Figure 1. Illustration of the idealized R\&D challenges and opportunities for hydropower........................2

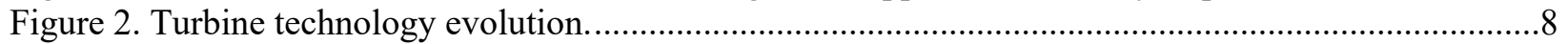

Figure 3. Locations of $\sim 600$ NPD sites with potential capacities $>1$ MW . .........................................10

Figure 4. Schematic of the two-level dam infrastructure and water resource clustering...........................11

Figure 5. Schematic of the smHIDEA modeling framework.................................................................14

Figure 6. Estimated capacity potentials $(\geq 100 \mathrm{~kW})$ from the ORNL NPD resource assessment...............17

Figure 7. Dam infrastructure clusters characteristics and member counts...............................................18

Figure 8. Summary of dam infrastructure clusters by major types and purposes.....................................19

Figure 9. Distribution of flow, head, and dam cluster ID\# for each water resource cluster.......................20

Figure 10. Summary of water resources clusters based on median flow and head data.............................23

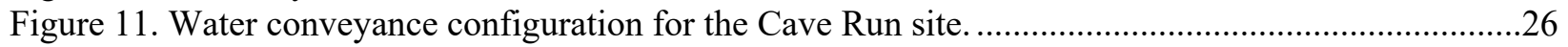

Figure 12. Water conveyance configuration for the Mississippi L\&D \#14 site. ....................................27

Figure 13. Baseline initial capital costs distribution for reference sites. ................................................30

Figure 14. Jennings Randolph Lake baseline plant power and efficiency profiles....................................31

Figure 15. Overton L\&D baseline plant power and efficiency profiles....................................................

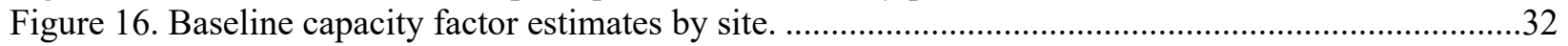

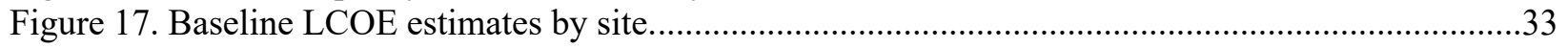

Figure 18. Comparison of HydroMatrix and baseline construction footprints. .........................................36

Figure 19. Baseline vs. near-term innovation capital cost changes for lake dams. ...................................40

Figure 20. Baseline vs. near-term innovation capital cost changes for lock dams. ..................................40

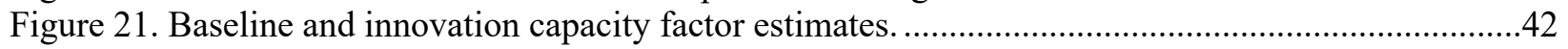

Figure 22. LCOE: baseline and near-term innovation cases...............................................................42

\section{LIST OF TABLES}

Table 1. Overview of technology options and TRL for small hydropower..............................................6

Table 2. Summary of representative sites from the water resource clustering algorithm........................22

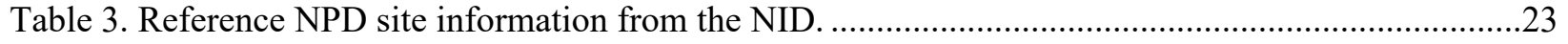

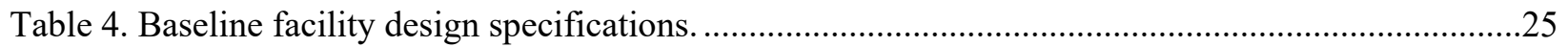

Table 5. Summary of baseline site design capacity, development, and civil works costs.........................29

Table 6. Near-term innovative hydropower facility design options. ........................................................3

Table 7. Potential medium- to long-term innovative facility design specifications. .................................37

Table 8. Capacity and initial capital costs for baseline vs. near-term cases. ............................................39

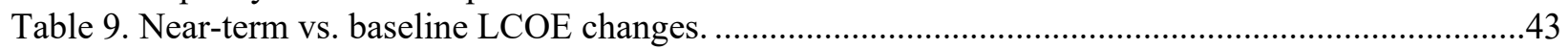




\section{ABBREVIATIONS}

$\begin{array}{ll}\text { DOE } & \text { US Department of Energy } \\ \text { FRP } & \text { fiberglass-reinforced polymer } \\ \text { HDPE } & \text { high-density polyethylene } \\ \text { HIDEA } & \text { Hydropower Integrated Design and Economic Analysis } \\ \text { LCOE } & \text { levelized cost of electricity } \\ \text { NID } & \text { National Inventory of Dams } \\ \text { NPD } & \text { non-powered dam } \\ \text { ORNL } & \text { Oak Ridge National Laboratory } \\ \text { PAM } & \text { partitioning around medoids } \\ \text { R\&D } & \text { research and development } \\ \text { RHT } & \text { Restoration Hydro Turbine } \\ \text { SmHIDEA } & \text { Small Hydropower Integrated Design and Economic Analysis } \\ \text { TRL } & \text { technology readiness level } \\ \text { U.S. } & \text { United States } \\ \text { USACE } & \text { United States Army Corps of Engineers } \\ \text { USBR } & \text { United States Bureau of Reclamation } \\ \text { VBA } & \text { Visual Basic for Applications } \\ \text { VLH } & \text { very low head } \\ \text { WPTO } & \text { Water Power Technologies Office }\end{array}$




\section{ACKNOWLEDGMENTS}

\section{Water Power Technologies Office, US Department of Energy}

The authors acknowledge and appreciate the Water Power Technology Office (WPTO) of the US Department of Energy for funding and oversight support for the project. In particular, the following individuals provided direct support for the Oak Ridge National Laboratory hydropower cost modeling project, as well as review feedbacks on the study:

- Hoyt Battey, Program Manager for Strategic Planning, Analysis and Outreach

- Marisol Bonnet, Project Engineer

Oak Ridge National Laboratory, US Department of Energy

The following individuals from Oak Ridge National Laboratory (ORNL) provided operational support and technical reviews for the project:

- Brennan Smith, ORNL Program Manager for WPTO Projects

- Shelaine Curd, ORNL Operations Manager for WPTO Projects

\section{Technical Reviewers}

Olivia Shafer, ORNL Technical Writer/Editor 


\section{EXECUTIVE SUMMARY}

\section{Overview and Scope}

This report provides a cost analysis of potential hydropower development for representative non-powered dam (NPD) sites in the United States. The overarching objective is to support the establishment of a basis for evaluating progress towards improving the competitiveness of new hydropower development for electricity generation. The representative sites, herein referred to as "reference sites", were selected from sites with detailed water resource data to support the cost analysis. Facility designs, capital costs, plant generation and efficiency profiles, capacity factors, and levelized costs of energy (LCOE) are presented for the sites under baseline and near-term innovation cases. The baseline case represents facility configurations using technologies that are already widely applied in the hydropower industry, whereas near-term innovations are technologies likely to reach wide acceptance within the next 5 to 10 years. Cost savings in the near-term relative to the baseline are discussed to illustrate the potential benefits to the hydropower industry from research and development (R\&D) and adoption of these innovations. Mediumto long-term innovation options expected from ongoing private and government R\&D efforts are also highlighted but are not quantified in this report because of a current lack of complete information on these options.

\section{Objectives}

Given that less than 3,000 of the more than 90,000 dams in the United States currently produce electricity, a considerable potential exists to increase hydropower generation at NPD sites. However, previous resource assessments have shown that most of the NPD sites have small potential capacities that may not be competitive with other sources of electricity because of limited economies of scale. This challenging characteristic of potential NPD sites for new hydropower development reflects the fact that, unlike other renewables such as solar or wind power, hydropower is a mature industry. Most of the large-capacity sites with significant economies of scale have already been developed, representing nearly $80 \mathrm{GW}$ of capacity that have provided clean, low-cost electricity to the power grid for many decades.

In addition to small-scale potential capacities, NPD sites in the United States have other challenging features, including diversity of dam infrastructure, high variability of water resources, and environmental impact mitigation requirements, among others. Given these challenges, the site-specific nature of hydropower infrastructure requirements and generation performance takes on greater importance because of the resulting higher levels of uncertainty and risks. New technologies to reduce the cost and investment uncertainty associated with hydropower at NPD sites require considerable R\&D efforts. In turn, R\&D efforts must be guided by a deep understanding of the multidimensional drivers of hydropower construction and operation costs at these sites.

Oak Ridge National Laboratory (ORNL) is providing support to the US Department of Energy's Water Power Technologies Office to better understand the role and importance of these drivers, and more importantly, the impacts of R\&D outcomes in reducing hydropower costs at these sites. Thus, the objectives of this study include the following:

- Identify a set of representative sites useful for understanding the wide-ranging site-specific drivers of developing hydropower at potential NPD sites in the United States.

- Evaluate baseline facility designs/costs and identify potential technological innovations that may achieve significant cost reductions for hydropower development at these sites over time. 
- Quantify, where the data allows, potential cost reductions from these innovations based on metrics such as capacity, capital costs, capacity factor, and LCOE.

- Further develop existing ORNL capabilities to analyze the costs of different existing and emerging hydropower technologies and facility configurations.

\section{Key Findings}

The key findings of the cost analysis in this study imply that near-term innovations could reduce the baseline costs of hydropower development at US NPD sites. Thus, if remaining R\&D issues with these near-term innovations can be resolved within the next 5 to 10 years, industry-wide adoption of these technologies and improved competitiveness of NPD hydropower development can be expected. Specific key findings of the analysis include the following:

- Potential installed capacity at the NPD sites evaluated in this study vary from $200 \mathrm{~kW}$ to $70 \mathrm{MW}$, representing two orders of magnitude variation across nearly 20 sites. This finding emphasizes the impetus for a systematic approach to analyzing the cost of hydropower at NPD sites in this study.

- Capital costs, not including development costs, for the sites evaluated in this study vary from $\$ 2,200 / \mathrm{kW}$ to $\$ 34,000 / \mathrm{kW}$ but are below $\$ 12,000 / \mathrm{kW}$ for most sites.

- Based on general facility configurations, the sites analyzed in this study can be broadly classified into lake dams and lock dams, but the variation in site-specific characteristics mean that each of these design groups cannot be treated as a unit.

- Lake dams are generally characterized by a larger share of water conveyance in baseline costs, whereas lock dam sites have larger powerhouse and electro-mechanical cost shares.

- Near-term innovations considered for lake dams focus on use of non-steel materials for water conveyance outlets lining and penstocks to reduce costs, whereas innovations considered for lock dams replace large turbines with modular matrix turbines to reduce the facility footprint and excavation requirements.

- Variations in flow-duration and median-head curves suggest that the theoretical capacity factor for most of the sites would be between $50 \%$ and $60 \%$. In accordance with this observation, simulation results found that baseline capacity factor estimates for lake dam sites are between $30 \%$ and $50 \%$ and between $30 \%$ and $61 \%$ for lock dams. Additionally, because of variations in head levels, results show considerable variation in generation, even when plants operate at design flows.

- Baseline LCOE estimates for lake dams are from $\$ 79 / \mathrm{MWh}$ to $\$ 790 / \mathrm{MWh}$ with most sites under $\$ 400 / \mathrm{MWh}$, whereas estimates for lock dams are from $\$ 134 / \mathrm{MWh}$ to $\$ 289 / \mathrm{MWh}$ with most sites under $\$ 200 / \mathrm{MWh}$.

- Reductions in capital cost per kilowatt under the near-term innovation case are from $-77 \%$ to $-14 \%$ for lake dams and $-21 \%$ to $-2.1 \%$ for lock dams (excluding one site with a $14 \%$ increase in perkilowatt capital costs).

- Capacity factors are essentially the same in the baseline and near-term innovation cases for lake dams but increased by between $2 \%$ to $9 \%$ for lock dams. 
- Combined changes in capital costs and capacity factors in the near-term case relative to the baseline lead to reductions in $\mathrm{LCOE}$ of $-71 \%$ to $-14 \%$ for lake dams and $-21 \%$ to $-14 \%$ for lock dams.

- Overall, LCOE reductions lead to 8 of the 18 sites under the near-term case having LCOE values below $\$ 150 /$ MWh compared with only 2 of 18 sites in the baseline case. ${ }^{1}$

\section{Methodological Approaches}

The primary modeling tool for the analysis in this study is the ORNL Small Hydropower Integrated Design and Economic Analysis (smHIDEA) tool. smHIDEA is a bottom-up tool for simulating the performance and costs of potential facility configurations at small hydropower sites. The tool is under active development, with many enhancements since FY19 to support the analysis presented in the current study. Given site resources and infrastructure data, basic hydropower design features (turbine type, design flow and head), facility component dimensions, and financial parameters, smHIDEA uses a combination of parametric and volumetric equations to design the facility and estimate capital costs. A performance optimization algorithm uses the design information to evaluate the efficiency and generation profile of the plant over 200 half-percentiles of the daily water flow and head data for each site. These are combined within the model to perform a cash flow analysis and calculate cost performance measures, including LCOE, net present value, and internal rate of return. The LCOE is the primary measure of competitiveness used in this study.

To reduce the number of sites to a manageable set for this study, a two-level clustering algorithm was used to group potentials sites based on available data. In the first level, $\sim 3,100$ sites selected from the ORNL resource assessment were grouped into 20 dam infrastructure clusters. In the second level, daily data on flow and head for 135 sites having this detailed information were combined with the dam infrastructure cluster identifiers from the first level to identify 20 resource clusters. The representative sites for these 20 clusters are the reference sites in this study.

\section{Data Sources}

The data employed for the analysis in this study comes from several sources. The starting point for the analysis is the ORNL resource assessment database which includes slightly more than 54,000 NPDs (Hadjerioua et al., 2012). Sites with estimated capacities of $100 \mathrm{~kW}$ or more were selected from this database (about 3,100 sites) for the analysis in this study. Data on features of the selected sites are from the National Inventory of Dams database compiled by the US Army Corps of Engineers (USACE, 2019), which includes information on dam location, ownership, features, and inspection records. Daily flow and head data for about 152 sites available from the US Army Corps of Engineers (USACE, 2015) were used to support the performance and cost simulations of reference sites. Small Hydro Consulting (SHC, 2019) provided civil works conceptual design and cost estimates for several sites that were included in the final analysis. These estimates provided a basis for understanding the design requirements for many of the reference sites analyzed in this study.

In addition to the above data, a review of the literature was performed to place the innovations considered in this study in context of the state of the art in the hydropower industry. The review found a variety of efforts, particularly turbine-generator innovations aimed primarily at low-head sites, reduced civil works requirements, and avoidance of environmental impacts. Other innovations are aimed at stronger and cheaper materials for hydropower, as well as improved control and monitoring systems. Hydropower $\mathrm{R} \& \mathrm{D}$ is diverse and promising, with the US Department of Energy providing support to several of these

\footnotetext{
${ }^{1}$ One of the 19 sites in the baseline case was not included in the near-term innovation case as it already has a construction license and its estimated baseline LCOE is close to the assumed target of $\$ 70 / \mathrm{MWh}$.
} 
efforts through its Water Power Technologies Office. Based on this review, near-term innovations considered in the cost analysis involve improved materials for water conveyance systems as well as modular matrix turbines. These innovations are closer to wide adoption in the hydropower industry than others. Many of the turbine-generator innovations aimed at breakthrough civil works cost reductions and environmental performance are moving through the development process, so their performance/costs should become more widely known in the medium to long term.

\section{Key Cost Simulation Assumptions}

A few key assumptions underly the cost analysis in this study. A 40-year project lifetime is used in the current analysis, with a capital recovery period of 20 years. A 5-year development/construction period is assumed, with the plant starting operation in the 6th year. The nominal discount rate is assumed to be $7.6 \%$ and the real discount rate is $5.4 \%$ based on an inflation/escalation rate of $2 \%$. A planned/forced outage rate of 5\% is assumed, and environmental costs are charged at $10 \%$ of the total cost of civil works and electro-mechanical equipment.

\section{Limitations and Assumptions}

Although the current study used a comprehensive approach to evaluate the potential costs and cost reduction potentials of innovations for hydropower at NPD sites, several limitations exist. Among these are the lack of complete information on dam attributes for the reference sites in the study. These attributes could affect facility design opportunities and challenges under the baseline and innovation cases, with potential implications for estimated costs. Another limitation is the lack of detailed resource information for the majority of $\sim 3,100$ sites with initial capacity estimates of $100 \mathrm{~kW}$ or more. This means that only 135 sites could be included in the final cost analysis. The results in this study may be applicable to other sites, but additional information and analysis would be necessary. Although available aerial photos of the sites were examined for this study, no tractable method can capture potential staging constraints at each site at this time, so this represents an additional source of uncertainty in the results.

In terms of the analysis itself, the facility design is not fully optimized since the LCOE measure used to evaluate costs - while providing a lifetime view of potential hydropower costs - may not capture all sources of costs. The LCOE also depends on several assumed parameters that are inherently uncertain, including assumptions about plant lifetime, development and construction periods, discount rates, and target electricity price in the regional market, among others. These sources of uncertainty may have important implications for NPD hydropower cost.

\section{Next Steps}

An obvious next step for this study is to address some of the limitations and uncertainties highlighted above. In particular, a need exists to compile detailed daily flow and head data for as many of the $\sim 3,100$ sites identified in this study as possible. A need also exists to identify and compile available information on NPD dam features that are important to hydropower cost estimation but not available from databases such as the National Inventory of Dams. Methods to extend cost estimates for the reference sites to the remainder of the 3,100 sites without necessarily performing a large number of detailed bottom analysis of the individual sites is needed. Studies are needed to ascertain the extent of barriers to the near-term innovations evaluated in this study and options for accelerating their deployment. Information on potential breakthrough turbine innovations to improve performance and costs of hydropower at NPD sites in the medium to long term is also an important next step. Finally, the smHIDEA tool would need to be continually enhanced with capabilities to evaluate the emerging technology and facility configurations for developing small hydropower capabilities at NPD and other sites. 


\section{INTRODUCTION}

This report presents the results of a bottom-up effort to evaluate the potential costs of hydropower development at non-powered dams (NPD) in the United States (US). The objective is to provide insights into the spectrum of water resources for hydropower at these sites, characterize the cost profile based on existing technologies and evaluate potential cost reductions from technological innovations. The study supports the US Department of Energy's (DOE's) Water Power Technologies Office (WPTO) effort to identify research and development (R\&D) opportunities to enhance the role of hydropower as a renewable source of electricity, among other potential benefits, within the US economy. The available data show that more than 90,000 NPD in the US were originally built for purposes, such as navigation, flood control, water storage, recreation, and irrigation, among others. A 2012 assessment found that there could be up to $12 \mathrm{GW}$ of hydropower potential at US NPD sites (Hadjerioua et al., 2012). This is a significant potential addition to the existing hydropower fleet, which currently produces more than $80 \mathrm{GW}$ of clean, renewable electricity and provides ancillary services to the power grid.

Despite the above potentials, hydropower development at NPD sites is constrained by several barriers. The primary barrier is the relatively small-scale potential capacity at these sites, typically $<30 \mathrm{MW}$. One of the key features of hydropower infrastructure development is economies of scale, defined as "the proportional increase in total costs brought about by a proportional increase in output, holding all input prices and the number of plants fixed" (Filippini and Luchsinger, 2007). Economies of scale in hydropower arise mainly from the lump sum nature of many plant cost components. Since lump sum or fixed costs change little with additional capacity at a given site, per-unit capacity costs for hydropower infrastructure tend to decrease with increasing capacity. However, the benefits of scale are limited by the technical or maximum available potential at the site. In this regard, Hadjerioua et al (2012) found that only 600 of the more than 54,000 NPD sites evaluated ${ }^{2}$ had capacities $\geq 1 \mathrm{MW}$, with the top 100 sites accounting for nearly two-thirds of the total. Thus, relative to existing large hydropower plants, with capacities up to $500 \mathrm{MW}$ or greater, most of the potential NPD sites are at a cost disadvantage that reduce their competitiveness for new electricity generation.

The technological development challenge of developing new hydropower at NPD sites in the US is illustrated in Figure 1, which shows idealized current and potential long-run supply curves of the total capacity potential under three categories. The unit cost, UC*, in Figure 1 represents the opportunity cost for hydropower development, which can be measured by either the market price of electricity or unit cost of the next best alternative to hydropower generation in the relevant market. The curves can generally be divided into three categories. The "mostly developed" category represents already developed hydropower facilities, which span a wide range of unit costs but are overall competitive with other sources of electricity generation. The significant economies of scale in hydropower is illustrated by the initial downward-sloping part of the supply curves. The second category of sites, "undeveloped/competitive", fall largely in the upward-sloping parts of the curves, with higher unit costs than most already developed hydropower facilities, but are still competitive with other sources of electricity generation. This category includes sites with the most active development interest in the short term. The last category, "undeveloped/non-competitive", in Figure 1 represents most of the remaining undeveloped hydropower potential. The steep rise on the right side of the current long-run cost curve is largely because these sites have small-scale capacity potentials and other challenges to hydropower development. Significant

${ }^{2}$ Of the more than 90,000 NPDs throughout the United States, 54,391 dams were analyzed, with the remaining dams eliminated from consideration due to erroneous geographic information, or erroneous flow or drainage area attributes that could not be resolved and corrected through independent investigation of maps and records. Anecdotal information suggests that these dams with missing or erroneous information are likely to be relatively small or have low potential to produce hydroelectric energy. Dams with a reported height of $<5 \mathrm{ft}$ were also excluded from analysis. 
technological, regulatory, and other advancements are necessary to make hydropower electricity at these sites competitive. The potential cost reduction benefit of these advancements is illustrated by the shaded area in Figure 1, showing that such cost reductions may extend to existing hydropower sites as well.

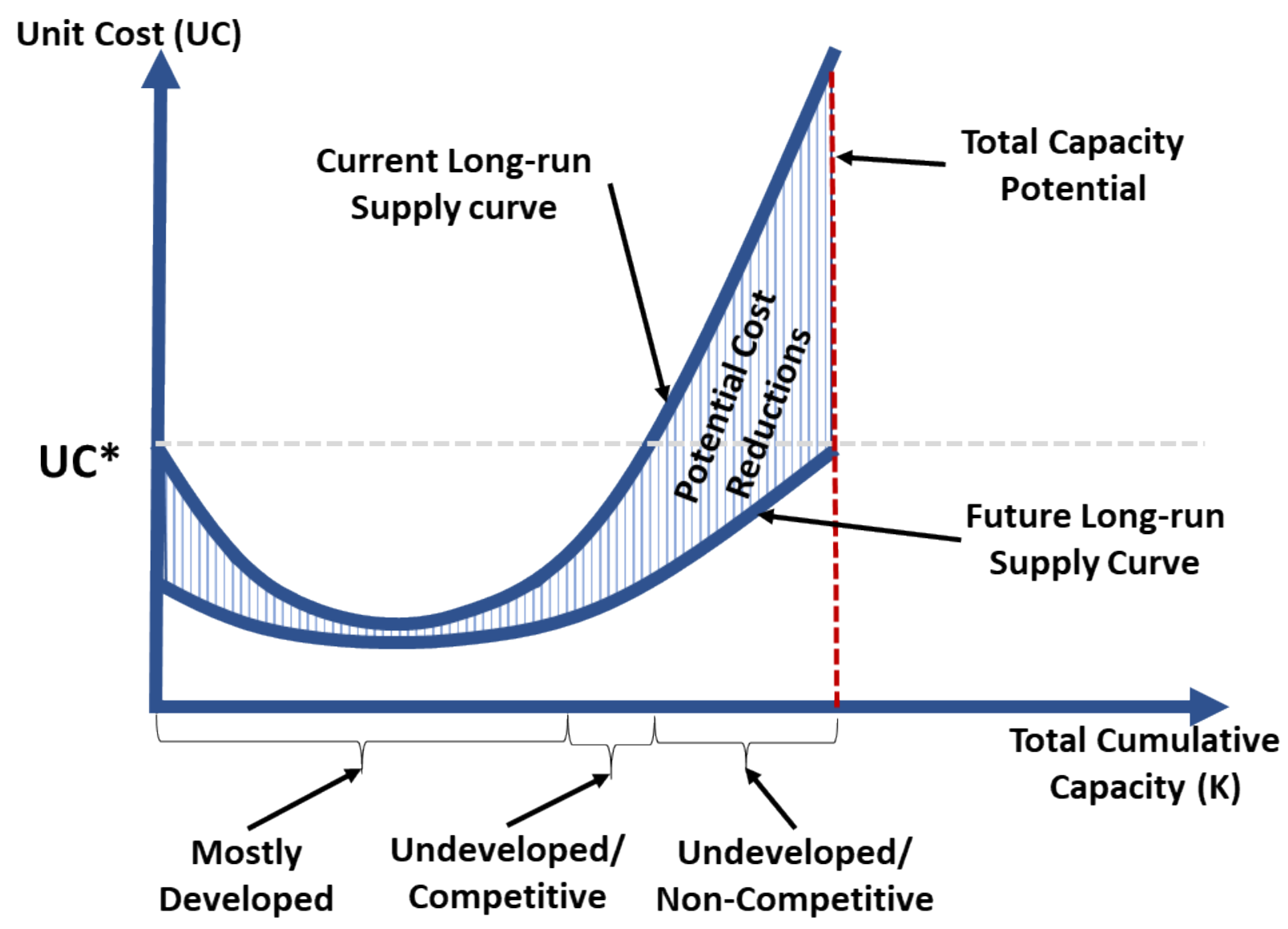

Figure 1. Illustration of the idealized R\&D challenges and opportunities for hydropower. (Source: Author Illustration).

The available empirical data confirm the overall cost disadvantage of small hydropower plant development as illustrated in Figure 1, particularly for low-head sites that constitute most of the remaining NPD potential in the US (Uria-Martinez et al., 2017). Additionally, a recent analysis shows that costs per unit capacity of environmental studies and impact mitigation measures required for hydropower development at NPD sites in the US are larger for small plants than large plants (Oladosu et al., 2021). Thus, the small-scale disadvantage of NPD hydropower extends to all aspects of development at these sites. These disadvantages motivated recent legislations aimed at speeding up the development of hydropower at NPD sites (FERC, 2019; H.R.267, 2013) by simplifying the licensing process for smallscale hydropower. In addition to simplifying the licensing process for small-scale hydropower, overcoming the barriers to the development of NPD sites requires significant additional efforts in several areas. These include deeper characterization of the potential NPD resource base, understanding the critical drivers of NPD development costs, development of new technologies to overcome barriers to NPD hydropower, and evaluating the potential for different technological innovations to reduce costs at these sites.

Towards the objective of identifying opportunities for innovations and the benefits, this study estimates the baseline profile of costs for hydropower development at NPD sites and estimates potential cost 
reductions from near-term innovations. The baseline and innovation cases are the empirical counterparts to the idealized current and potential cost curves illustrated in Figure 1. Since the actual resource base for NPD sites is defined by many attributes, the empirical cost curves are far from the idealized forms in Figure 1. For the purposes of this study, potential NPD sites are grouped into more consistent or homogenous classes. A reference site, which is representative of the dam infrastructure, water resources, and hydropower potential, is identified for each NPD class or cluster. Cost estimates for the reference sites under the baseline and near-term innovation cases are presented. This study also discusses potential medium- to long-term innovations that could achieve breakthrough cost reductions but cannot be fully appraised at this time.

The primary cost measure used for the analysis in this study is the levelized cost of electricity (LCOE), defined in its simplest form as the ratio of the annualized present value of costs to the annualized electricity generation over the specified lifetime of the project. The LCOE is an estimate of the current year price, given all assumptions in estimating costs and energy generation (e.g., efficiency, capacity factor, inflation rate, interest rates), necessary for the project to have a present value of zero. The LCOE is used in similar DOE efforts to evaluate electricity generation costs (Beiter et al., 2016; Vimmerstedt et al., 2019) and provides a combined summary of costs during all stages of the construction and operation of a plant over the given lifetime. The estimates presented here are not definitive costs for individual sites but can be described as pre-feasibility estimates aimed at establishing the importance of different cost components in NPD hydropower development, relative costs of different sites and technologies, and the cost reduction potential of innovations.

The components of this study, including data, methodologies, capital cost estimates, and results of simulations to estimate the LCOE for NPD sites, are presented in the following sections.

\section{TECHNOLOGY NEEDS AND OPTIONS FOR NPD HYDROPOWER}

Hydropower is a mature renewable source of electricity with technologies that are cost-competitive with other sources of electricity for large portions of the total technical potential in many countries. In the US and other nations, where most of the large-scale resources have already been developed, small-scale hydropower has been receiving greater attention. The cost disadvantages of small-scale hydropower relative to their large-scale counterparts presents a technological challenge that can be addressed through R\&D. Other related challenges at small-scale NPD sites that must be jointly addressed to accelerate the future contribution of hydropower to renewable electricity generation include the following:

1. Diversity of NPD site features: There is a variety of features for characterizing NPD dams. These include many features that are not currently captured by the available database on dams, such as the National Inventory of Dams (NID) but must be addressed by developers evaluating a site. Thus, a one-size-fits all approach to NPD hydropower facility design does not exist, requiring new innovative ways to arrange facility components or entirely new approaches to facility configurations and components.

2. Multipurpose water resource uses: Since NPD sites were originally developed for different, often multiple, purposes other than hydropower, the operation of these facilities are adapted for these purposes. A common requirement for hydropower additions at these sites is to preserve the original purpose and patterns of water resources use. This means that developers of NPD sites are constrained by resource use requirements, which are likely to be less than optimal from a hydropower generation viewpoint. 
3. Higher variability of water resources: In addition to the small potential of hydropower at most undeveloped US NPD sites, the water flow and head at these sites generally have higher levels of variation than at hydropower sites with large amounts of reservoir storage. Even in cases in which the water flow and head variation are similar to those for much larger sites, the coefficient of variation, which is the ratio of the standard deviation to the mean, of head and flow values would be higher for the smaller sites. Since hydropower plants are traditionally designed for a specific optimal flow and head, higher variations pose a challenge for existing conventional technologies and require new technological advances.

4. Environmental impact mitigation requirements: Hydropower projects at NPD sites with $10 \mathrm{MW}$ or less capacity can benefit from licensing exemptions but are still required to submit environmental assessment documents. Environmental assessment documents identify measures to mitigate any environmental impacts of the project, and those required by the Federal Energy Regulatory Commission (FERC) must be implemented during hydropower development. The proportionally higher cost burden of these environmental requirements on smaller plants relative to larger plants implies a need for technological advancements to reduce environmental impact mitigation costs to accelerate NPD hydropower developments in the US (Oladosu et al., 2021).

5. Transmission requirements: Many potential NPD hydropower resources are not large enough to support the additional cost of constructing separate transmission lines and associated electrical infrastructure, requiring existing grid connection points near the site. Thus, the cost of electricity transmission can become a limiting factor for the development of NPD sites beyond 1 or 2 miles, depending on the actual project size.

6. Staging space limitations: Since NPD sites are already developed for purposes other than hydropower, the land surrounding these sites is often already developed or assigned to different purposes such as recreation, wildlife conservation, and so on. As a result, the cost of developing hydropower at an NPD site may be significantly affected by the need to account for space limitations around the construction site, potentially leading to increases in labor requirements, longer construction timeline, nonoptimal construction equipment, and nonoptimal facility design and technology choices, among other impacts.

\subsection{OVERVIEW OF HYDROPOWER TECHNOLOGY INNOVATIONS}

There is a considerable amount of ongoing work across the world to address the challenges to small-scale hydropower development. Previous studies on hydropower technological needs and advancements were evaluated to identify the state of the art, long-term vision, remaining barriers, and potentials. The available literature describes a mix of private industry, academic, government, and other institutional efforts, including several efforts supported by WPTO (Kougias, et al., 2019; Sari et al., 2018; IEA, 2019; Smith et al., 2017; O'Connor et al., 2016; O'Connor et al., 2016a, UNIDO, 2019; Zhou and Deng, 2017; Corà et al., 2019; Ardizzon et al., 2014). Smith et al. (2017) provides a list of 31 ideas in 8 key areas, outlining the current situation, vision, existing opportunities, and future directions for advancing hydropower development in the US. The following ideas, related to advanced and improved technology, new materials and manufacturing processes, and standardized and modular designs are particularly relevant to the cost analysis in this study:

- Use of alternative and composite materials instead of cast iron and steel

- Smaller and reduced reinforced-concrete structures

- New turbine technology to reduce or eliminate civil construction

- Three-dimensional printing of turbines and components

- Fish-friendly turbines, standard designs for conduit hydropower 
- Standardized, factory-assembled small-hydropower equipment packages

- Modular components to facilitate project operation and maintenance

Most of the hydropower technology innovations in the literature can be identified with one or more of the above areas. Additionally, each technological innovation may be at different stages of development, which is indicated using technology readiness levels (TRL). TRLs are numbers between 1 and 10 assigned to each technology, with larger numbers indicating higher levels of market maturity. Appendix A shows TRL numbers used for hydropower from two sources that, although separated by five years, are almost identical (Zhang et al., 2012; De Rose et al., 2017). Table 1 provides a list of technological innovations identified in the literature, focusing on small-scale hydropower under three main categories: (1) turbine-generator and civil works; (2) environmental impacts mitigation; and (3) controls, monitoring, and others. Innovations in the first two categories are more common in the literature and are discussed briefly in the following sections.

\subsection{TURBINE-GENERATORS AND CIVIL WORKS INNOVATIONS}

Conventional turbines can often be used at small hydropower sites, but their performance may deteriorate at low heads/flows while incurring significant civil work costs. Figure 2 from Sari et al., 2019 provides a chronological overview of turbine innovations, many of which are also identified in Table 1, demarcating innovations that are mostly designed to address small-scale hydropower requirements from conventional technologies. The turbine-generator innovations include modularization of traditional turbine designs, as well as new designs that have not previously been used in conventional hydropower plants. These innovations include impulse, reaction, and gravity type turbines, but most of the innovations are based on the reaction, Kaplan-type turbine.

The Voith StreamDiver (Voith, 2020) is a modular (standardized, small-scale) turbine based on the conventional bulb-Kaplan/Propeller turbine that can be arranged in matrix form and reduces civil work requirements. The Andritz Hydromatrix turbine and the Obermeyer Matrix turbine are essentially the same concept as the StreamDiver (Andritz, 2020). The modular bulb turbine, which has undergone labscale testing, is an effort to modularize the bulb-Kaplan turbine (Krouse, 2014). The AmJet ATS turbine is similar in concept, as it is based on the Kaplan-type turbine, but it takes inspiration from marine waterjet propulsion engines produced by AmJet (AmJet, 2015). The Very Low Head (VLH) turbine is another innovation based on the Kaplan-type turbine, using a larger runner with higher number of blades at a slower rotational speed than conventional Kaplan turbines. Many of the other turbine-generator innovations are based on new or existing designs that have not been commonly used for hydropower. These include hydropower turbine designs using ancient technologies such as the Archimedean Screw and the Waterwheel, as well as newer designs such as the vertical axis hydrokinetic turbine. Several of these turbine-generator innovations, including the modular bulb turbine, Propel, AmJet and others, have received support from WPTO. 
Table 1. Overview of technology options and TRL for small hydropower.

\begin{tabular}{|c|c|c|c|c|}
\hline Technical innovations & Barriers addressed & TRL & Features/limitations & Sources \\
\hline \multicolumn{5}{|c|}{ Turbine-generator and civil works innovations } \\
\hline Matrix bulb turbine-generators & $\begin{array}{l}\text { Low head; high civil works } \\
\text { costs }\end{array}$ & 9 & $\begin{array}{l}\text { Low civil works cost estimates; low power density } \\
\text { leads to large electro-mechanical costs }\end{array}$ & $\begin{array}{l}\text { Voith (2020), } \\
\text { Andritz (2020) }\end{array}$ \\
\hline Modular bulb turbine & $\begin{array}{l}\text { Low head; high civil works } \\
\text { costs }\end{array}$ & 4 & $\begin{array}{l}\text { Low civil works cost estimates/Still in early } \\
\text { development }\end{array}$ & Krouse (2014) \\
\hline AmJet hydropower turbines & $\begin{array}{l}\text { Low head; high civil works } \\
\text { costs }\end{array}$ & 4 & $\begin{array}{l}\text { No powerhouse required; compact design, } \\
\text { alternative materials }\end{array}$ & Sari et al. (2018) \\
\hline Very low head turbine & $\begin{array}{l}\text { Low head; high civil works } \\
\text { costs }\end{array}$ & & $\begin{array}{l}\text { No powerhouse required; slow speed allows for } \\
\text { downstream fish passage }\end{array}$ & $\begin{array}{l}\text { MJ2 Technologies } \\
(2020)\end{array}$ \\
\hline $\begin{array}{l}\text { Hydrodynamic screws and gravity } \\
\text { water wheels. }\end{array}$ & $\begin{array}{l}\text { Low head; high civil works } \\
\text { costs }\end{array}$ & 5 & $\begin{array}{l}\text { Max efficiency. } 80 \% \text {, but } 50 \%-70 \% \text { typical; fish- } \\
\text { friendly and debris-tolerant; low power density }\end{array}$ & $\begin{array}{l}\text { Kougias (2019), } \\
\text { Sari et al. (2018) }\end{array}$ \\
\hline $\begin{array}{l}\text { New water wheels: turbine water } \\
\text { wheel }\end{array}$ & $\begin{array}{l}\text { Low head; high civil works } \\
\text { costs }\end{array}$ & 4 & $\begin{array}{l}\text { Low civil works cost estimates/Still in early } \\
\text { development }\end{array}$ & Kougias (2019) \\
\hline Hydrostatic pressure machine & Low head & 1 & $\begin{array}{l}\text { No head drop needed; } 60 \%-65 \% \text { efficiency; } \\
\text { improved power-takeoff to reduce losses needed }\end{array}$ & Kougias (2019) \\
\hline Mavel siphon turbine & Low head & 8 & $\begin{array}{l}\text { No powerhouse required; requires draft tube; } \\
\text { limited application }\end{array}$ & Sari et al. (2018) \\
\hline Vertical axis hydrokinetic turbine & Low head & 6 & Based on flow only & Sari et al. (2018) \\
\hline Ultralow head turbine-generator & Very low head sites & 1 & $\begin{array}{l}\text { Low civil works cost estimates/Still in early } \\
\text { development }\end{array}$ & $\begin{array}{l}\text { Chen and Engeda } \\
(2020) \text {, Zhou et al. } \\
(2019)\end{array}$ \\
\hline $\begin{array}{l}\text { Passive/active water injection with } \\
\text { flow feedback method for } \\
\text { Francis/Propeller turbines }\end{array}$ & $\begin{array}{l}\text { High variation in hydropower } \\
\text { operating conditions }\end{array}$ & 3 & $\begin{array}{l}\text { Lower variation in plant operation/Still in early } \\
\text { development }\end{array}$ & Kougias (2019) \\
\hline $\begin{array}{l}\text { Converter-fed synchronous and } \\
\text { doubly fed induction machines }\end{array}$ & $\begin{array}{l}\text { Variable head/flow and } \\
\text { operation }\end{array}$ & 10 & $\begin{array}{l}\text { Not commonly used (mostly pumped storage } \\
\text { hydropower); costly ( } 7 \%-15 \% \text { of plant); low range } \\
\text { of operation; insulation issues }\end{array}$ & Kougias (2019) \\
\hline High-efficiency axial flux generators & Low power density & 4 & $\begin{array}{l}\text { Currently limited application: typically made with } \\
\text { permanent magnets and coupled with power } \\
\text { electronics for speed control }\end{array}$ & $\begin{array}{l}\text { Moreels and Leijne } \\
(2018)\end{array}$ \\
\hline $\begin{array}{l}\text { High-density polyethylene and } \\
\text { fiberglass-reinforced polymer } \\
\text { penstock/lining materials }\end{array}$ & High cost of steel and concrete & 7 & $\begin{array}{l}\text { Lower cost than steel/Pressure requirements need to } \\
\text { be met }\end{array}$ & \\
\hline
\end{tabular}




\begin{tabular}{|l|l|l|l|l|}
\hline \multicolumn{1}{|c|}{ Technical innovations } & \multicolumn{1}{|c|}{ Barriers addressed } & TRL & \multicolumn{1}{c|}{ Features/limitations } & \multicolumn{1}{c|}{ Sources } \\
\hline $\begin{array}{l}\text { Precast concrete dams (French } \\
\text { System) }\end{array}$ & $\begin{array}{l}\text { High civil works cost; long } \\
\text { construction time }\end{array}$ & & $\begin{array}{l}\text { Reduced project duration; offsite } \\
\text { manufacturing/Potential transportation limitations }\end{array}$ & $\begin{array}{l}\text { Drown and French } \\
(2017)\end{array}$ \\
\hline
\end{tabular}

Table 1. Overview of technology options and TRL for small hydropower (continued).

\begin{tabular}{|l|l|l|l|l|l|}
\hline \multicolumn{7}{|c|}{ Technical innovations } & \multicolumn{1}{|c|}{ Barriers addressed } & TRL & \multicolumn{1}{c|}{ Features/limitations } & Sources \\
\hline \multicolumn{5}{|c|}{ Environmental impacts mitigation innovations } \\
\hline Alden (Francis) & Fish protection & 10 & Alden: 93.6\% Efficiency/ $>98 \%$ fish survival & Kougias (2019) \\
\hline $\begin{array}{l}\text { Voith minimum gap runner (Kaplan- } \\
\text { type turbine) }\end{array}$ & Fish protection & 10 & Voith: $\geq 95 \%$ fish survival & Kougias (2019) \\
\hline $\begin{array}{l}\text { Natel Restoration Hydro Turbine } \\
\text { (Kaplan) }\end{array}$ & Low head; fish protection & 4 & $\begin{array}{l}\text { Natel: }>88 \% \text { Efficiency } />99 \% \text { fish survival; shorter } \\
\text { draft tube; lower cavitation risk than conventional } \\
\text { turbines }\end{array}$ & Natel Energy (2020) \\
\hline Aerating turbines & Low dissolved oxygen & 8 & \multicolumn{5}{|c|}{ Control, monitoring, and other innovations } & $\begin{array}{l}\text { Potential of advanced monitoring to reduce outage } \\
\text { times by 20\% }\end{array}$ & $\begin{array}{l}\text { HEA (2013), } \\
\text { Kougias (2019) }\end{array}$ \\
\hline $\begin{array}{l}\text { Digital avatars of units for combined } \\
\text { advanced simulations to evaluate } \\
\text { transient operations and flexibility }\end{array}$ & $\begin{array}{l}\text { Operation and maintenance } \\
\text { cost; dwindling skilled } \\
\text { workforce }\end{array}$ & 3 &
\end{tabular}


Most of the available turbine-generator innovations are aimed at reducing civil work requirements; improving ease of construction, operation, and maintenance; improving low-head performance; and so on. However, there are trade-offs among these different objectives. For example, the Archimedean Screw has been found to be a versatile low-head and fish-friendly turbine but has a low power density (i.e., the combined power output for the same volume of multiple smaller turbines, focusing on the motive components of the turbine-generator package, is lower than that of a similar volume of larger turbines) and its low-speed requires speed-increasers that reduce efficiency. Similarly, modularized conventional turbine designs reduce construction footprints and civil works cost but have slightly lower efficiencies than their larger counterparts, as well as lower power densities. Lower power densities increase the perkilowatt cost of a turbine-generator package that may offset savings on civil works and other facility costs, making applications to small capacity sites less competitive. These trade-offs need to be carefully examined in applications to a given site.

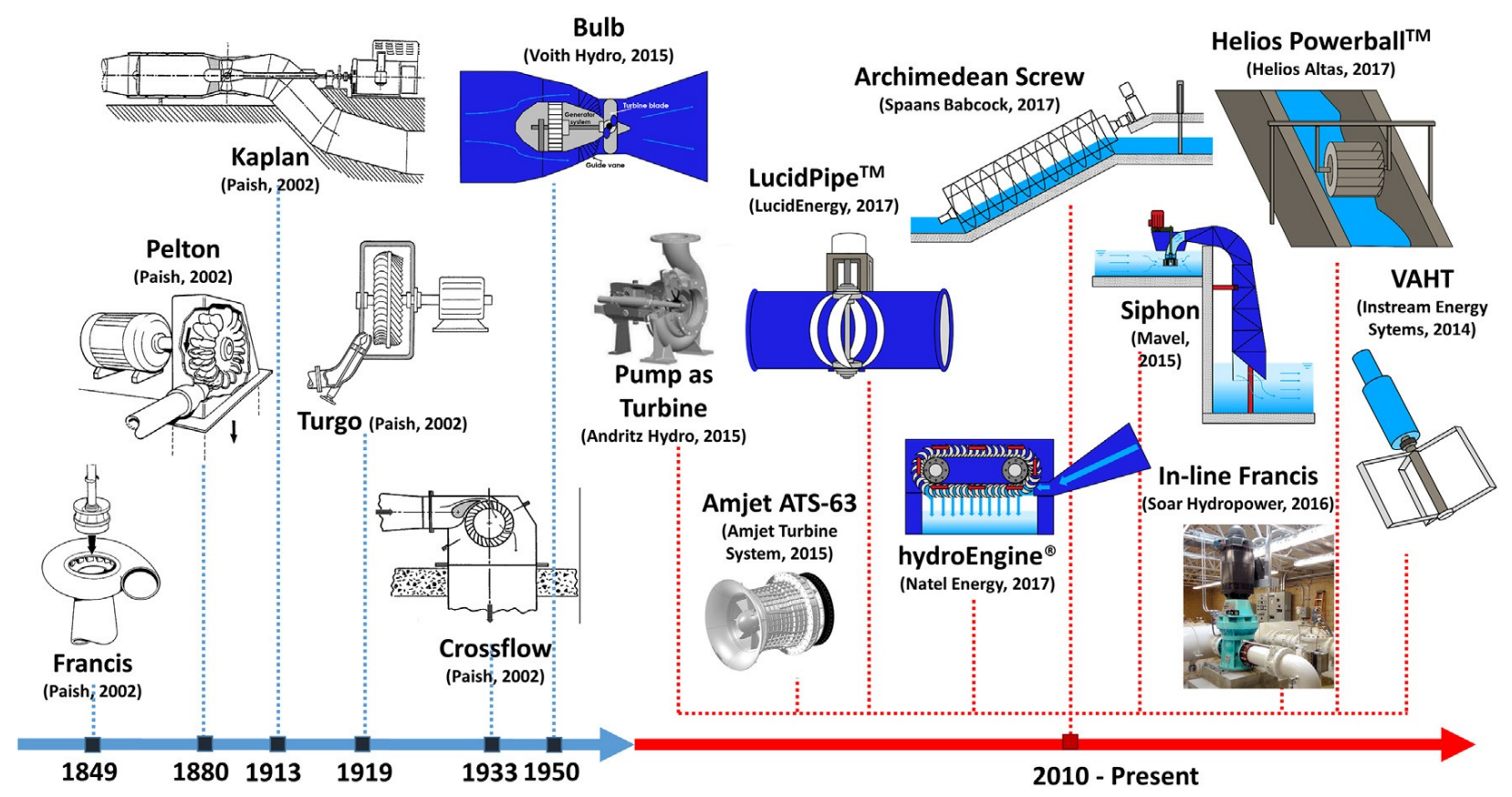

Figure 2. Turbine technology evolution. (Source: Figure 2 from Sari et al. 2018)

\subsection{ENVIRONMENTAL IMPACT MITIGATION INNOVATIONS}

Stringent regulatory requirements and associated cost disadvantages for small hydropower plants (Oladosu et al., 2021) have pushed technological innovations addressing environment impacts to the forefront of hydropower industry R\&D. Fish impacts have received the greatest attention because many existing dams are barriers to fish migration, requiring the construction of a fish bypass or, in some cases, dam removal. Additionally, fish entrainment and impingement are directly related to conventional hydropower turbine operation. "Entrainment" refers to fish passage through turbines while "impingement" refers to fish that may be trapped on entrance screens or between other components of the turbine-generator assembly. Disruptions to fish migration may lead to species loss, among other ecological impacts. Entrainment and impingement can lead to fish mortality or injury (Rytwinski et al., 2017). A key technological innovation for reducing fish migration disruption, entrainment, and impingement is to design turbines that can allow fish passage without causing injury. Table 1 lists three turbine redesign efforts by Alden, Voith, and Natel (Kougias, 2019; Natel Energy, 2020), with the first as a variation on the Francis turbine and the latter two as variations on the Kaplan-turbine. However, only the Natel Energy Restoration Hydro Turbine (RHT) is directly aimed at small-scale hydropower. Many of 
the new turbine designs discussed above would also allow fish entrance and passage downstream without significant injury and mortality. Other innovations to screen or attract fish away from turbine entrances, including by light, sound, bubble curtains, and electrical currents have been developed (Rytwinski et al., 2017). New fish passage technologies for small hydropower sites, such as nature-like rock-ramp, lowhead dams, whoosh systems, and so on, are also under development (Godinho et al., 2020).

\section{DATA AND METHODOLOGY FOR NPD COST ANALYSIS}

The analysis of NPD hydropower costs in this study has two main components:

- Identification of reference US NPD sites

- Cost analysis of reference US NPD sites

The data and methodology employed for each of these components are discussed in this section.

\subsection{OVERVIEW OF DATA SOURCES}

- Oak Ridge National Laboratory (ORNL)—Hadjerioua et al. (2012) performed an initial resource assessment of more than 54,000 NPD sites, including estimates of potential capacity. Sites with capacity estimates of $\geq 100 \mathrm{~kW}$ from the resource assessment were selected as the starting point for the analysis in this study. A cutoff capacity of $100 \mathrm{~kW}$ was used in this study, representing about 3,100 of the $>54,000$ sites because the rest were considered micro-hydropower sites. These microhydropower sites are more numerous at about 51,000; likely to be highly varied, lacking in data to support detailed assessment and representing a small amount of capacity relative to the $\sim 3,100$ sites selected.

- US Army Corp of Engineers (USACE, 2019) compiles the NID database of dams in the United States. The database includes information on dam location, ownership, features, and inspection records. The 2019 NID database includes more than 90,000 dam records.

- US Army Corps of Engineers (USACE, 2015) collected daily data for about 150 sites that it manages as part of an initial assessment of hydropower potential at these sites. These daily data were adopted in this study for evaluating performance and costs at these sites. More than 130 of these sites are included in the $\sim 3,100$ sites selected from the ORNL resource assessment discussed above.

- Small Hydro Consulting (SHC 2019) provided civil works conceptual design and cost estimates for both baseline and innovative cases for seven sites. These estimates served as a basis for understanding the design requirements for many of the reference sites analyzed in this study.

\subsection{IDENTIFICATION OF REFERENCE US NPD SITES}

The starting point for characterizing the US NPD resource base is data from the resource assessment of more than 54,000 NPD sites by Hadjerioua et al. (2012). The data from Hadjerioua et al. (2012) include estimates of average head and monthly flows at NPD sites, which were combined with estimated turbine efficiencies and capacity factors to estimate potential capacities and monthly energy generation. Although the underlying approach means that these estimates may differ from site-specific potentials, the capacity estimates in Hadjerioua et al. (2012) provide insights into the relative viability of these sites. 
Figure 3 shows the distribution of $\sim 600$ US NPD sites with potential capacities of $>1$ MW from the ORNL resource assessment. The sites considered as representative of the technical US NPD hydropower resource base in the current study are those with estimated capacities of $100 \mathrm{KW}$, representing slightly more than 3,100 sites.

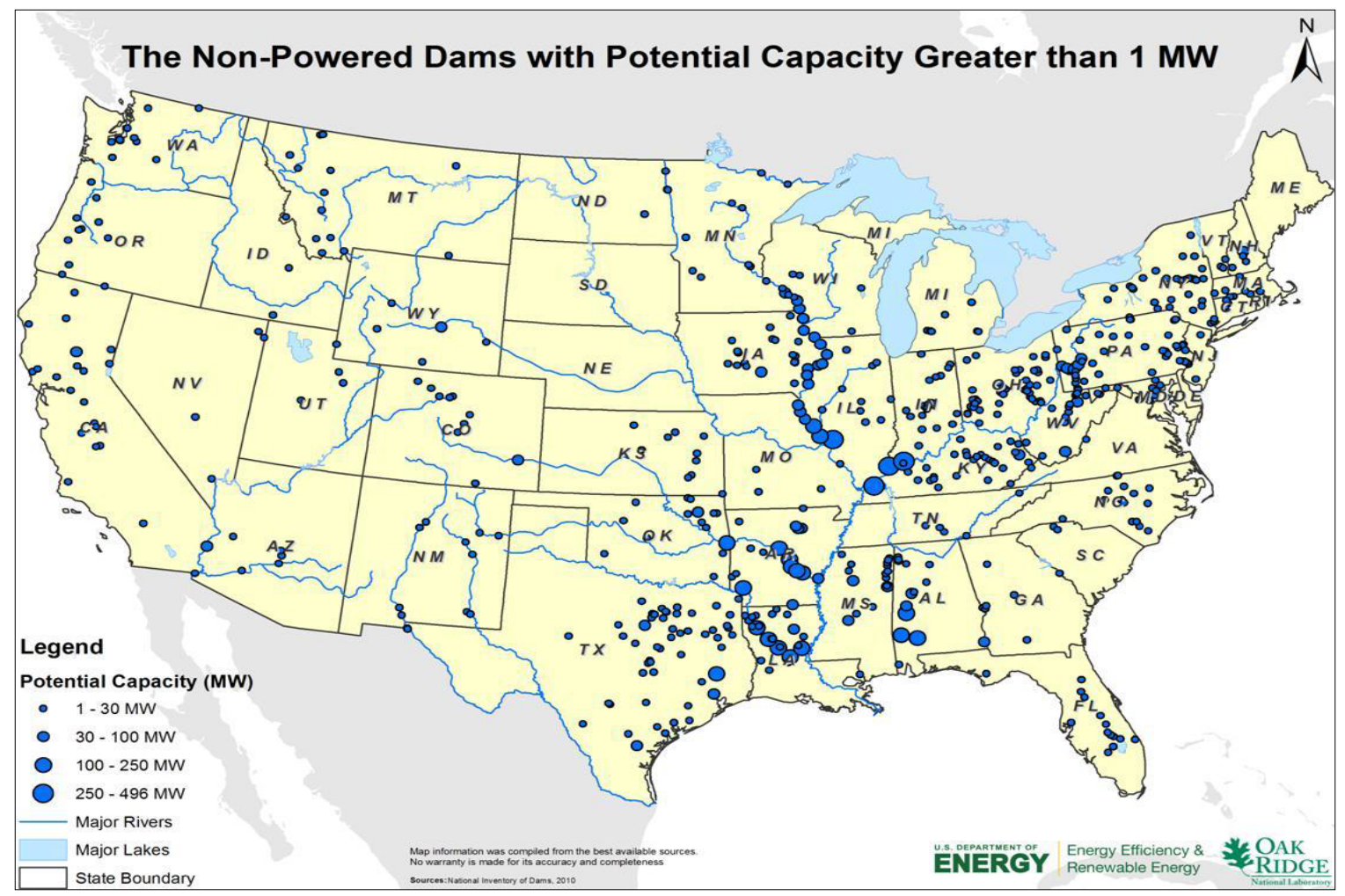

Figure 3. Locations of $\sim 600$ NPD sites with potential capacities $>1$ MW. (Source: Figure 11 of Hadjerioua et al., 2012)

\subsubsection{Clustering Approach}

Resources at the $\sim 3,100$ NPD sites identified above were analyzed using a clustering method. Clustering methods essentially partition the records in a data set into a smaller number of groups or clusters, minimizing within-cluster information differences and maximizing between-cluster information differences (Meilă, 2007; Rokach and Maimon, 2005). Data records may include numeric, nominal, binary, or other data types that cannot be easily combined into a single measure. Clustering analysis methods are designed to: (1) measure the information content of each data record; (2) measure the distance between the combined information across records and evaluate the value of each cluster; and (3) compare different sets of clusters derived from the same data set (Rokach and Maimon, 2005).

The $K$-means algorithm is one of the most popular clustering methods and partitions data records into a given number $(K)$ of groups based on the distance between each record and the centroid of each cluster. Th $K$-means algorithm is computationally intensive because the number of $K$ partitions from a data set of $N$ records is approximately $K^{N} / K$ ! (e.g., for $N=25$ and $K=4$, there are nearly 50 trillion potential partitions) (Steinley, 2006). Since complete enumeration of all potential partitions is nearly impossible for optimization of real data sets, the $K$-means algorithm in practice is iterative and optimality is determined based on a stopping criterion. The method begins with an initial set of values for the centroids in each cluster, and each feature (variable) of a cluster's centroid is updated during each iteration as the average value of that feature across all records in the cluster. The $K$-means algorithm based on centroids as 
described above is suitable for numeric or continuous data but has also been adapted for non-numeric data. The clustering analysis in this study uses PAM (partitioning around medoids), which is an extension of the $K$-means algorithm that is robust to non-numeric data types and uses medoids rather than centroids as the basis for computing clusters (Schubert and Rousseeuw, 2019; Maechler, 2019). A medoid is the member of a cluster with the minimum dissimilarity across members of the cluster. The PAM approach is appropriate for this study since the objective is to identify a limited number of sites, referred to herein as "reference sites," that are representative of hydropower resources at groups or classes of sites. The cost estimates for each reference site can then be used to rank NPD costs and could serve as the basis for scaling costs to each site in the NPD resource base.

A two-level clustering analysis was performed in this study as illustrated in Figure 4 because of a lack of complete data for the relevant variables at all sites and to reduce the computational burden of the clustering process. On the first level, clusters of NPD sites are identified based on dam infrastructure variables. The dam infrastructure clusters for a subset of the sites obtained in the first level are used with available daily data on water resources (i.e., flow and head) in the second level to produce combined dam infrastructure and water resource clusters.
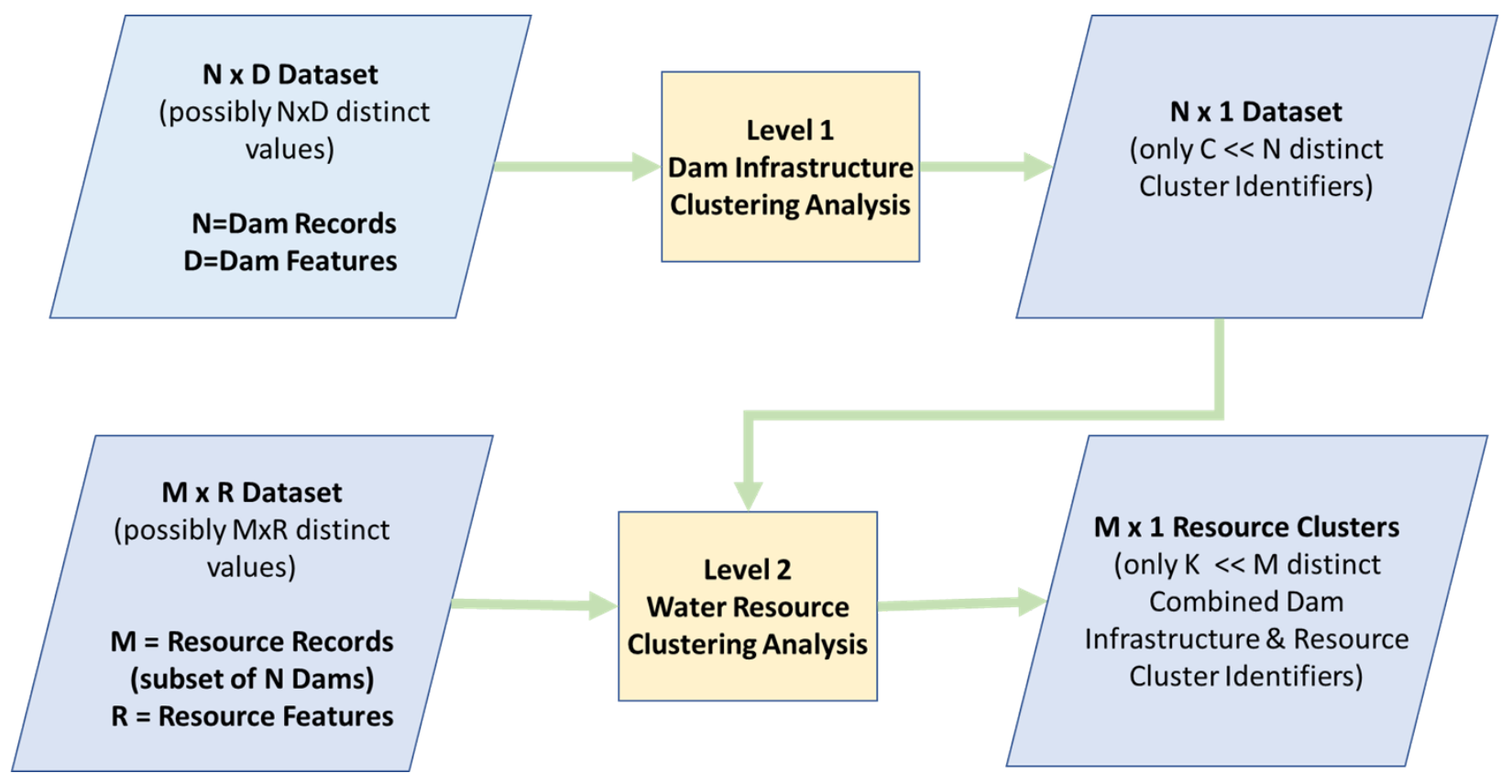

Figure 4. Schematic of the two-level dam infrastructure and water resource clustering.

\subsubsection{Data for NPD Clustering Analysis}

Data for the first-level clustering of dam infrastructure in this study were from the NID, which is compiled by the US Army Corp of Engineers (USACE 2019) The NID contains information such as dam name, location, ownership, year of construction, inspection dates, and findings. The NID also contains design elements, including purpose of the dam, dam type, dam length and height, reservoir surface area, drainage area, reservoir storage capacity, discharge capacity, and spillway/outlet characteristics. As noted by Hadjerioua et al. (2012), many of the records for these variables are incomplete or inaccurate.

Nevertheless, the NID provides the most comprehensive and accessible data on dam characteristics at the national scale. The analysis in this study selected the following three variables, which are well populated in the NID database and are relevant to the potential cost of adding power at an NPD site: 
- Purpose: Most dams in the NID database serve multiple purposes, which are indicated by a set of letters listed in order of decreasing priority, so that the first letter indicates the primary purpose of the dam. The 12 purpose categories in the NID are combined into 5 categories for this study: hydropower ${ }^{3}$, navigation, water supply, flood control, and other (this category includes purposes such as recreation, fish and wildlife pond, fire protection pond, debris control, tailings and gradient stabilization, and the original NID "other" category).

- Type: Dam type provides a composite description of the structure of the construction at a site. There are 12 dam types in the NID but, as with the purpose data, the dam types data are often a combination of the individual types. The dam types in the NID were combined into four groups for this study: concrete (concrete, roller compacted concrete, buttress, arch, multi-arch, masonry), embankment (rockfill, earth), gravity, and other (stone, timber crib, etc.).

- Spillway/outlet: Three data columns in the NID — spillway type, spillway width, and outlet gate type - provide information on the type of dam water outlet structure. However, many records in these columns are missing. Additionally, the outlet gate type, which has the potential to provide additional details of the water management structure at the dams, has more than 12 categories with a multiplicity of these present in different numbers. Therefore, this data column is inconsistent and likely to be inaccurate. A similar observation applies to the spillway width column of the NID. The spillway type is included in this analysis and has three categories that are retained: controlled, uncontrolled, and none. Missing spillway type data are assigned to the "none" category.

Data for the second level clustering analysis were daily water resources (head and flow) data for about 152 sites managed by the US Army Corps of Engineers (USACE, 2015). Out of these 152 sites, 135 are a subset of the $\sim 3,100$ sites included in the first-level clustering analysis described previously. Daily water resources data were considered necessary to understand the hydropower potential and associated costs for this study. Data from river gauges along major rivers and tributaries in the US are often available at daily intervals, preserving the essential patterns in more granular data while avoiding the severe averaging effect in monthly or annual data. For the clustering analysis, the dependency between the flow and head data were captured according to the following procedure:

- Flow variables: The daily flow data in cubic feet per second for each site were used to compute a 10 -point flow duration curve at 10 percentile increments. These were divided by $200 \mathrm{cfs}$ to normalize the values. The median flow in original units (cfs) for each site was also included as a variable.

- Head variables: For each site, head level in feet was calculated as the median of head values for each of the 10 flow levels above. These were divided by $75 \mathrm{ft}$ to normalize the values. The median head value for each site in original units (ft) was also included as a variable.

The above procedure produces 22 variables that, along with the dam infrastructure identifier from the first level, were used in the second-level clustering analysis to identify resource clusters (or NPD classes) used to select the reference sites.

\subsection{COST ANALYSIS METHODOLOGY FOR REFERENCE SITES}

ORNL has developed two types of hydropower cost modeling capabilities in support of WPTO. The Baseline Cost Model uses cost data from existing plants to fit parametric models of initial capital costs to a power function of capacity and head for several hydropower project classes, including NPD sites (O’Connor et al., 2016). The Hydropower Integrated Development and Economic Analysis (HIDEA)

\footnotetext{
${ }^{3}$ By definition, NPD sites exclude those with existing hydropower.
} 
Model is a bottom-up framework that models the cost components of a hydropower plant using a combination of parametric and volumetric equations (O'Connor et al., 2017). Although the Baseline Cost Model remains useful for rapid assessment of costs for a given site and is being updated, the current study requires capabilities that are beyond the Baseline Cost Model framework. As already discussed in this report, the remaining NPD sites in the US have relatively small-scale potentials, with other attributes that would make cost estimation based on the existing Baseline Cost Model inadequate. Plant design features, such as turbine size, plant size, water conveyance configuration, and environmental mitigation requirements, among others, are determined by site-specific conditions. The bottom-up modeling framework underlying the HIDEA model is better suited for these purposes and is used in the current study. Given that most of the NPD sites in the US have $<30 \mathrm{MW}$ of potential hydropower capacity, the model is focused on small hydropower (hence is now referred to as "smHIDEA" in this study).

\subsubsection{Basic Features of the smHIDEA Model}

The initial smHIDEA model was based on concepts in existing tools such as the US Bureau of Reclamation Hydropower Energy and Economic Analysis Tool ${ }^{4}$ (USBR 2011) and RETScreen small hydropower guidelines ${ }^{5}$ (RETScreen, 2004) with a focus on conventional technologies and is primarily implemented as a Microsoft Excel Workbook. Figure 5 is a schematic of the smHIDEA conceptual framework, and its design features are briefly described below. As shown in Figure 5, the basic user inputs for the smHIDEA model include site information, facility design criteria, and financial parameters. The facility design module performs overall project design based on the input parameters using a combination of exogenous, parametric, heuristic, and engineering-based specifications. Project costs can be estimated with parametric as well as unit- and rate-based equations by combining dimension and materials information from the facility design modules with other user inputs. The high variability of dam infrastructure and water resource characteristics at NPD sites lead to uncertainties that require detailed evaluation of the electricity generation performance for a given facility design. Therefore, relatively detailed performance analysis is important to understanding the implications of facility design choices for plant efficiency and cost effectiveness. Initial versions of the smHIDEA model incorporated linearized efficiency curves and a mixed-integer linear program framework to optimize plant generation using head and flow duration curves derived from flow data or synthetic hydrographs. The facility design specifications, cost data, and performance optimization results are combined to perform an economic analysis for a given site. Outputs of the economic analysis include the LCOE, net present value, and internal rate of return, among other summaries of physical attributes and cost results, which are used to evaluate the cost and performance of electricity production options at each site. Since 2019, the smHIDEA model has been further enhanced to incorporate features that enable a more complete analysis of hydropower costs at potential sites as outlined below.

\subsubsection{Updates to smHIDEA Model Capabilities since 2019}

The conventional design approach originally incorporated in the smHIDEA model constrains the ability to evaluate the multiplicity of emerging design options and technological innovations aimed at costeffective hydropower generation at sites with small potential capacities. Thus, a need exists for greater flexibility in the smHIDEA approach to facility design, costing, and optimization. The following updates to enhance the capabilities of smHIDEA were implemented in 2019 and 2020, as part of an ongoing effort:

\footnotetext{
${ }^{4}$ Available online from https://www.usbr.gov/power/data/data.html

${ }^{5}$ Available online from http:/www.nrcan.gc.ca/energy/software-tools/7465
} 


\section{Basic User Inputs}

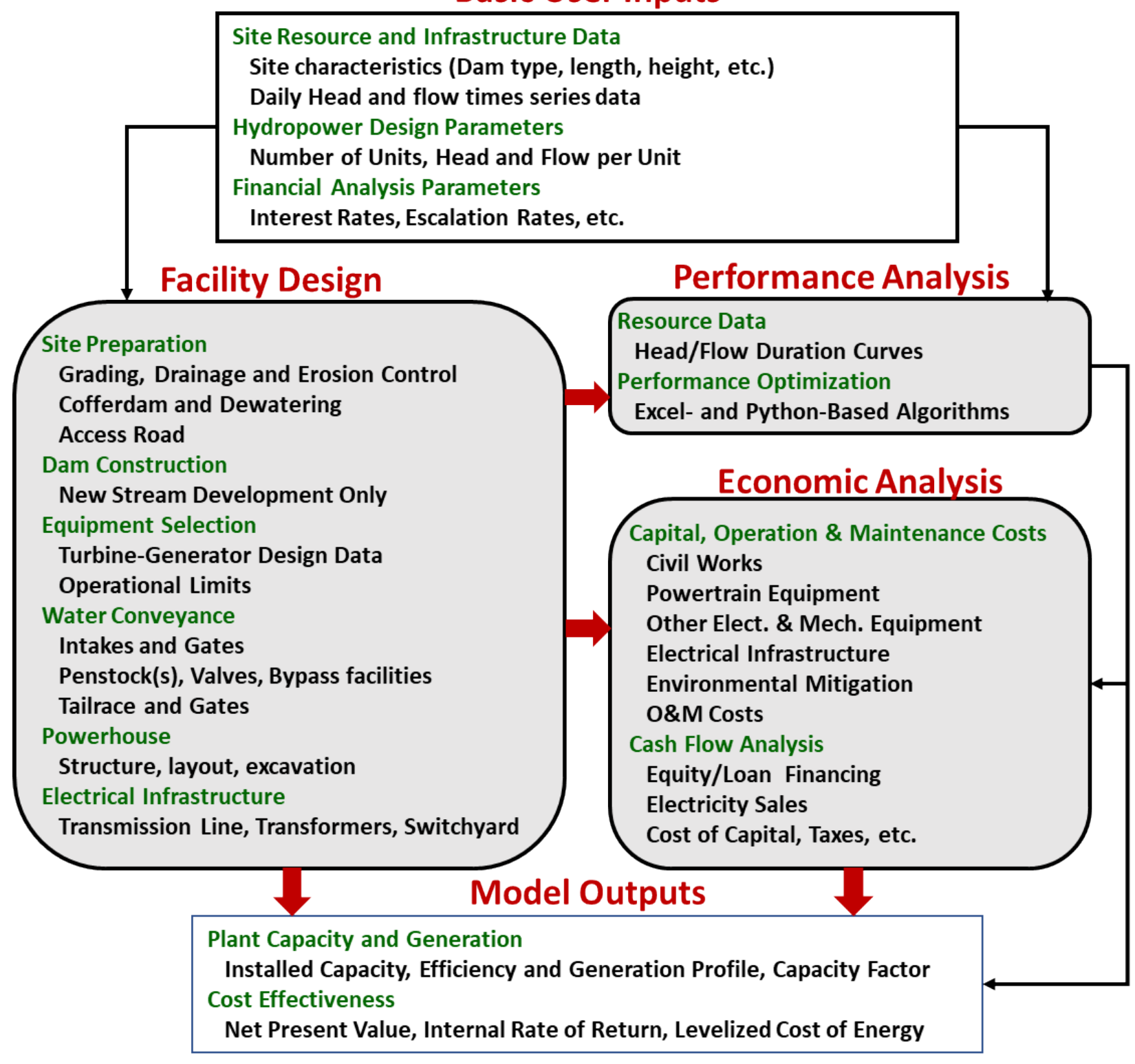

Figure 5. Schematic of the smHIDEA modeling framework.

1. Flexible hydropower facility design specification: A re-write of the underlying VBA (Visual Basic Applications) model code was implemented to:

- Reduce the number of embedded parameters in the code. Many of the embedded parameters were moved out of the VBA code to Excel sheets, where they can be easily modified as needed for new specifications.

- Enable addition of new facility components (see below) and facilitate modifications to the model by separating the single water conveyance design module into three modules: intake, penstock, and tailrace.

- Enable flexibility in compiling facility components and evaluating different configurations by revising the design code using the Dictionary object in VBA. In line with this, the user interface 
for the model was enhanced with a "Facility Configuration" table where the user provides information on the arrangement of facility components identifying the start and end points for each component, as well as basic information on number, status, and flow levels.

2. New hydropower infrastructure options: As highlighted above, the initial version of the smHIDEA model included options for specifying intake, penstock (including bypass and bifurcation), and tail races for water conveyance. Additional components are needed to represent the variety of potential NPD facilities. A user interface and associated code for intake channel/canal design and costing has been added to the model for this purpose. User interfaces for the existing components have also been enhanced, along with required code changes, to enable more detailed specifications of component dimensions and type, and allow for multiple, identical/nonidentical components arranged in series or parallel. Additional options under consideration include siphon and tunnel water conveyance components, new turbine technologies, and powerhouses specialized for low-head hydropower.

3. Excel-based performance simulation algorithm: The original performance simulation method in the smHIDEA model was based on the mixed-integer linear program algorithm through a link between Python and Excel, as well as a web-based Global Optimization Program (Dakota Engine). For easier control and use, a new algorithm for the performance simulations based on the crossentropy maximization method (Ernst et al., 2007) was designed and incorporated in the smHIDEA workbook. Although the cross-entropy approach, like the mixed-integer linear program, is not a global optimization method, it can directly use the highly nonlinear functions that are inherent to hydropower performance evaluation, avoiding the need to linearize these functions for simulations.

4. New head curve: Unlike the usual head-duration curve, which is calculated independently of flow levels, a new head curve derived as the median of head levels associated with each point on the flow duration curve, referred to as the "median-head" curve, has been added to the smHIDEA model. The interdependence between the flow-duration curve and the new median-head curve enables a more realistic evaluation of changes in plant performance under simultaneous changes in head and flow levels. In many cases, the overall slope, fluctuation, and shape of the median-head curve are quite different from those of the conventional head-duration curve.

5. Automated resource data loading: Functionalities were added to the smHIDEA workbook to automate loading of head and flow data from a separate workbook. The first three columns of the individual sheets of the latter workbook must provide the date, flow, and head data in that order. The loading algorithm automatically adjusts the receiving table in the smHIDEA workbook to the size of the resource data.

6. Direct use of exogenous cost data: The smHIDEA model was designed to calculate facility costs based on internally designed hydropower infrastructure. Although the facility design options incorporated in the model have been extended as described above, small hydropower technology is an evolving area. Therefore, the smHIDEA facility design options will continue to evolve over time. To facilitate evaluation of generation and economic performance for design options for a given site that are not explicitly captured in the model, an option and required code have been added to bypass the internally generated facility designs and costs in the model. Thus, exogenous cost components matching the model's hydropower cost structure for a specific facility configuration and site can be provided and combined with the performance simulation capabilities of the model for a complete cost analysis. 


\subsubsection{Key Parameters and Assumptions for smHIDEA Simulation}

A few assumptions and parameters are necessary for simulating hydropower plant performance and costs within the smHIDEA model. For this study, these include the following:

- 2019 as current year

- 40-year project lifetime

- 20-year capital recovery period

- 5-year development/construction period

- $2 \%$ inflation/escalation rate

- $7.6 \%$ nominal discount rate

- $5.4 \%$ real discount rate

- Contingency rates: $20 \%$ for civil works, $15 \%$ for electro-mechanical equipment

- $5 \%$ planned/forced outage rate

- $\$ 70 / \mathrm{MWh}$ target electricity cost

- No production incentives

- Environmental impact mitigation cost at $10 \%$ of the sum of civil works and electro-mechanical costs

\section{NPD RESOURCE CHARACTERISTICS AND REFERENCE SITES}

This section provides an overview of the $\sim 3,100$ potential NPD hydropower sites identified for analysis in this study based on previous resource assessments. It also discusses results of analysis to group sites into a set of clusters with relatively homogenous characteristics within each cluster.

\subsection{NPD SITE CHARACTERISTICS}

Resource data for the $\sim 3,100$ sites with $100 \mathrm{~kW}$ or more of estimated potential capacity from Hadjerioua et al. (2012) are plotted in Figure 6. The plot shows estimated capacity by flow and head for six categories of dam heights. Estimated capacities are grouped into seven categories with the first three $\leq 1$ MW and the last two $\geq 10 \mathrm{MW}$. Although there is some correspondence between dam height and estimated head, average available head and flow estimates from the resource assessment are widely distributed. Figure 6 shows that most of the capacity categories can be found within each dam height category and are $\leq 3 \mathrm{MW}$. The largest estimated potential capacities (i.e., $\geq 49 \mathrm{MW}$ ) are found mostly in the 50-100 ft dam height category, with fewer sites in the 20-50 ft and 100-200 ft categories. Figure 6 suggests that the relationship between average flow and head across these sites is slightly negative. Overall, the wide spread of estimated capacities within each dam height category emphasizes the need for a systematic approach for evaluating the potential cost of hydropower and the role of innovations to reduce costs at NPD sites. 


\section{Site Capacity Potential by Flow and Head}

Dam Height (ft): (0-10)

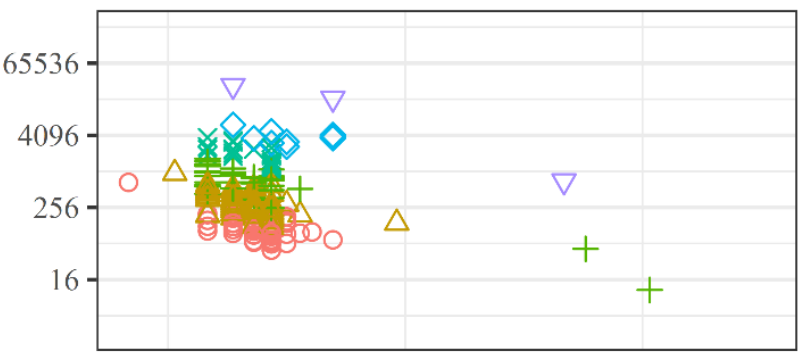

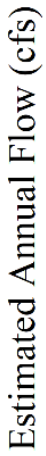

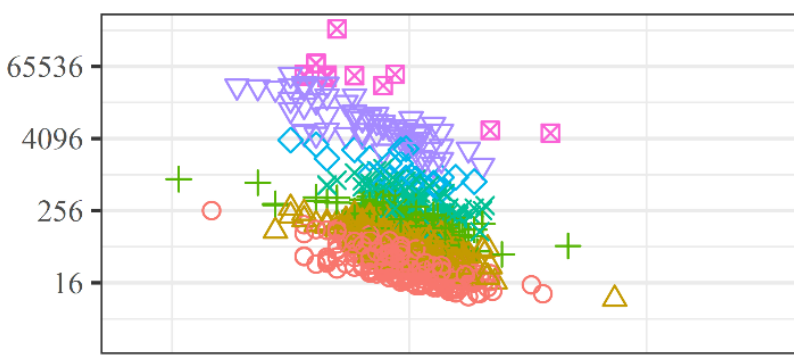

Dam Height (ft): (100-200)

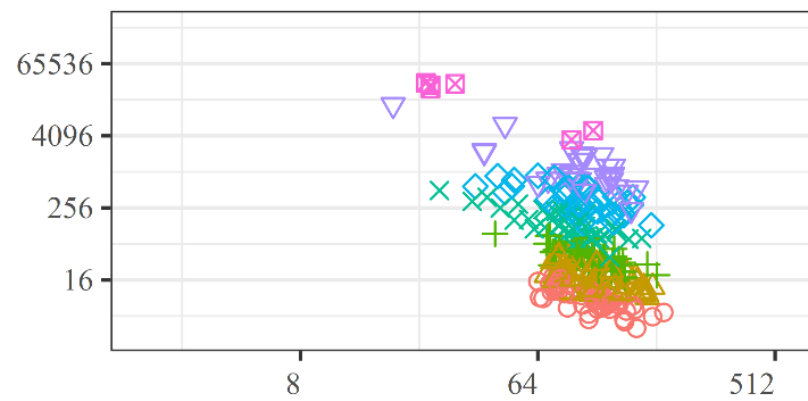

Dam Height (ft): (10-20)

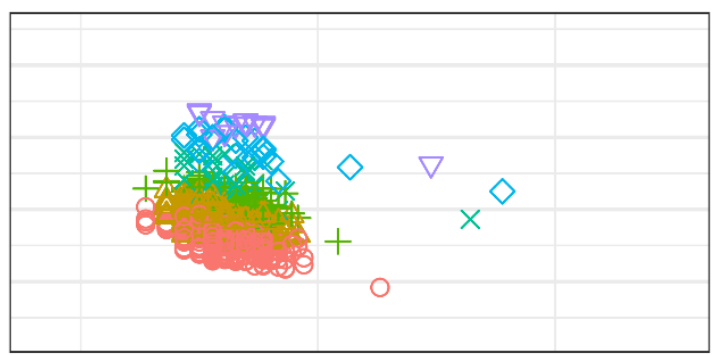

Dam Height (ft): (50-100)

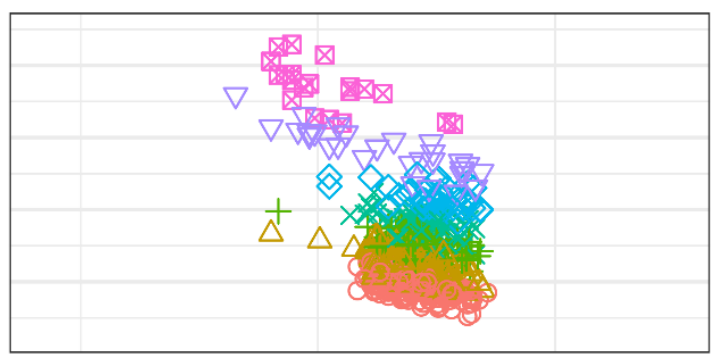

Dam Height (ft): (200-800)

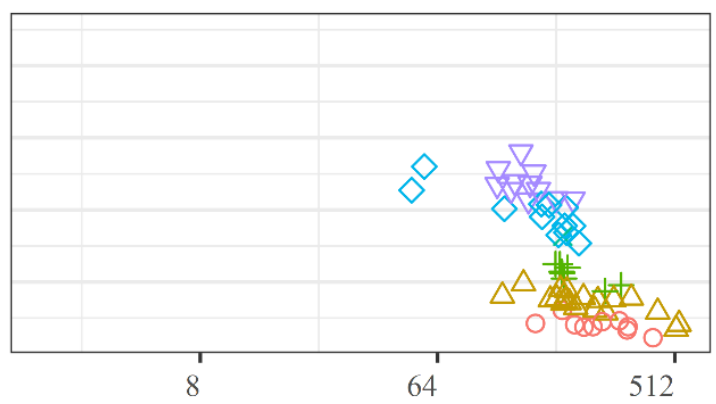

Estimated Head (ft)

Capacity Ranges (MW)

$\begin{array}{ll}\bigcirc & (0.1-0.2) \\ \triangle & (0.2-0.5)\end{array}$

$+\quad(0.5-1)$
$\times \quad(1-3)$

$\diamond(3-9.9)$

$\nabla \quad(9.9-49.3)$

$\otimes \quad(49.3-496)$

Figure 6. Estimated capacity potentials $(\geq 100 \mathrm{~kW})$ from the ORNL NPD resource assessment. Both axes are drawn on a base $2 \log$ scale for clarity.

\subsection{DAM INFRASTRUCTURE CLUSTERS}

Figure 7 provides a visual interpretation of results from the first-level clustering analysis of dam infrastructure for the $\sim 3,100$ NPD sites in this study. The analysis identified 20 cluster groups based on dam purpose, dam type, and dam spillway type. Figure 7 also shows a count of the sites within each cluster, which are unevenly distributed across the 20 clusters. Clusters 2, 3, and 5 have the largest number of members with between 300 and 500 sites, together accounting for nearly half of all the sites. Clusters 4, 14, and 16 each have about 200 members, with most of the remaining clusters having less than 100. Clusters with the largest number of members are nearly all embankment dams. Additionally, most members of clusters $1,7,12,15$, and 17 are also embankment dams, along with nearly half of the 
members of cluster 19. Cluster 8 consists of entirely other dam types. Clusters $9,10,13$, and 16 are mostly concrete dams, while gravity dams make up the majority of clusters $6,11,18,19$, and 20 . Given these observations, a useful, though imprecise, aggregation of the 20 clusters in Figure 7 based on the majority of dam types is as follows:

- Embankment dams: clusters 1-5, 7, 12, 14, 15, and 17

- Concrete dams: clusters 9, 13, and 16

- Gravity dams: clusters 6, 11, 18-20

- Other dams: cluster 8
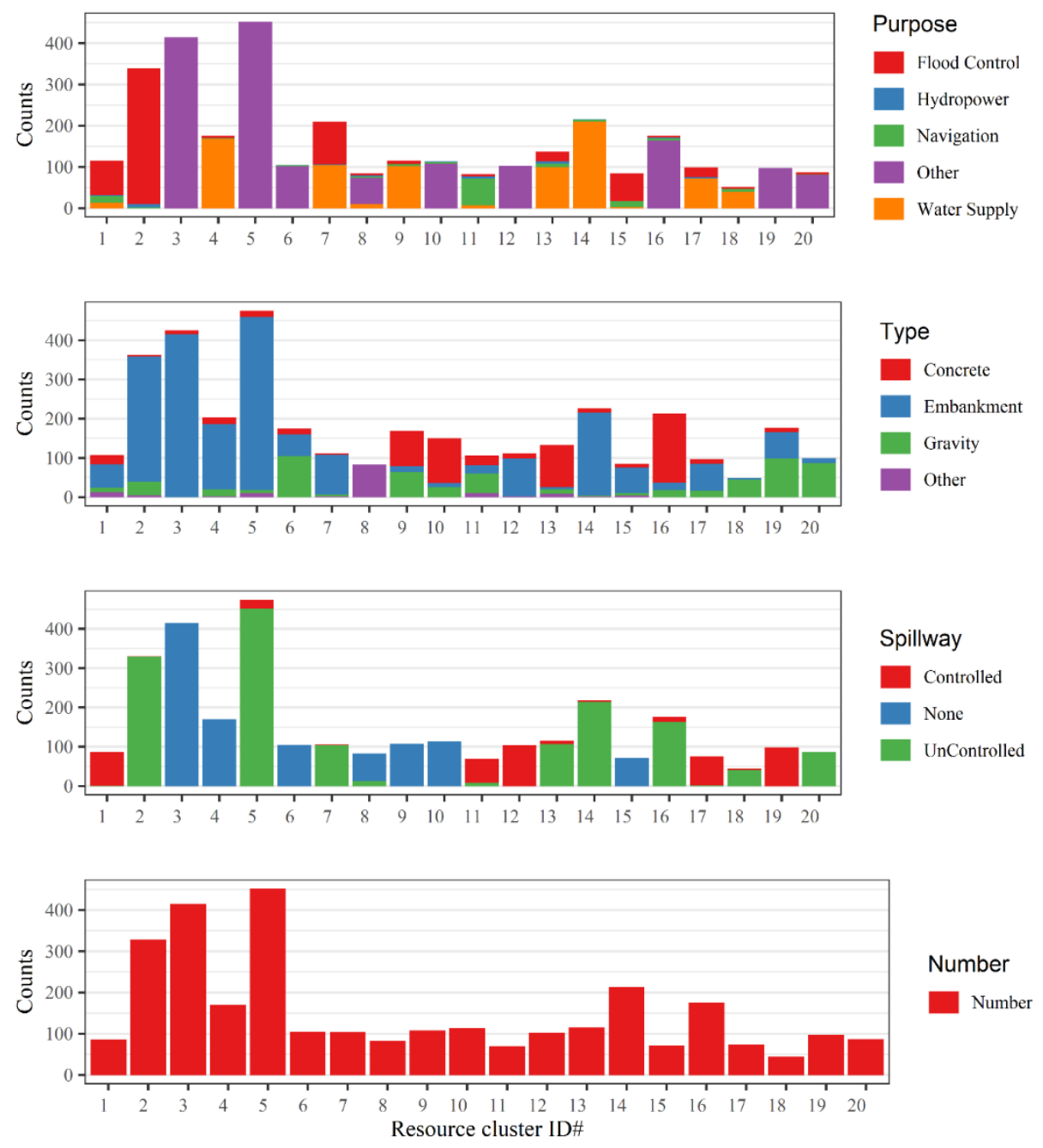

Figure 7. Dam infrastructure clusters characteristics and member counts.

Purpose and spillway type characteristics of the clusters within each of the above dam type partitions are mixed, but there are also common patterns. The only cluster in the "other" dam type category, cluster 8 , is also entirely of the "none" spillway type. Embankment dam types are split mainly between "none" and "uncontrolled" spillway types, with only clusters 1 and 7 having the "controlled" spillway type. The primary purposes for embankment dam types are "flood control" (clusters 1, 2, and 15) and "other" (clusters 3,5, and 12). Of the remaining clusters in the embankment dams partition, the sites in cluster 4 and 14 are nearly all primarily used for "water supply," whereas cluster 7 is evenly split between primary use for "flood control" and "water supply." Spillway types for the four gravity dam members are "none" 
for cluster 6, "uncontrolled" for cluster 18 and "controlled" for clusters 11 and 19. Primary purposes for these clusters are generally "other" for clusters 6 and 19, "navigation" for cluster 11 and "water supply" for cluster 18. Cluster 11 is the only one with "navigation" as the majority primary purpose, which combined with its majority "controlled" spillway type identifies this cluster as almost all lock \& dam sites. Spillway types for the three concrete dam clusters are "none" for cluster 9 and "uncontrolled" for clusters 13 and 16. The primary purpose for the concrete dam partition are "water supply" for clusters 9 and 13, and "other" for cluster 16.

Figure 8 summarizes the dam type and purpose information in Figure 7 based on their representation within the clusters. It shows that most dams used for flood control are embankment dams, and that most navigation dams are gravity-type dams. Water supply dams can be of the embankment, concrete, or gravity type. The "other" purpose category represents dams that are primarily not used for flood control, water supply, or navigation and can be any of the four types of dams identified in Figure 8. However, most sites are used for multiple purposes.

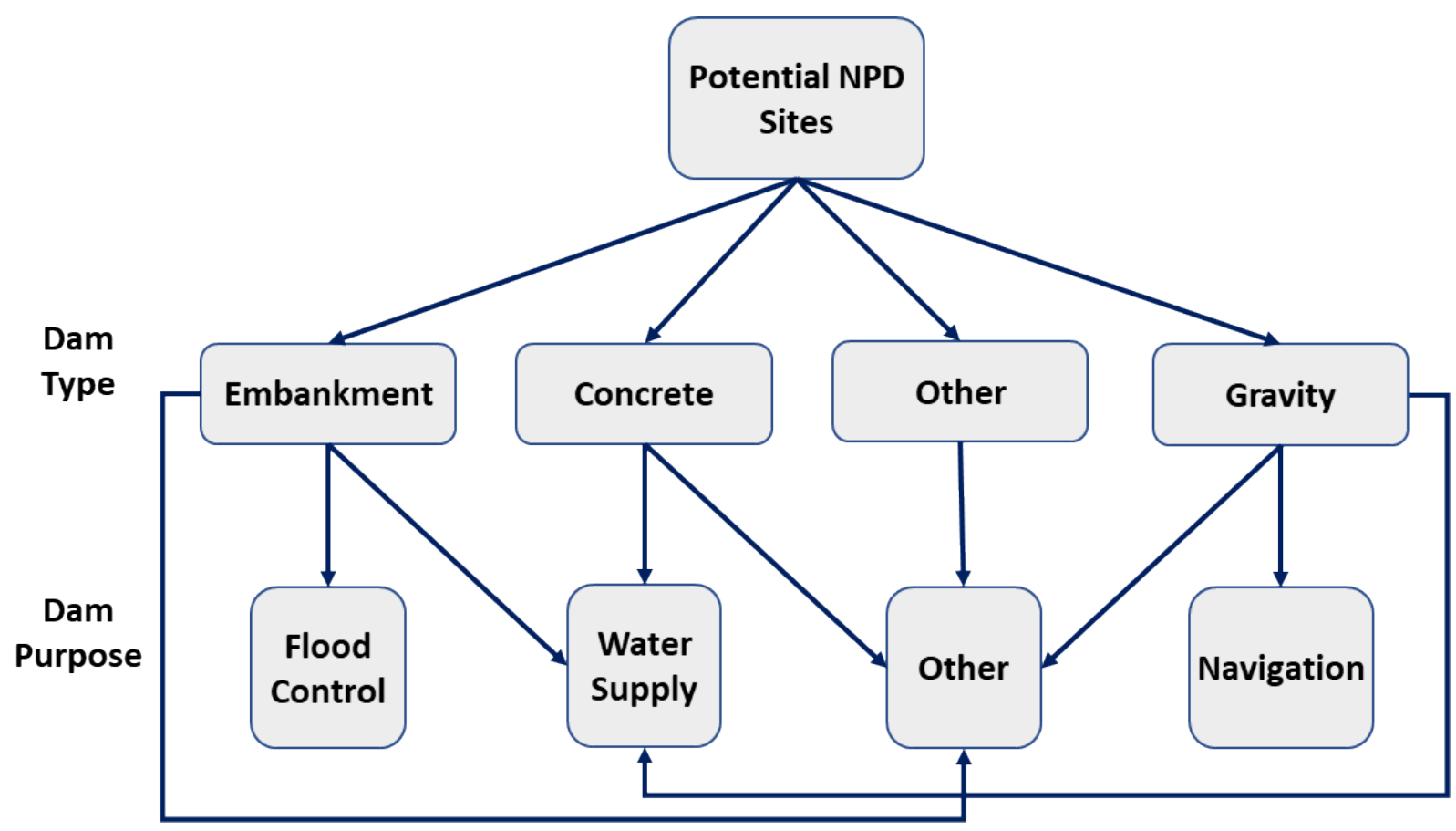

Figure 8. Summary of dam infrastructure clusters by major types and purposes.

\subsection{WATER RESOURCE CLUSTERS}

The 135 sites included in the second-level clustering analysis were grouped into 20 clusters. Figure 9 shows distributions of the underlying variables used in the clustering analysis across all members and the representative site. The boxplots show the median, first, and third quartile values (box); lower and upper bounds defined as first quartile $-1.5 \times$ interquartile range and third quartile $+1.5 \times$ interquartile range, respectively (whiskers); and outliers (points) for flow and head variables across all members of each cluster. Variable values for the representative sites are plotted to the right of each boxplot. Comparisons of daily flow and head distributions across all members to values for the representative site show that the latter provides a good coverage of each cluster in most cases. This result follows from the definition of medoids under the clustering algorithm used in this study. Although several clusters have outliers, the representative sites either cover the entire range or tend toward the middle of the distribution. The last panel of Figure 9 shows the number of sites for each combination of dam cluster ID\# and Resource 
Cluster ID\# for the 135 sites. As expected, the largest number of sites within each cluster corresponds to the dam cluster ID\# for the representative sites (red-color number in bottom panel of Figure 9). The dam cluster ID\#s included among the 20 representative sites are 2, 7, 8, 11, 13, and 17.
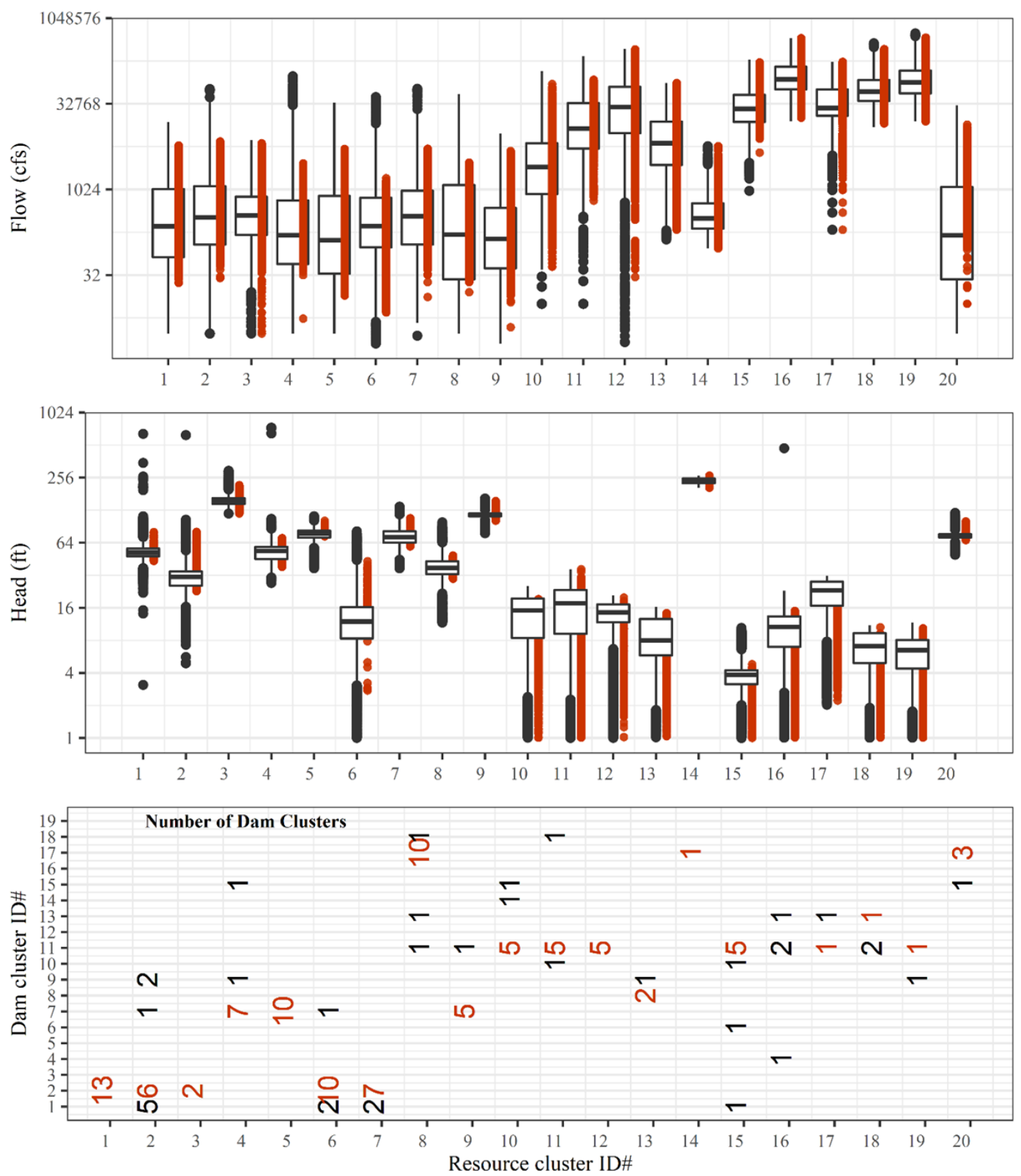

Figure 9. Distribution of flow, head, and dam cluster ID\# for each water resource cluster. Representative sites are indicated by red points and numbers. Flow and head data are in base $2 \log$ scale.

The water flow, head, and dam infrastructure characteristics for each representative site are shown in Appendix B, and these are summarized in Table 2. Column 1 of Table 2 shows the second-level cluster identifiers, referred to as "resource clusters," and column 2 shows the number of members/sites in each cluster. Column 3 contains the dam name for the representative site of each cluster. Columns 4 and 5 provide the median (and range) of the daily flow and head data for each of the sites. Since the flowduration curve is always upward sloping, columns 6 and 7 focus on the shape of the median-head curve 
by its general direction and local variation in that direction. Each point on the median-head curve is the median daily head for the corresponding point on the flow-duration curve.

Given that the flow and head data are continuous variables, partitioning the clusters in Table 2 into a smaller set of groups is not straightforward. Still, the direction and fluctuation values of the median-head curve provide a starting point for understanding differences across the clusters. The following combinations of direction/fluctuations of the median-head curve can be identified as follows:

- Increase/Low: cluster 5

- Flat/Low: cluster 6

- Decrease/Low: clusters 1, 7, 8, 10-12, and 15-19

- Decrease/High: clusters 2-4

- Indeterminate/High: clusters 9, 13, 14, 20

This aggregation of resource clusters based on median-head curves can be further analyzed using the flow and head data (columns 4 and 5 of Table 2). For hydropower development, the "Increase/Low" and "Flat/Low" partitions are the most desirable. However, cluster 5, the only member of the "Increase/Low" partition, corresponds to a representative site with relatively high head but low flow levels. Cluster 6, also the only member of the "Flat/Low" partition, has a representative site with both low head and flow levels. Cluster 5 has 10 members, whereas cluster 6 has 13 members accounting for 23 of the 135 sites (nearly one-fifth).

The "Decrease/Low" partition includes 11 of the 20 clusters in Table 2 and has 73 member sites. Most clusters in this partition ( 8 clusters with 38 members) have lock and dam representative sites combining of medium to very high flow and very low to low head levels. Three other clusters with 35 members in this partition have combinations of low to medium flows and medium to high head levels. The "Decrease/High" partition includes 3 clusters with 25 sites combining medium flow with medium to high head levels. The "Indeterminate/High" partition includes 4 clusters with 14 sites. The representative site for cluster 14 in this partition has the highest head but medium flows in Table 2. However, cluster 14 is a singleton, consisting of only one site. Representative sites for two of the remaining clusters in this partition have relatively high heads but very low flows. The representative site for the fourth cluster of the partition is a lock and dam site that combines relatively high flow with very low head levels.

The flow and head water resource variations in Table 2 are summarized in Figure 10. The figure shows that among the 20 reference water resources sites, lock and dam sites have generally high to very high flow but low to very low head. In contrast, the remaining sites (designated lake dams) consist of a wide combination of head and flow levels.

\subsection{REFERENCE SITE INFORMATION}

The 20 representative sites identified from the second-level clustering analysis are the reference sites for the current study. Table 3 lists the NID identification number, dam length, height, primary dam type, and primary purpose for these sites (USACE, 2019). The costs of developing hydropower at these sites are analyzed and presented in the remaining sections of this study. Appendix $\mathrm{C}$ contains a profile of each reference site. 
Table 2. Summary of representative sites from the water resource clustering algorithm.

\begin{tabular}{|c|c|c|c|c|c|c|}
\hline \multirow{3}{*}{$\begin{array}{c}\begin{array}{c}\text { Resource } \\
\text { cluster }\end{array} \\
\text { ID\# } \\
\end{array}$} & \multirow{3}{*}{$\begin{array}{c}\begin{array}{c}\text { Number of } \\
\text { members }\end{array} \\
\# \\
\end{array}$} & \multicolumn{5}{|c|}{ Representative site data } \\
\hline & & & \multirow{2}{*}{$\begin{array}{c}\text { Flow (cfs) } \\
\text { Median (Range) }\end{array}$} & \multirow{2}{*}{$\begin{array}{c}\text { Head (ft) } \\
\text { Median (Range) } \\
\end{array}$} & \multicolumn{2}{|c|}{ Median head curve shape } \\
\hline & & Dam name & & & Direction & Fluctuation \\
\hline 1 & 13 & Tioga Dam & $248(39-6,057)$ & $52(52-50)$ & Decrease & Low \\
\hline 2 & 14 & Dillon Dam & $416(97-7,107)$ & $32(34-33)$ & Decrease & High \\
\hline 3 & 2 & R. D. Bailey Dam & $449(95-6,621)$ & $150(153-149)$ & Decrease & High \\
\hline 4 & 9 & Monroe Lake Dam & $201(53-2,925)$ & $54(55-51)$ & Decrease & High \\
\hline 5 & 10 & Cowanesque Dam & $141(19-5,252)$ & $78(77-78)$ & Increase & Low \\
\hline 6 & 13 & Westville Dam & $143(33-1,610)$ & $11(11-12)$ & Flat & Low \\
\hline 7 & 9 & Cave Run Lake Dam & $352(67-5,302)$ & $76(81-68)$ & Decrease & Low \\
\hline 8 & 13 & Lake O’The Pines & $52(25-3,035)$ & $41(43-35)$ & Decrease & Low \\
\hline 9 & 6 & William H. Harsha Lake Dam & $82(31-4,852)$ & $115(113-115)$ & Indeterminate & High \\
\hline 10 & 7 & Chouteau Lock \& Dam & $2,009(214-72,692)$ & $18(19-3)$ & Decrease & Low \\
\hline 11 & 7 & Jonesville Lock \& Dam and Closure Dam & $11,936(2,964-86,420)$ & $10(24-0)$ & Decrease & Low \\
\hline 12 & 5 & Col. Charles D. Maynard Lock \& Dam & $28,000(3,000-29,5000)$ & $17(17-4)$ & Decrease & Low \\
\hline 13 & 3 & Green River Lock \& Dam 2 & $7,320(1,280-76,000)$ & $7(14-1)$ & Indeterminate & High \\
\hline 14 & 1 & Jennings Randolph Dam & $317(147-58,89)$ & $238(240-232)$ & Indeterminate & High \\
\hline 15 & 8 & Lock \& Dam \#7 & $27,800(13,000-17,4625)$ & $4(4-2)$ & Decrease & Low \\
\hline 16 & 4 & Lock \& Dam 24 & $85,630(43,300-46,5060)$ & $10(14-1)$ & Decrease & Low \\
\hline 17 & 2 & John Overton Lock \& Dam & $27,500(8,600-178,520)$ & $22(24-6)$ & Decrease & Low \\
\hline 18 & 3 & Mississippi River Lock \& Dam \#16 & $56,846(29,637-29,8960)$ & $6(8-0)$ & Decrease & Low \\
\hline 19 & 2 & Mississippi River Lock \& Dam \#21 & $78,540(37,789-47,6700)$ & $6(9-1)$ & Decrease & Low \\
\hline 20 & 4 & Waco Lake & $20(10-14,077)$ & $77(74-79)$ & Indeterminate & High \\
\hline
\end{tabular}




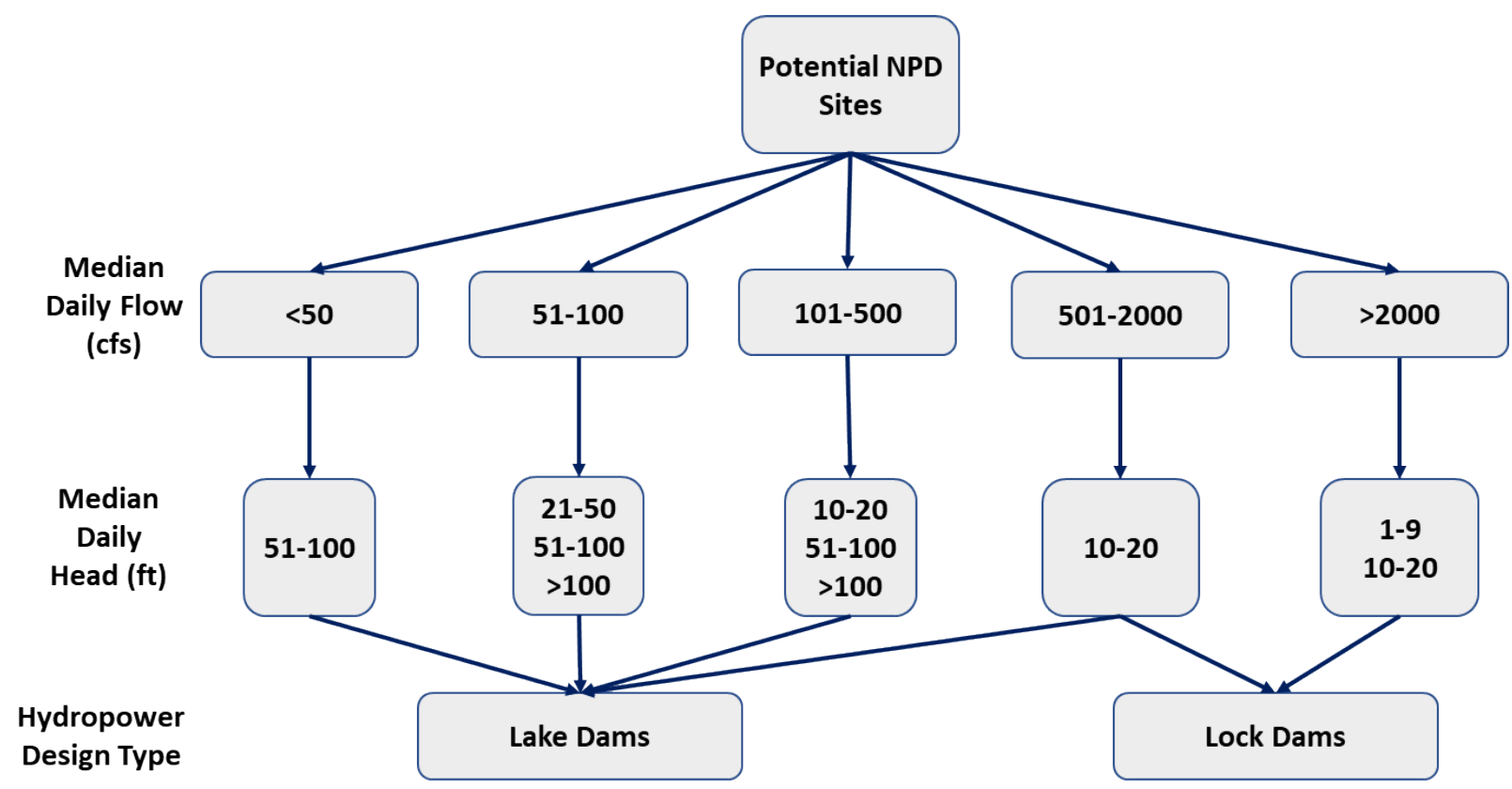

Figure 10. Summary of water resources clusters based on median flow and head data.

Table 3. Reference NPD site information from the NID.

\begin{tabular}{lrrrrr}
\hline \multicolumn{1}{c}{ Reference sites } & NID ID & Length (ft) & Height (ft) & Primary type & Primary purpose \\
\hline Tioga Dam & PA01132 & 2,710 & 140 & Earth & Flood control \\
Dillon Dam & OH00007 & 1,400 & 118 & Earth & Flood control \\
R. D. Bailey Dam & WV10924 & 1,397 & 310 & Rockfill & Flood control \\
Monroe Lake Dam & IN03001 & 1,350 & 93 & Earth & Flood control \\
Cowanesque Dam & PA01134 & 3,100 & 151 & Earth & Flood control \\
Westville Dam & MA00972 & 560 & 72 & Earth & Flood control \\
Cave Run Lake Dam & KY03055 & 2,700 & 148 & Earth & Flood control \\
Lake O'The Pines & TX00010 & 13,020 & 86 & Earth & Flood control \\
William H. Harsha Lake Dam & OH00929 & 1,450 & 205 & Earth & Flood control \\
Chouteau Lock and Dam & OK10303 & 11,690 & 53 & Earth & Navigation \\
Jonesville Lock \& Dam & LA00175 & 920 & 94 & Gravity & Navigation \\
Maynard Lock and Dam & AR00166 & 7,780 & 61 & Concrete & Navigation \\
Green River Lock \& Dam 2 & KY03003 & 615 & 26 & Other & Navigation \\
Jennings Randolph Dam & MD00069 & 2130 & 296 & Earth & Flood control \\
Lock \& Dam \#7 & MN00587 & 10,860 & 41 & Concrete & Navigation \\
Lock \& Dam 24 & MO10300 & 4,584 & 76 & Concrete & Navigation \\
John Overton Lock and Dam & LA00581 & 914 & 104 & Gravity & Navigation \\
Mississippi River Dam 16 & IA00008 & 4,400 & 34 & Gravity & Navigation \\
Mississippi River Dam 21 & MO10304 & 3,116 & 48 & Gravity & Navigation \\
Waco Lake & TX00016 & 17,400 & 145 & Earth & Flood control \\
\hline
\end{tabular}




\section{BASELINE DESIGNS AND COST ANALYSIS}

\subsection{BASELINE PLANT DESIGN}

Although dam infrastructure and water resources at the reference sites identified in this study vary widely, the potential facility configuration across these sites can be grouped into two broad categories: lake dams and lock dams. Table 4 shows this label for each of the 20 references sites, along with overall information on turbine type and water conveyance variables. Sites with an asterisk in Table 4 are those with preliminary civil works design and cost estimates provided by Small Hydro Consulting (SHC, 2019). Three of these sites are in the list of reference NPD sites identified from the clustering analysis and the others are included as part of the full cost analysis. Given the available information, cost analysis was not performed for 5 of the 24 sites in Table 4 because hydropower development is currently impractical at these sites because of either very low head (lock dam) or negligible water flow (lake dam). However, future breakthroughs may make development at these sites possible.

One of the key motivations for this study is to quantify opportunities for cost reductions through the use of innovative design options for new hydropower facilities. Although the distinction between conventional and innovative designs is not always clear, conventional facility designs are based on the most common existing design practices in the hydropower industry, referred to as the "baseline" in this study. Designs used for the baseline simulation in this study are discussed here.

\subsubsection{Plant Design for Lake Dams}

Many lake dams are equipped with single or multiple (often multi-level) tower structures for water intake and concrete-lined outlet tunnel(s). For these sites, the default conventional hydropower design option considered in this study would be to slip-line ${ }^{6}$ the outlet, which would be connected to a new penstock that feeds water to the turbines. The existing outlet works are generally controlled by a valve on the upstream side of the outlet or at mid-span within the dam. The section of the outlet downstream of the control valve is unpressurized. This section of outlet would be pressurized with the addition of a hydropower plant on the downstream side. This configuration is referred to as the "Steel-Lined Outlet + Steel" in Table 4. A key cost component for this water conveyance configuration is the length of outlet to be slip-lined, as well as the need for a bypass capable of directing the full plant's design flow away from the penstock as needed. The bypass would be equipped with a downstream gate for maintaining head when discharging flow above the plant capacity and dissipating energy in the system. The length of outlet to be lined is determined by the breadth of the dam, the location of the control valve in the outlet, and whether the outlet is excavated or tunneled through native abutment material. The data on these three variables are not available in public databases such as the NID but can be obtained from existing documents on individual dams or estimated from aerial photos of the sites. When the outlet passes directly under the dam, the entire outlet downstream of the control valve would need to be slip-lined to prevent safety issues and preserve the integrity of the dam. For cases in which the outlet passes through competent native abutment material ${ }^{7}$, the section of the outlet downstream of the control valve to be sliplined may be relatively short, depending on an evaluation of potential static and dynamic pressure from hydropower and quality of the tunnel rock at the site. Although definitive data on lining length would require specific investigation of each site, estimated values for sites in Table 4 that use this configuration range from 50 to $1,800 \mathrm{ft}$. A $250 \mathrm{ft}$-long penstock is assumed to be used to connect the tunnel lining to the turbines along with a radial gate bypass for most of the lake dam sites in Table 4. Figure 11 shows a

\footnotetext{
${ }^{6}$ Slip-lining is the installation of a smaller diameter pipe in an existing pipe or conduit.

7 That is, material capable of withstanding an applied load under given conditions without falling or collapsing.
} 
preliminary engineering drawing of the "Steel-Lined Outlet + Steel" for the Cave Run site to illustrate the general configuration.

Alternative water conveyance configurations for hydropower at lake dams include construction of a new pressurized tunnel through or around the dam, as well as siphons over or around the dam. New tunnels are viable only at sites with high heads/potential capacity and dam/abutment conditions amenable to major excavations. Given the extra costs, these are not generally compatible with most remaining NPD sites. The Jennings Randolph site is the only one simulated in this study using a "Tunnel around Dam + Steel" water conveyance system, which is based on an existing license for hydropower development at the site (FERC, 2012). Siphon water conveyance is a potential option but is restricted by operational dam heights and reservoir water surface levels. The Tar River site is simulated with a siphon water conveyance system because it has a municipal water system to which its pressurized outlet is likely dedicated.

Table 4. Baseline facility design specifications.

\begin{tabular}{|c|c|c|c|c|c|}
\hline Reference sites & $\begin{array}{l}\text { Lake/ } \\
\text { lock }\end{array}$ & $\begin{array}{l}\text { Turbin } \\
\text { e type }\end{array}$ & Water conveyance & $\begin{array}{c}\text { Conduit/lining/ } \\
\text { channel/ (ft) }\end{array}$ & $\begin{array}{l}\text { Penstock/ } \\
\text { conduit (ft) }\end{array}$ \\
\hline Tioga & Lake & Kaplan & Steel-Lined Outlet + Steel & 650 & 250 \\
\hline Dillon & Lake & Kaplan & Steel-Lined Outlet + Steel & 650 & 250 \\
\hline R. D. Bailey & Lake & Kaplan & Steel-Lined Outlet + Steel & 1,800 & 250 \\
\hline Monroe & Lake & Kaplan & Steel-Lined Outlet + Steel & 520 & 250 \\
\hline Cowanesque & Lake & Kaplan & Steel-Lined Outlet + Steel & 1,100 & 250 \\
\hline Westville & Lake & Kaplan & Steel-Lined Outlet + Steel & 63 & 250 \\
\hline Cave Run* & Lake & Kaplan & Steel-Lined Outlet + Steel & 750 & 250 \\
\hline Lake O'The Pines & Lake & Kaplan & Steel-Lined Outlet + Steel & 350 & 250 \\
\hline William H. Harsha & Lake & Kaplan & Steel-Lined Outlet + Steel & 1,500 & 250 \\
\hline Chouteau L\&D & Lock & Bulb & Channel around Dam & $300 ; 250$ & 60 \\
\hline Jonesville L\&D & Lock & Bulb & Channel around Dam & $400 ; 400$ & 60 \\
\hline Maynard L\&D & Lock & Bulb & Channel around Dam & $750 ; 1,200$ & 60 \\
\hline Green River L\&D 2 & Lock & \#N/A & $\# \mathrm{~N} / \mathrm{A}$ & \#N/A & \#N/A \\
\hline Jennings Randolph* & Lake & Francis & Tunnel around Dam + Steel & 1,400 & 1,000 \\
\hline L\&D \#7 & Lock & $\# \mathrm{~N} / \mathrm{A}$ & $\# \mathrm{~N} / \mathrm{A}$ & $\# \mathrm{~N} / \mathrm{A}$ & $\# \mathrm{~N} / \mathrm{A}$ \\
\hline $\mathrm{L} \& \mathrm{D} \# 24 *$ & Lock & Bulb & Channel through Dam & $400 ; 450$ & 60 \\
\hline John Overton L\&D & Lock & Bulb & Channel around Dam & $615 ; 450$ & 60 \\
\hline Mississippi L\&D \#6 & Lock & \#N/A & $\# \mathrm{~N} / \mathrm{A}$ & $\# \mathrm{~N} / \mathrm{A}$ & $\# \mathrm{~N} / \mathrm{A}$ \\
\hline Mississippi L\&D \#21 & Lock & $\# \mathrm{~N} / \mathrm{A}$ & $\# \mathrm{~N} / \mathrm{A}$ & $\# \mathrm{~N} / \mathrm{A}$ & $\# \mathrm{~N} / \mathrm{A}$ \\
\hline Waco Lake & Lake & $\# \mathrm{~N} / \mathrm{A}$ & $\# \mathrm{~N} / \mathrm{A}$ & $\# \mathrm{~N} / \mathrm{A}$ & $\# \mathrm{~N} / \mathrm{A}$ \\
\hline \multicolumn{6}{|l|}{ Other sites } \\
\hline Mississippi L\&D \#14* & Lock & Bulb & Channel through Dam & $400 ; 450$ & 60 \\
\hline Crooked Creek* & Lake & Kaplan & Steel-Lined Outlet + Steel & 50 & 250 \\
\hline Tar River* & Lake & Kaplan & Siphon Steel & 0 & 1150 \\
\hline East Sydney* & Lake & Kaplan & Steel-Lined Outlet + Steel & 50 & 600 \\
\hline
\end{tabular}

Notes: 1) Sites with an asterisk in Table 4 are those with preliminary civil works design and cost estimates provided by Small Hydro Consulting (SHC, 2019); 2) L\&D = Lock and Dam 


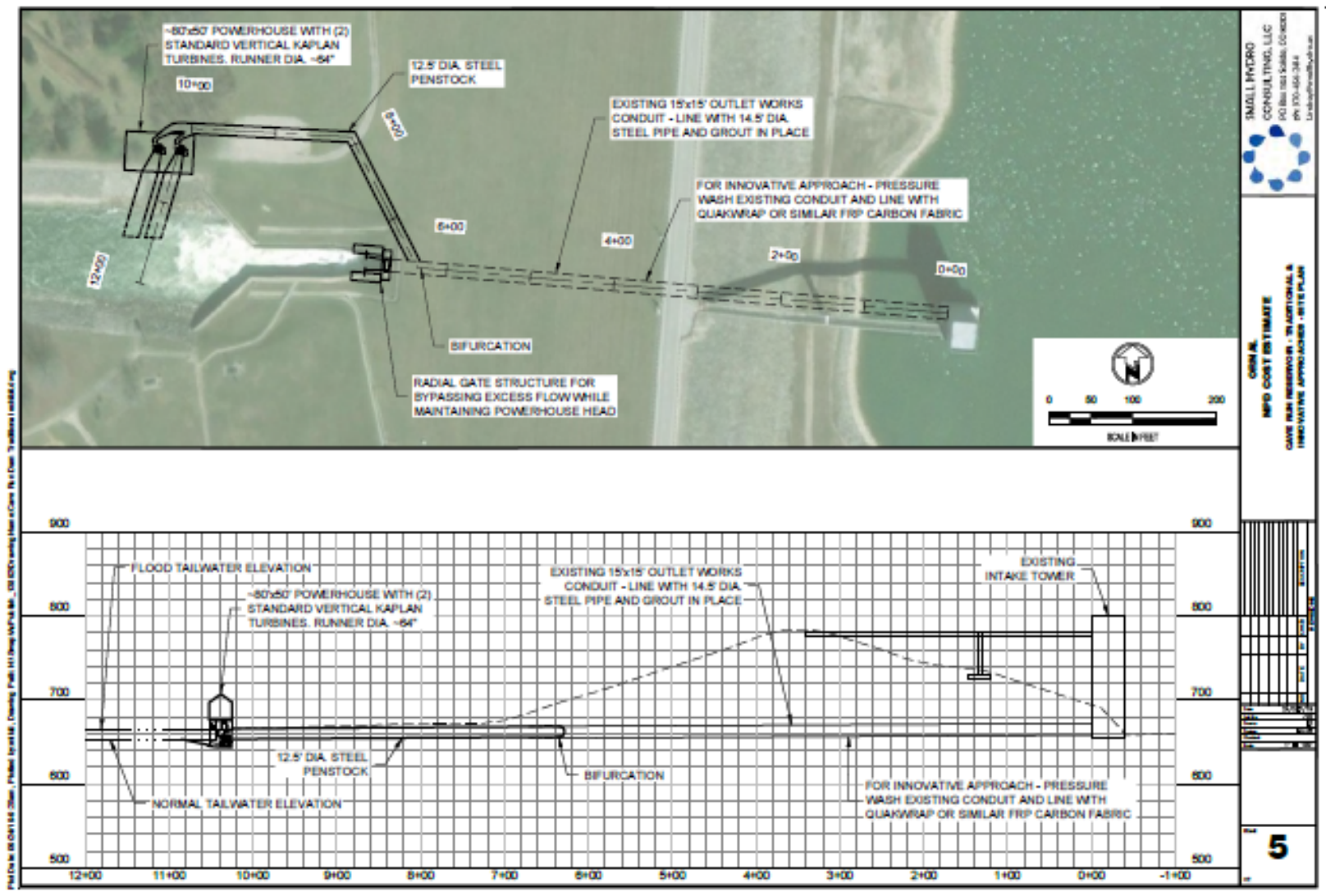

Figure 11. Water conveyance configuration for the Cave Run site. (Source: SHC, 2019)

\subsubsection{Plant Design for Lock Dams}

The lock dam sites in Table 4 are all low-head dams used for navigation purposes. The default designs for these sites make use of Kaplan bulb turbines in a new channel/conduit built around the abutment of the dam or integrated into a rebuilt section of the existing dam with sufficient length for such integration. Examples of this type of development include Arkansas River Dam No. 2 (AECC, 2002) and American Municipal Power's Smithland, Medahl, Willow Island and Cannelton projects (AMP 2015). This configuration requires a significant amount of excavation for the inlet and intake structures, powerhouse, and tailrace channels. The inlet channel is connected to the powerhouse through a formed intake and the powerhouse is designed to be overtopped by flood waters. Costs at these sites are driven not just by the significant amount of excavation required but also by site conditions. Many of the sites are surrounded by flooded lands, natural wildlife preserves, residential areas, or other developments that leave little room for the large staging area necessary for this type of hydropower development. Figure 12 illustrates this configuration for the Mississippi L\&D \#14 site. 


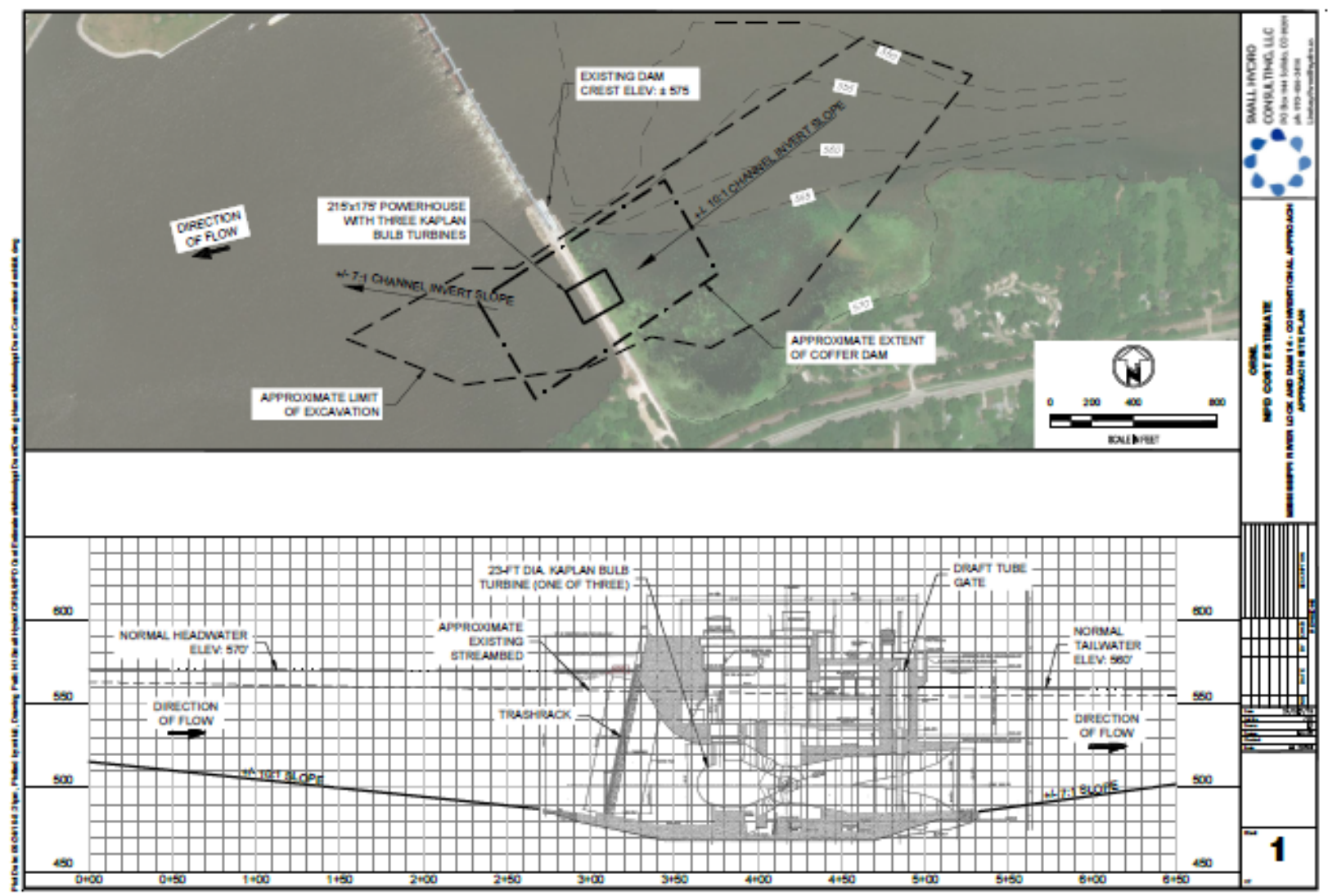

Figure 12. Water conveyance configuration for the Mississippi L\&D \#14 site. (Source: SHC, 2019)

\subsection{BASELINE INSTALLATION CAPACITY AND COST ESTIMATES}

Daily flow and head data were used for the cost analysis of the 19 sites analyzed in the smHIDEA model (the 24 sites listed in Table 4 minus 5 sites that were deemed impractical). These are the same data underlying the second-level water resource clustering analysis. The daily flow data for each site were summarized into 200 half-percentile points, and the median head value for each flow point was calculated. The number of data points used is intended to strike a balance between differences in the number of years of data available for each site and the need for insights into the impact of resource fluctuations on hydropower viability.

An initial analysis was performed to find an appropriate flow exceedance level for facility design by evaluating each half-percentile point as a potential design flow and calculating the minimum difference between the expected generation and "unavailable" generation (i.e., the theoretical generation minus expected generation). This initial exploration assumes an efficiency of $100 \%$ and no infrastructure or cost constraints, so that the theoretical generation is based on total flow and median head for a given potential flow point. The expected generation for each flow point uses the same assumptions but accounts for changes in generation due to fluctuations in flow and head over all 200 points. In many cases, this heuristic minimization approach identifies an exceedance level that is close to the $30 \%$ exceedance often used for hydropower design in the industry. A design flow point within $\pm 5 \%$ of the identified exceedance level is selected and used to perform initial simulations before a final design flow is fixed. The design head is generally based on the median head for the design flow point, but slight variations around this value were also evaluated as part of the initial exploration. 
In some cases, particularly the large flow, low-head lock dam sites, the design flow identified using the above method cannot be installed at the site because of space limitations for the plant itself and for construction staging. In these cases, the design flow was reduced to reflect site constraints. The number of turbine-generator units was determined by comparing the design flow with hill charts and typical industry installation sizes for the turbine options identified for each site. Variations in the number of units were also explored as part of initial simulations.

Table 5 presents the design head, flow capacity, and number of units for the 19 sites evaluated in this study. Initial capital costs and development cost estimates based on smHIDEA calculations are also provided. The initial capital costs in Table 5 include all constructions costs, while development costs include permitting, licensing, site acquisition, site characterization, and initial engineering, estimated as a percentage of initial capital cost. The capacity and capital cost results in Table 5 reflect the variations in infrastructure and water resource across the 19 sites. For the Jennings Randolph site, the cost analysis is directly based on estimates provided by Small Hydro Consulting since design and costing of the "Tunnel + Penstock" water conveyance system cannot be fully simulated in the smHIDEA model at this time. The smallest capacity in Table 5 is at the Westville site with only $200 \mathrm{~kW}$, and the largest capacity is for the Overton L\&D site with nearly $70 \mathrm{MW}$. The capital cost per kilowatt, which is an important metric for evaluating the viability of a hydropower site, varies from about $\$ 2,200 / \mathrm{kW}$ for the Jennings Randolph site to nearly $\$ 34,000 / \mathrm{kW}$ for the Westville site, with most sites between $\$ 5,000 / \mathrm{kW}$ and $\$ 15,000 / \mathrm{kW}$.

Figure 13 shows the distribution of initial capital costs among the major components. As expected, the three major cost items in nearly all cases are water conveyance, powerhouse, and electro-mechanical (mainly the powertrain). However, a clear difference exists in the distribution of costs between lake dams and lock dams. For lake dams, the water conveyance system accounts for the largest percentage of costs with between $40 \%$ and $60 \%$ in most cases. For lock dams, the powerhouse and electro-mechanical components constitute the largest share of costs. This reflects the need for large capacity turbines to make use of large flows and compensate for the low head available at lock dam sites. Although lock and dam sites require significant excavation and staging areas, the costs of these components are still smaller than the costs of the powerhouse and electro-mechanical components. 
Table 5. Summary of baseline site design capacity, development, and civil works costs.

\begin{tabular}{|c|c|c|c|c|c|c|c|c|}
\hline \multirow{2}{*}{ Reference sites } & \multirow{2}{*}{ Head (ft) } & \multirow{2}{*}{ Flow (cfs) } & \multirow{2}{*}{ Units (\#) } & \multirow{2}{*}{ Capacity (MW) } & \multicolumn{2}{|c|}{ Initial capital costs } & \multicolumn{2}{|c|}{ Development costs } \\
\hline & & & & & (million \$) & $(\$ / \mathbf{k W})$ & (million \$) & $(\$ / \mathbf{k W})$ \\
\hline Tioga & 50 & 600 & 2 & 2.40 & 26.99 & 11,106 & 1.26 & 519 \\
\hline Dillon & 32 & 1030 & 2 & 2.70 & 32.13 & 12,097 & 1.39 & 523 \\
\hline R. D. Bailey & 140 & 1000 & 2 & 11.10 & 54.47 & 4,894 & 3.20 & 287 \\
\hline Monroe & 55 & 610 & 2 & 2.70 & 24.96 & 9,182 & 1.27 & 469 \\
\hline Cowanesque & 77 & 340 & 1 & 2.10 & 26.88 & 12,696 & 1.22 & 577 \\
\hline Westville & 11 & 340 & 1 & 0.20 & 7.50 & 33,777 & 0.28 & 1,260 \\
\hline Cave Run & 79 & 1200 & 2 & 7.70 & 37.25 & 4,838 & 2.33 & 303 \\
\hline Lake O'The Pines & 41 & 190 & 1 & 0.60 & 11.21 & 17,865 & 0.51 & 817 \\
\hline William H. Harsha & 112 & 240 & 1 & 2.10 & 32.57 & 15,299 & 1.36 & 639 \\
\hline Chouteau L\&D & 15 & 4000 & 2 & 4.30 & 34.47 & 7,995 & 1.59 & 369 \\
\hline Jonesville L\&D & 18 & 6000 & 2 & 8.20 & 50.98 & 6,211 & 2.45 & 298 \\
\hline Maynard L\&D & 15 & 32000 & 4 & 34.80 & 280.11 & 8,047 & 9.16 & 263 \\
\hline Jennings Randolph & 240 & 861 & 3 & 16.70 & 36.87 & 2,206 & 3.55 & 212 \\
\hline L\&D \#24 & 11 & 36000 & 3 & 24.20 & 262.21 & 10,846 & 7.84 & 324 \\
\hline John Overton L\&D & 17 & 54000 & 3 & 69.50 & 434.52 & 6,250 & 14.54 & 209 \\
\hline Mississippi L\&D \#14 & 11 & 36000 & 3 & 24.20 & 262.21 & 10,846 & 7.84 & 324 \\
\hline Crooked Creek & 42 & 492 & 2 & 1.70 & 13.53 & 8,103 & 0.80 & 480 \\
\hline East Sydney & 50 & 180 & 1 & 0.70 & 7.23 & 9,955 & 0.45 & 617 \\
\hline Tar River & 16 & 750 & 3 & 0.90 & 9.41 & 10,832 & 0.42 & 481 \\
\hline
\end{tabular}



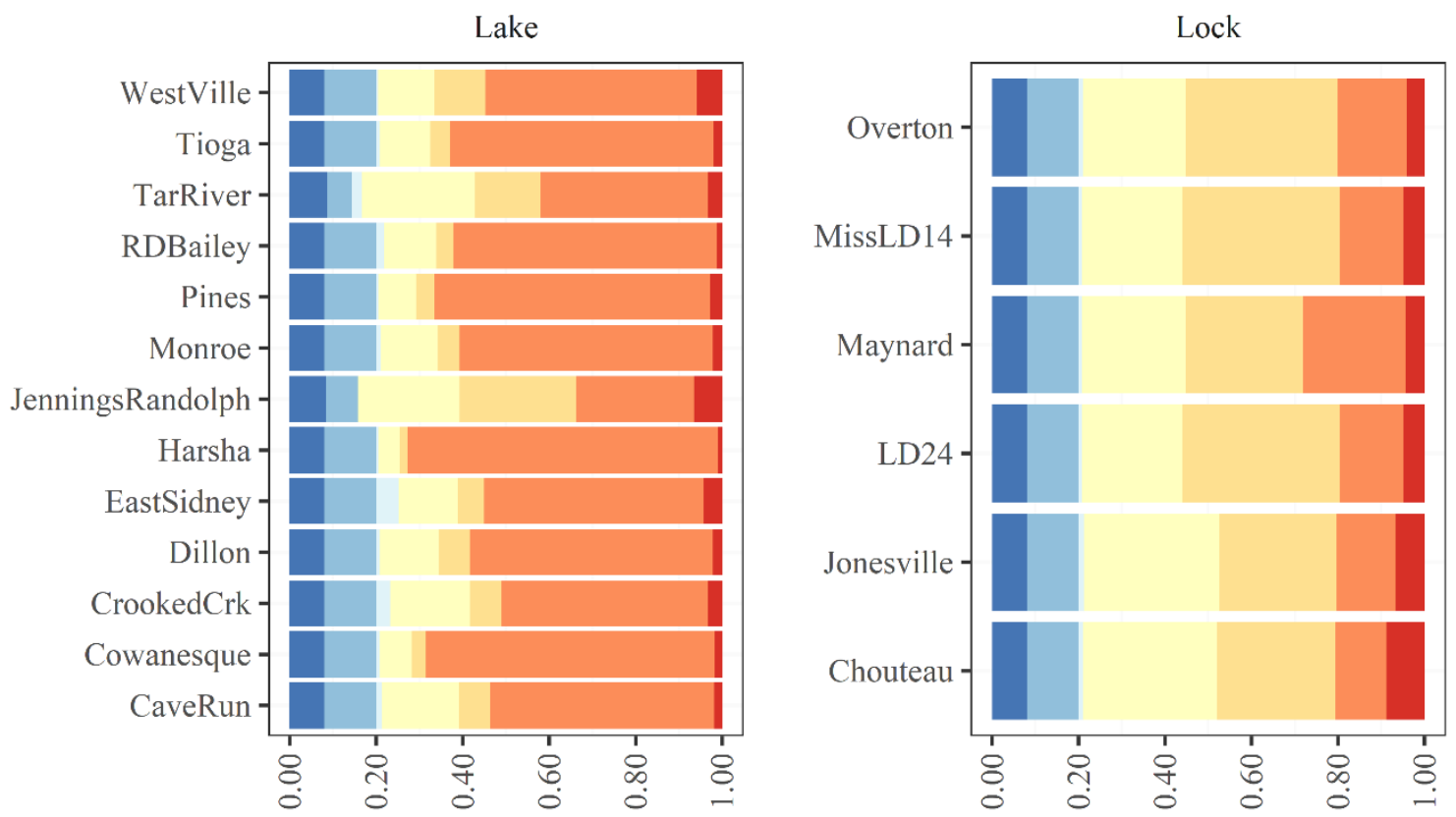

Shares

Site Preparation

Powerhouse

Electrical Infrastructure

Env.\&Reg. Compliance
Water Conveyance

Electro-Mechanical

Eng.\&Const. Management

Figure 13. Baseline initial capital costs distribution for reference sites.

\subsection{BASELINE PERFORMANCE SIMULATION RESULTS}

High levels of variation in head and flow at NPD sites mean that power generation for a given installed capacity may change significantly over time. The results of simulations with the smHIDEA model include a profile of the plant generation performance based on the flow-duration and median-head curves. The generation and efficiency profile curves are illustrated in Figure 14 for the Jennings Randolph (lake dam) site and Figure 15 for the John Overton (lock dam) site. The rest of the power and efficiency profile curves are presented in Appendix D.

These results illustrate the important effects of variations in flow and head at NPD sites. Plant flows generally vary from zero to the design flow at these sites since they are operated in run-of-release mode to preserve the original purposes of the dam. Additionally, the turbine would cease generation below given minimum water flow and head limits. The maximum flow in Figures 14 and 15 show plant operation at design flow. The spread of points at the design flow on the power curves reflects the effect of higher and lower head levels, whereas large hydropower plants are traditionally assumed to produce at design capacity when operating at the design flow because of much higher heads. Although the variation in generation at the design flow is more pronounced for the lock dam site in Figure 15 than for the lake dam site in Figure 14, Appendix D shows that large variations also exist for several of the lake dam sites. The efficiency profile curves show that variations in flow and head also affect plant efficiency. Although the 
variation is largely within $80 \%$ to $90 \%$, decreases in efficiency contributes to unavailability of the design capacity for a given plant.

JenningsRandolph Site
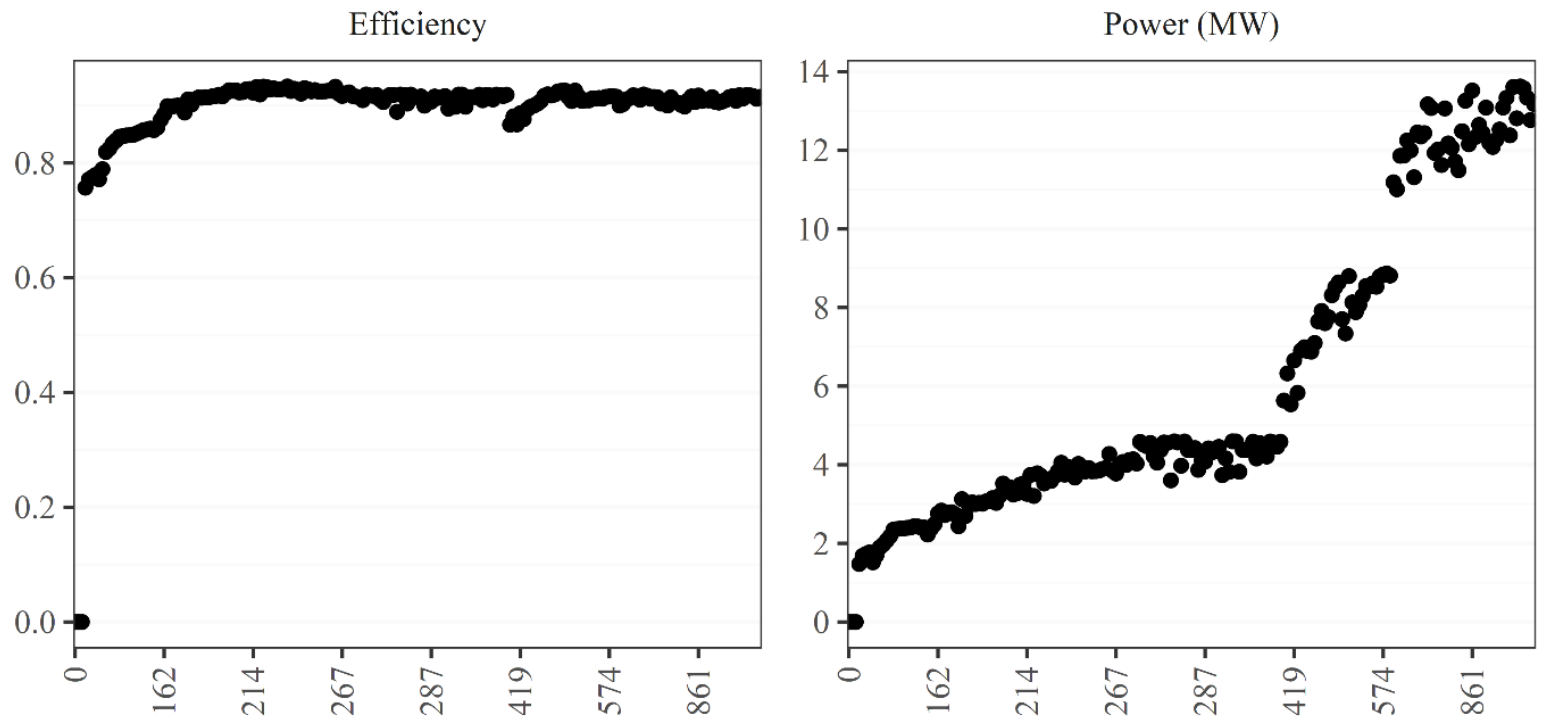

Plant Operating Flow (cfs)

Figure 14. Jennings Randolph Lake baseline plant power and efficiency profiles.

Overton Site
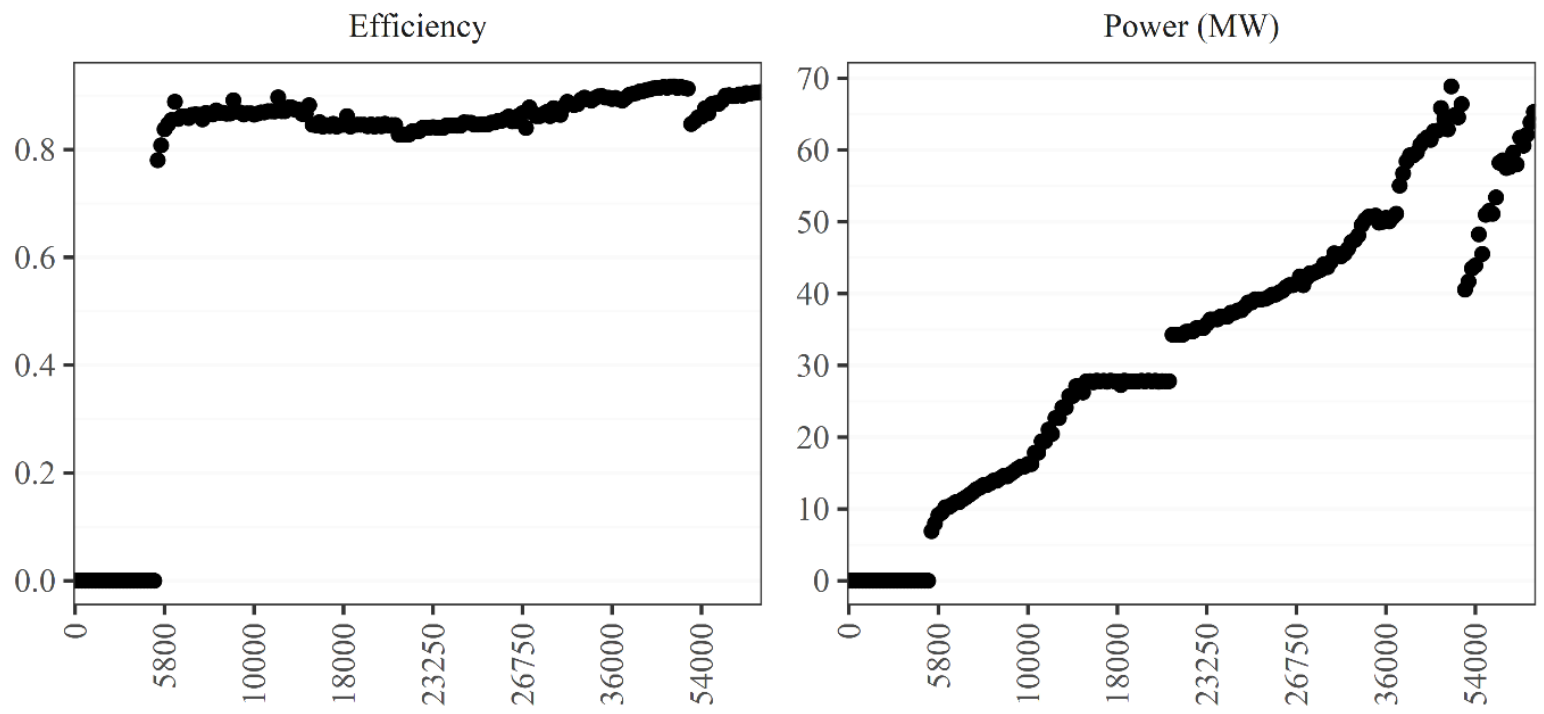

Plant Operating Flow (cfs)

Figure 15. Overton L\&D baseline plant power and efficiency profiles.

Figure 16 summarizes the resulting baseline capacity factors for all 19 sites simulated in this study with lake dams and lock dams in different panels. The generation profiles for all sites in Appendix D suggest that nearly all sites would be limited to capacity factors of between 0.50 and 0.60 due solely to variations 
in flow and head. This is confirmed by the range of capacity factors in Figure 16 with a median of 0.36 (range of 0.33 to 0.48 ) for lake dams and median of about 0.46 (range of 0.31 to 0.61 ) for lock dams. Thus, the median and maximum capacity factors for lake dams in Figure 14 are below those for lock dams by about 0.1 .

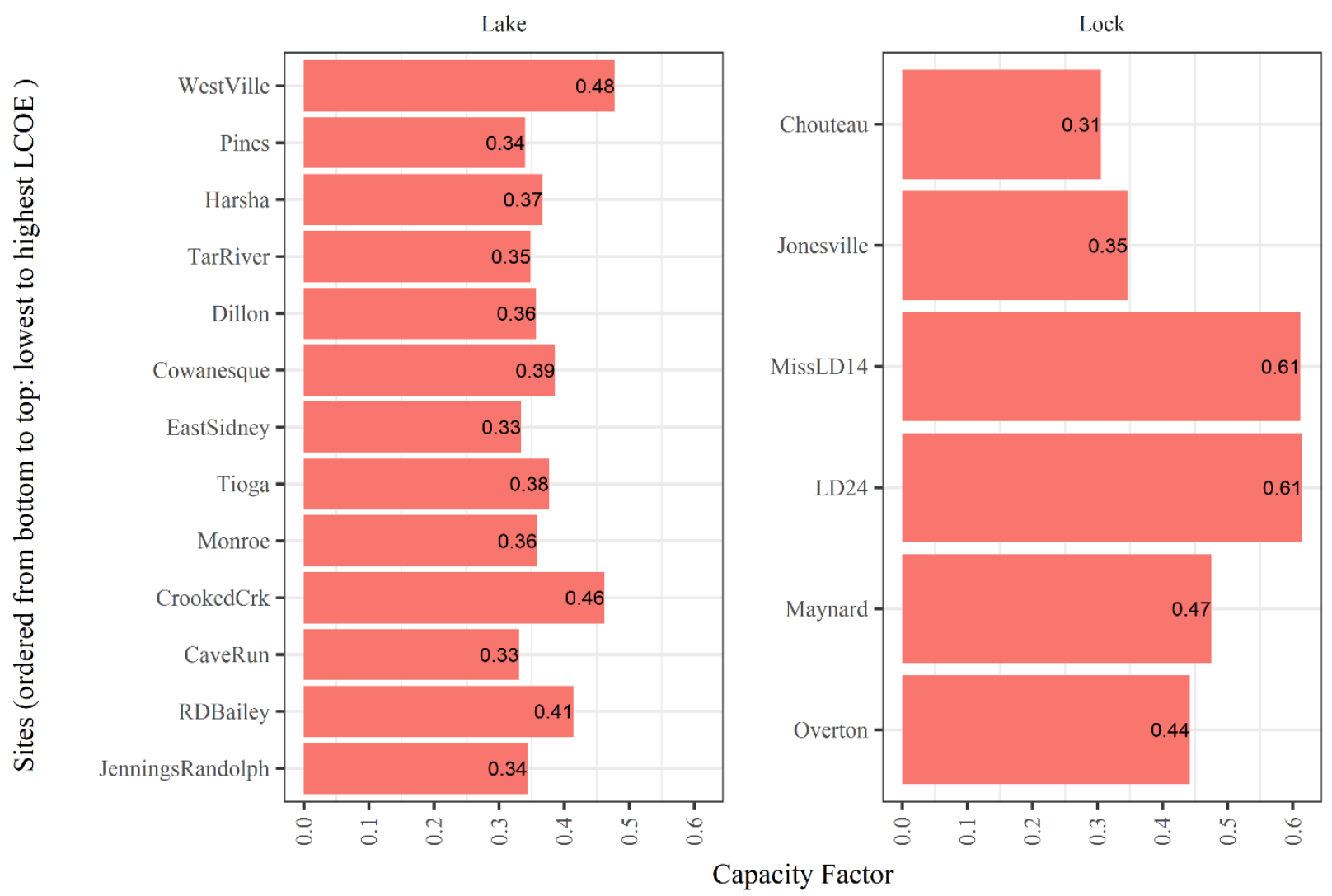

Figure 16. Baseline capacity factor estimates by site.

\subsection{BASELINE LCOE RESULTS}

Generation estimates, capital costs, and operations and maintenance costs are combined with financial parameters in the smHIDEA model to produce a cash flow balance sheet over the lifetime of the project. The plant is assumed to start operations in the year after the construction period with a constant annual generation rate based on the performance simulations discussed above. Two forms of the LCOE estimates are calculated in smHIDEA (Aldersey-Williams and Rupert, 2019). The first approach is based on overnight capital $\operatorname{costs}^{8}$, a capital recovery factor, and the plant capacity factor. The second approach is based on cash flows over the lifetime of the plant. Estimates for the latter are generally higher than for the former but can also be lower (assuming the same lifetime in both cases). For the projects in this study, the cash balance LCOE estimates differ from the overnight LCOE estimates by between $-\$ 12 / \mathrm{MWh}$ and \$15/MWh.

Figure 17 shows the cash balance LCOE estimates for the baseline case. Across all 19 sites, the LCOE estimates range from \$79/MWh for the Jennings Randolph site to \$790/MWh for the Westville site. Although the smallest capacity site has the largest LCOE, reflecting lack of economies of scale, the lowest LCOE estimate is not for the largest capacity site reflecting the interplay of water resources and

${ }^{8}$ Overnight costs assume that no interests are incurred by the project during construction. 
infrastructure requirements at individual sites. Both the overall lowest and largest LCOE estimates are for lake dam sites. The lock dam sites have a narrower, yet still wide, range of LCOE values of \$134/MWh for Overton to \$289/MWh for Chouteau.

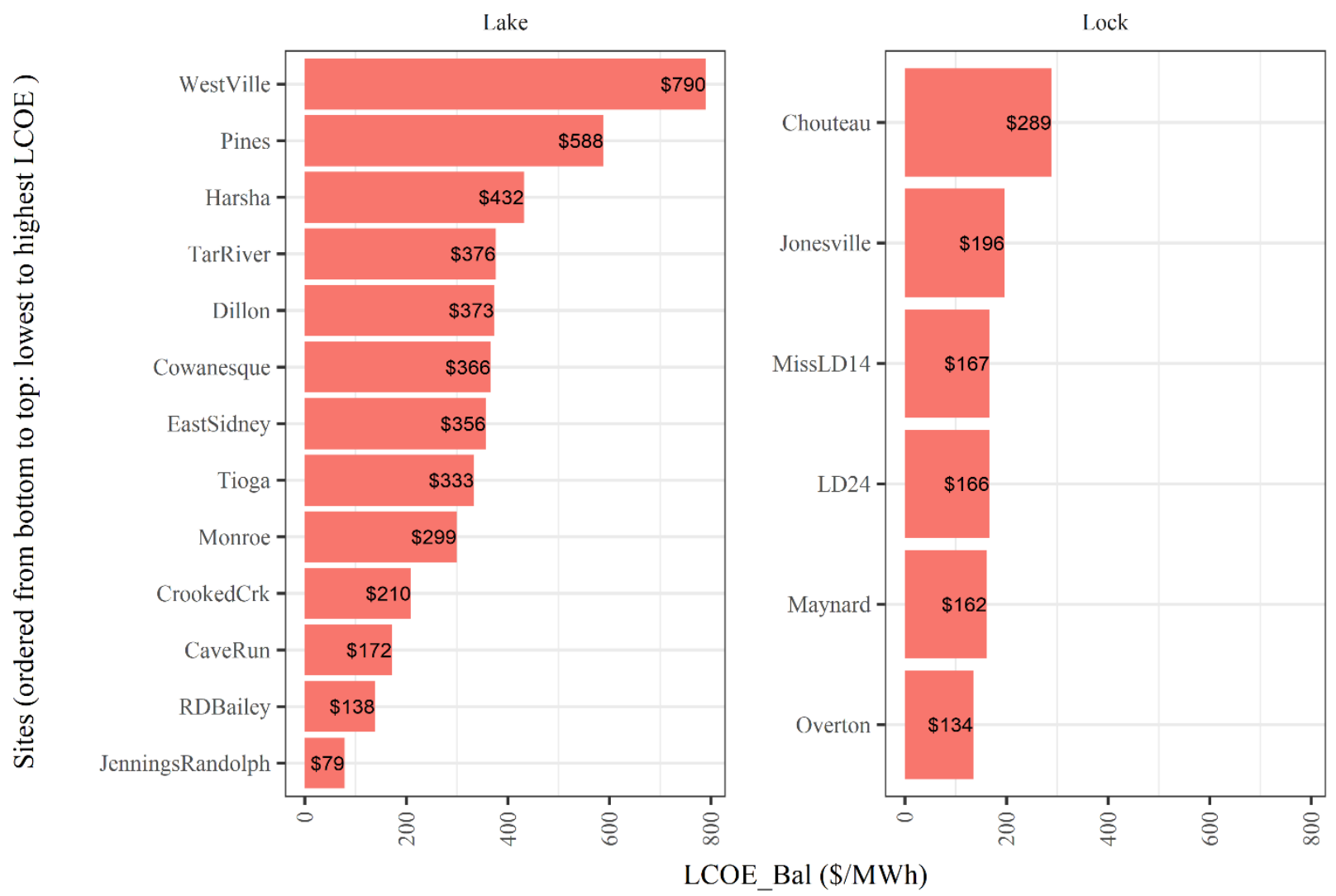

Figure 17. Baseline LCOE estimates by site.

\section{INNOVATIVE DESIGNS AND COST REDUCTION ANALYSIS}

The baseline simulation results provide insights into the key cost drivers of hydropower at reference sites based on technologies already widely deployed in the industry. Potential innovations for improving the cost effectiveness of hydropower at these sites, including those highlighted in this report, are classified into two categories for the purposes of this study. The first category of innovations, termed "near-term," focus on cost reductions that affect components of the facility but do not fundamentally change the baseline configuration itself. These innovations are near-term because they are considered to be feasible within the next 5 to 10 years, with TRL numbers between 7 and 10. The second category of innovations are medium-to long-term, termed "medium-term," representing combinations of potential component and new facility design cost reduction options that may be achievable within the next 10 to 20 years. These medium-term innovations, with TRL numbers from 1 to 6 , are more speculative than the near-term innovations since they represent emerging technologies that are not yet fully understood in their performance and cost. 


\subsection{NEAR-TERM INNOVATIVE DESIGN OPTIONS}

Apart from variations in head and flow, the key drivers of cost per kilowatt for lake dam sites in Table 4 are the length of outlet to be slip-lined and the length of penstock required to supply water to the turbines. Reductions in the lengths of these components are not considered in this study to impose strict dam safety requirements on the cost estimates. Therefore, the near-term innovations evaluated for lake dams focus on use of non-steel materials for slip-lining the outlet and the penstock. For lock dam sites, the key drivers of baseline costs are the significant site preparation and excavation requirements, and the footprint of the large turbines required to produce power from the large flow and low head at these sites. Thus, near-term innovations for lock dam sites focus on adoption of turbines with reduced footprint and excavation requirements. Table 6 lists the near-term innovations applied to the turbine type or water conveyance system or both.

Table 6. Near-term innovative hydropower facility design options.

\begin{tabular}{|c|c|c|c|c|c|}
\hline Reference sites & $\begin{array}{l}\text { Lake/ } \\
\text { lock }\end{array}$ & $\begin{array}{l}\text { Turbine } \\
\text { type }\end{array}$ & Water conveyance type & $\begin{array}{l}\text { Lining/tunnel/ } \\
\text { channel (ft) }\end{array}$ & $\begin{array}{l}\text { Penstock/ } \\
\text { conduit (ft) }\end{array}$ \\
\hline Tioga & Lake & Kaplan & FRP-Lined Outlet + HDPE & 650 & 250 \\
\hline Dillon & Lake & Kaplan & FRP-Lined Outlet + HDPE & 650 & 250 \\
\hline R. D. Bailey & Lake & Kaplan & FRP-Lined Outlet + HDPE & 1,800 & 250 \\
\hline Monroe & Lake & Kaplan & FRP-Lined Outlet + HDPE & 520 & 250 \\
\hline Cowanesque & Lake & Kaplan & FRP-Lined Outlet + HDPE & 1,100 & 250 \\
\hline Westville & Lake & Kaplan & FRP-Lined Outlet + HDPE & 63 & 250 \\
\hline Cave Run & Lake & Kaplan & FRP-Lined Outlet + HDPE & 750 & 250 \\
\hline Lake O'The Pines & Lake & Kaplan & FRP-Lined Outlet + HDPE & 350 & 250 \\
\hline William H. Harsha & Lake & Kaplan & FRP-Lined Outlet + HDPE & 1,500 & 250 \\
\hline Chouteau L\&D & Lock & Matrix & Channel around Dam & $300 ; 250$ & 60 \\
\hline Jonesville L\&D & Lock & Matrix & Channel around Dam & $400 ; 400$ & 60 \\
\hline Maynard L\&D & Lock & Matrix & Channel around Dam & $750 ; 1,200$ & 60 \\
\hline Green River L\&D 2 & Lock & $\# \mathrm{~N} / \mathrm{A}$ & \#N/A & \#N/A & \#N/A \\
\hline Jennings Randolph & Lake & Baseline & Baseline & 1,400 & 1,000 \\
\hline L\&D \#7 & Lock & $\# \mathrm{~N} / \mathrm{A}$ & \#N/A & \#N/A & \#N/A \\
\hline L\&D \#24 & Lock & Matrix & Channel through Dam & $400 ; 450$ & 60 \\
\hline John Overton L\&D* & Lock & Bulb & Channel around Dam & $615 ; 450$ & 60 \\
\hline Mississippi L\&D \#6 & Lock & \#N/A & $\# \mathrm{~N} / \mathrm{A}$ & \#N/A & \#N/A \\
\hline Mississippi L\&D \#21 & Lock & \#N/A & $\# \mathrm{~N} / \mathrm{A}$ & $\# \mathrm{~N} / \mathrm{A}$ & \#N/A \\
\hline Waco Lake & Lake & \#N/A & \#N/A & $\# \mathrm{~N} / \mathrm{A}$ & \#N/A \\
\hline \multicolumn{6}{|l|}{ Other sites } \\
\hline Mississippi L\&D \#14 & Lock & Matrix & Channel through Dam & $400 ; 450$ & 60 \\
\hline Crooked Creek & Lake & Kaplan & FRP-Lined Outlet + HDPE & 50 & 250 \\
\hline Tar River & Lake & Kaplan & Siphon HDPE & 0 & 1150 \\
\hline East Sydney & Lake & Kaplan & FRP-Lined Outlet + HDPE & 50 & 600 \\
\hline
\end{tabular}

*The near-term case for Overton is the same as the baseline but with reduced design capacity. 
For lake dams, innovations consist of replacing steel with fiber-reinforced polymer (FRP) carbon fabric for slip-lining the dam outlet and using high-density polyethylene (HDPE) for penstock. FRP and HDPE are examples of new materials for reducing the cost of hydropower. The advantages of these alternative materials include lower cost, good impact resistance, and tensile strength, ease of processing, high resistance to abrasion, corrosion and climate changes, and reduced friction (Plastics Insights, 2017). Although these are not yet industry standards, their adoption as alternatives to steel for hydropower is been increasingly demonstrated (see Box 1). Wide adoption of these innovations in the hydropower industry requires attention to a few remaining issues. For example, HDPE has lower pressure tolerance and significantly higher thermal expansion than steel, and market availability constraints may exist for specifications required for hydropower. These issues can potentially be resolved over the next 5 to 10 years since small-scale hydropower does not have the very high-pressure requirements of large plants, and high-pressure-tolerant fiber-reinforced HDPE is beginning to appear on the market (PE100+ Association, 2019).

\section{Box 1: New Materials for Hydropower Water Conveyance}

FRP Goes Deep and Far in Minneapolis: "The I-35W/I-94 tunnel system in Minneapolis, ranges in size from 8 - to $14 \mathrm{ft}$ in diameter and varies from 50 to $130 \mathrm{ft}$ underground. Cycles of pressurization and depressurization have led to structural distress of the liner and subsequently caused erosion of the friable St. Peter sandstone in which the tunnel was constructed . . . a segment ... was experiencing high groundwater pressure, inflow and a noticeable decrease in effective liner thickness. As such, this segment of $12 \mathrm{ft}$ in diameter, at approximately 100 $\mathrm{ft}$ below grade level, needed a structural repair. A proprietary fiber reinforced polymer (FRP) system (StifPipe) with a 3D core layer was selected by the project engineer for this point repair with high loads and limited access. The StifPipe system was installed layer by layer and cured in place with increased ambient temperature by using heaters. Another challenge the project team had to face was to complete installation in a short time period to control pumping cost. The project was completed with success without any significant issues encountered at the project site. The I-35 tunnel repair project marks a record as the deepest application of an FRP system for fullystructural tunnel rehabilitation." Source: https:/trenchlesstechnology.com/frp-goes-deep-and-far-in-minneapolis/

96" FRP for Hydropower Penstock Reduces Cost: "As part of the Franquelin River Hydroelectric Project in Quebec, Canada, Owner/Engineer/Contractor Axor Group needed 1,370 LF of penstock pipe for their 9.9-MW power station. Axor's original design of the project specified 110-inch-diameter steel pipe. However, with the introduction of an FRP (fiber reinforced plastic) pipe supplier capable of producing pipe that could meet the pressure requirements for the application, they looked into the option of using filament-wound FRP pipe instead. With its superior hydraulic efficiencies and inherent corrosion resistance, large-diameter FRP appeared to be the right solution over steel pipe. Source: https://thompsonpipegroup.com/96-frp-for-hydropower-penstock-reducescost/

PE \& HDPE PE100 Pipe: Properties and Types - PE100 RC: "RC indicates resistance to cracking. PE100 RC is a resin that has an increased stress crack resistance while maintaining the same MRS and rapid crack propagation resistance as conventional PE100. It is intended for use in more severe conditions and is especially suitable for trenchless methods. Bimodal PE 100 materials with high resistance to slow and rapid crack propagation are classified as set out in PAS (Publicly Available Specification) 1075...there are three different types of RC pipe: Type 1: Single-layer solid wall pipes made of PE $100 \mathrm{RC}$; Type 2: Pipes with dimensionally integrated protective layers of PE 100 RC; Type 3: Pipes with dimensions conforming to DIN 8074/ISO 4065 with an outer protective casing. Inner pipe made of PE 100 RC." Source: https://www.pe100plus.com/PEPipes/Technical-guidance/Trenchless/Methods/PE-Pipe-i1341.html

HDPE Key to Alaskan Hydroelectric and Water Hatchery Project: "The original design for the Whitman Lake Hydroelectric project consisted of elevated steel penstock piping ... it was found that replacing the steel penstock with buried HDPE lines could greatly reduce the cost of the project and bring it closer to anticipated budget numbers." Source: https://www.mcelroy.com/fusion-static/pdf/newsletter/august_13.pdf 
For lock dam sites, the near-term option in this study is replacement of the baseline bulb-Kaplan turbine with Andritz/Obermeyer matrix turbines. The latter turbines, as previously highlighted, are smaller versions of the bulb-Kaplan/Propeller turbines which can be arranged in matrix form and have a shorter draft tube, reducing the footprint and excavation requirements for the facility. These turbines are available in the market and have been used for a number of projects (SAF, 2020). Figure 18 illustrates differences in the footprint between the Andritz Hydromatrix turbines and the bulb-Kaplan turbine for the Mississippi L\&D \#14 site. For the simulations in this study, the lengths of intake and tailrace channels were reduced by one-third for the same capacity of the matrix turbines relative to the bulb-Kaplan turbine. An option to increase the capacity factor and improve per-unit cost effectiveness at hydropower sites is to use a reduced amount of design flow that would then be available for longer periods during the year. A couple of lock dam sites were simulated with reduced design flows to test this potential.

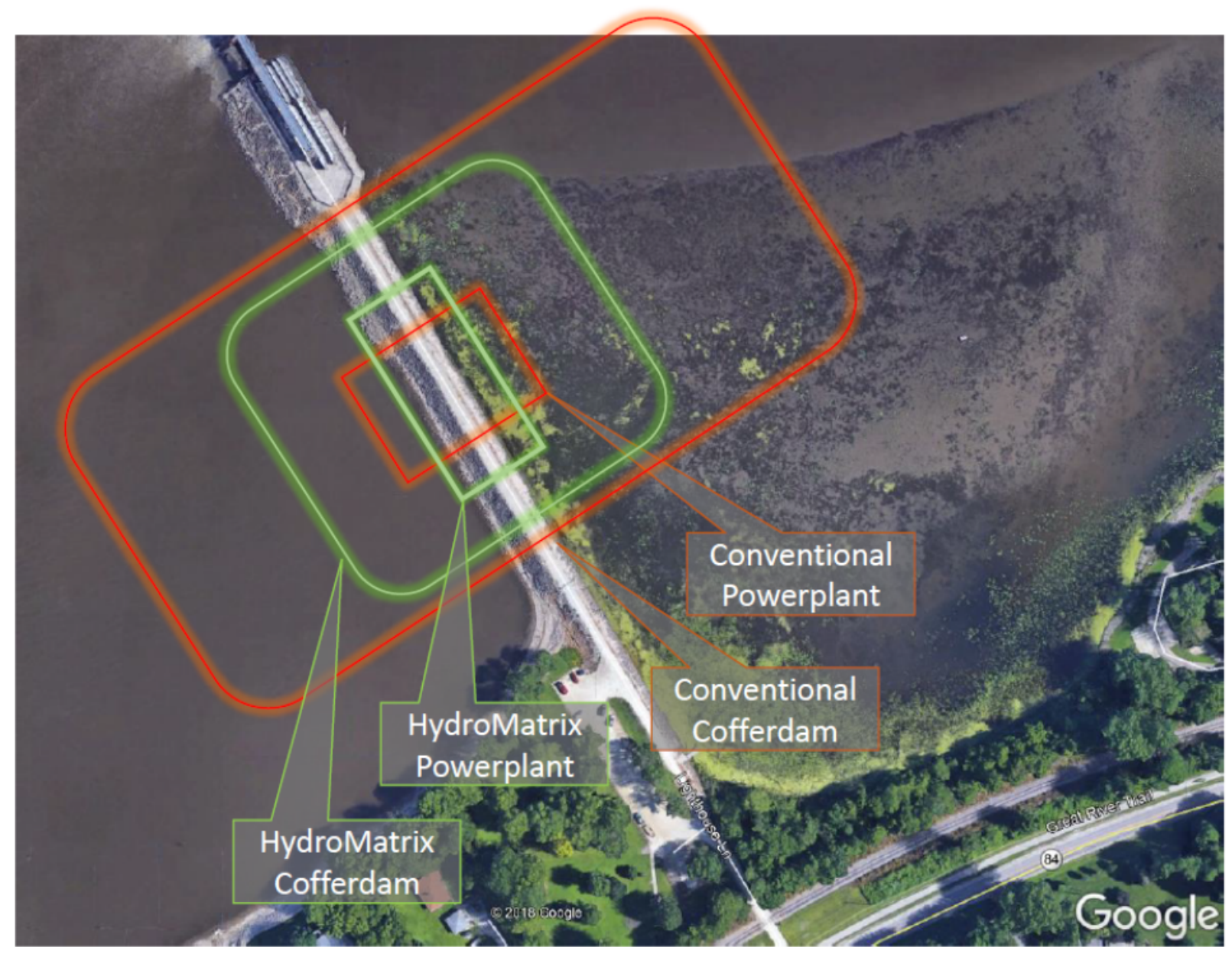

Figure 18. Comparison of HydroMatrix and baseline construction footprints.

\subsection{MEDIUM- TO LONG-TERM INNOVATIVE DESIGN OPTIONS}

In addition to the near-term innovations for which costs were estimated, several other emerging technologies could lower the cost of hydropower development. However, the limited amount of data currently available for these innovations is not adequate for generating pre-feasibility cost estimates at this time or the nature of the innovation is too specialized to apply broadly to the classes identified in this 
study. These innovations are considered to have the potential to lower hydropower development costs in the medium to long term, referred to as "medium-term." Table 7 provides information about potential applications of these medium-term innovations to the reference sites examined in this study, which are briefly discussed below.

Table 7. Potential medium- to long-term innovative facility design specifications.

\begin{tabular}{|c|c|c|c|}
\hline & Lake/ lock & Turbine type & Water conveyance type \\
\hline \multicolumn{4}{|l|}{ Reference sites } \\
\hline Tioga & Lake & Inlet matrix & Integrated \\
\hline Dillon & Lake & Inlet matrix & Integrated \\
\hline R. D. Bailey & Lake & Kaplan & Tunnel around Dam \\
\hline Monroe & Lake & Inlet matrix & Integrated \\
\hline Cowanesque & Lake & Kaplan & Integrated \\
\hline Westville & Lake & Propel & FRP-Lined Outlet + Penstock \\
\hline Cave Run & Lake & Kaplan & Pumped Siphon Penstock \\
\hline Lake O'The Pines & Lake & Kaplan & FRP-Lined Outlet + Penstock \\
\hline William H. Harsha & Lock & Kaplan & FRP-Lined Outlet + Penstock \\
\hline Chouteau L\&D & Lock & Screw & Integrated \\
\hline Jonesville L\&D & Lock & Matrix/Dive & Channel around Dam \\
\hline Maynard L\&D & Lock & Matrix/Dive/AmJet & Channel around Dam \\
\hline Green River L\&D 2 & Lock & VLH & $\# \mathrm{~N} / \mathrm{A}$ \\
\hline Jennings Randolph & Lake & Baseline & Baseline \\
\hline L\&D \#7 & Lock & VLH & $\# \mathrm{~N} / \mathrm{A}$ \\
\hline L\&D \#24 & Lock & Matrix/Dive/AmJet & Channel around Dam \\
\hline John Overton L\&D & Lock & Matrix/Dive/AmJet & Channel around Dam \\
\hline Mississippi L\&D \#6 & Lock & VLH & \#N/A \\
\hline Mississippi L\&D \#21 & Lock & VLH & \#N/A \\
\hline Waco Lake & Lake & Propel & $\# \mathrm{~N} / \mathrm{A}$ \\
\hline \multicolumn{4}{|l|}{ Other sites } \\
\hline Mississippi L\&D \#14 & Lock & Matrix/Dive/AmJet & Channel around Dam \\
\hline Crooked Creek & Lake & Kaplan & FRP-Lined Outlet + Penstock \\
\hline Tar River & Lake & AmJet/Dive/Natel & Gate Replacement \\
\hline East Sydney & Lake & Propel & FRP-Lined Outlet + Penstock \\
\hline
\end{tabular}

The RHT developed by Natel Energy features a runner geometry designed to enable safe downstream passage of small- to moderate-size fish that access the turbine through standard, wide-spaced bar racks. Because relative velocities (i.e., fish strike velocities) are highest at the tip for any turbine, the RHT runner blade was designed with a progressively acute slant angle near the blade tip. The slant angle is expected to reduce the amount of force imparted on a fish struck by the turbine blade in the high-speed region by enabling a glancing contact, rather than direct collision. Additionally, the RHT is designed with thick leading edges and a low number of blades to reduce the severity and probability of strike. Testing is ongoing, but initial results showed a strike survival $>98 \%$ for two fish group sizes at a strike speed of 7 
$\mathrm{m} / \mathrm{s}$. The high survival rates achieved present an opportunity to design blades for high strike survival while enabling economically feasible turbine and generator speeds (Amaral et al., 2020). The RHT is expected to be competitive with other variable-speed propeller turbines. Potential cost reductions resulting from the ecological benefits of the turbine require further research.

Propel $^{9}$, Dive ${ }^{10}$, and AmJet ${ }^{11}$ are three different variable-speed propeller turbines with submersible generators. These turbines are all available in smaller runner diameters than the Voith StreamDiver ${ }^{12}$ and Andritz HydroMatrix ${ }^{13}$. The Andritz HydroMatrix and Obermeyer Hydro ${ }^{14}$ turbines were used as innovative turbine options in this study because of the availability of cost data for the turbines' civil works. Other variable-speed propeller turbines that are available or under development may be suitable alternatives in similar or varied configurations. The use of variable-speed turbines requires power electronics to standardize the frequency of the electricity fed to the grid. The configuration of power electronics significantly affects the total cost of the mechanical/electrical package. Many of the costs involved in power electronics do not scale with size. An inverter, for example, has a certain base cost no matter the kilowatt rating (Patel et. al., 2017). Advancements in power electronics technology may be an opportunity to improve the economics of variable-speed hydropower turbines.

The VLH turbine by MJ2 Technologies, $\mathrm{SAS}^{15}$ is designed for operation at sites with VLH and is fishfriendly because of the low rotational speed of the runner. The slow speed results in a turbine with a much higher footprint than other Kaplan or propeller turbines. Because of the large footprint and relatively high equipment cost, the suitability of the VLH is very site-specific and depends highly on a site's head and flow fluctuation and the available physical space within the existing infrastructure. Suitability of lowspeed positive displacement technologies such as the Archimedean screw are similarly very site-specific.

An alternative to the intake design concepts used in this study is to use a pumped siphon. The normal reservoir operating level is too low at many flood control dams for a traditional siphon to be placed over the crest of the dam; the lift is too high. To reduce lift, the siphon would need to be installed through the dam within the flood pool, and this may not be acceptable at earthen flood control dams. A floating pump barge could be used to pump water from the reservoir high enough to be siphoned over the dam crest. The energy used by the intake pump barge would be mostly recovered at the hydropower facility by specifying higher head equipment than what would otherwise be used at the site. A pumped siphon has not been used in this type of scenario to our knowledge but may provide a lower-cost, innovative solution that is more acceptable to a dam owner than other intake alternatives.

\subsection{NEAR-TERM VS. BASELINE CAPACITY AND CAPITAL COSTS}

Table 8 shows the baseline vs. near-term capacity and capital cost estimates for the sites evaluated for near-term innovations in this study. Table 8 does not include the Jennings Randolph site, which has the lowest baseline LCOE. The last column of Table 8 shows percentage changes in capital costs in the nearterm relative to the baseline case. There are slight differences in capacities between the baseline and nearterm cases for lock dam sites due to the different turbine types, which lead to small changes in design flow and efficiency. The overall range of changes in capital cost estimates in the near-term relative to the

\footnotetext{
${ }^{9}$ Available online from https://www.ricklyhydro.com/propel-turbine

${ }^{10}$ Available online from https://www.dive-turbine.de/hydropower/DIVE-Turbine

${ }^{11}$ Available online from http://www.amjethydro.com/products.html

${ }^{12}$ Available online from http://voith.com/corp-en/hydropower-components/streamdiver.html

13 Available online from https://www.andritz.com/products-en/group/products/hydromatrix

14 Available online from http://obermeyerhydro.com/node/48

${ }^{15}$ Available online from http://www.vlh-turbine.com/products/vlh-turbine/
} 
baseline is $-77 \%$ to $15 \%$. The range of cost changes for lake dams is $-77 \%$ to $-14 \%$, which is much larger than for lock dams with a range of $-21 \%$ to $-2.1 \%$ (excluding the Overton site).

Table 8. Capacity and initial capital costs for baseline vs. near-term cases.

\begin{tabular}{|c|c|c|c|c|c|c|}
\hline & \multirow{2}{*}{ Lake/lock } & \multicolumn{2}{|c|}{ Capacity (MW) } & \multicolumn{2}{|c|}{ Capital costs $(\$ / k W)$} & \multirow{2}{*}{$\begin{array}{c}\text { Cost change } \\
(\%)\end{array}$} \\
\hline & & Base & Near-term & Base & Near-term & \\
\hline Tioga & Lake & 2.4 & 2.4 & 11,106 & 6,845 & -38.4 \\
\hline Dillon & Lake & 2.7 & 2.7 & 12,097 & 8,551 & -29.3 \\
\hline R. D. Bailey & Lake & 11.1 & 11.1 & 4,894 & 2,501 & -48.9 \\
\hline Monroe & Lake & 2.7 & 2.7 & 9,182 & 6,074 & -33.9 \\
\hline Cowanesque & Lake & 2.1 & 2.1 & 12,696 & 4,214 & -66.8 \\
\hline Westville & Lake & 0.2 & 0.2 & 33,777 & 26,851 & -20.5 \\
\hline Cave Run & Lake & 7.7 & 7.7 & 4,838 & 2,676 & -44.7 \\
\hline Lake O'The Pines & Lake & 0.6 & 0.6 & 17,865 & 8,164 & -54.3 \\
\hline William H. Harsha & Lake & 2.1 & 2.1 & 15,299 & 3,565 & -76.7 \\
\hline Chouteau L\&D & Lock & 4.3 & 4.4 & 7,995 & 7,829 & -2.1 \\
\hline Jonesville L\&D & Lock & 8.2 & 8.2 & 6,211 & 6,079 & -2.1 \\
\hline Maynard L\&D & Lock & 34.8 & 35.0 & 8,047 & 7,696 & -4.4 \\
\hline L\&D \#24 & Lock & 24.2 & 28.5 & 10,846 & 9,653 & -11.0 \\
\hline John Overton L\&D * & Lock & 69.5 & 48.2 & 6,250 & 7,146 & 14.3 \\
\hline Mississippi L\&D \#14 & Lock & 24.2 & 28.5 & 10,846 & 9555.3 & -11.9 \\
\hline Crooked Creek & Lake & 1.7 & 1.7 & 8,103 & 5192.3 & -35.9 \\
\hline East Sydney & Lake & 0.7 & 0.7 & 9,955 & 7696.7 & -22.7 \\
\hline Tar River & Lake & 0.9 & 0.9 & 10,832 & 9335.2 & -13.8 \\
\hline
\end{tabular}

*The near-term case for Overton is the same as the baseline but with reduced design capacity.

The capital cost impacts of near-term innovations for lake dams is determined by the relative share of outlet slip-lining and penstock in the baseline costs, which is reflected in the water conveyance cost share in Figure 13. Thus, the Harsha, Cowanesque, and R. D. Bailey sites, which have the largest shares of water conveyance in baseline costs, show the largest percentage reductions in capital costs in Table 8 . These three sites have long outlets that would need to be slip-lined for hydropower at 1,100, 1,500, and $1,800 \mathrm{ft}$, respectively. The lower percentage reduction in capital costs for $\mathrm{R}$. D. Bailey, despite a much longer outlet, is due to its larger capacity since other plant components then represent a larger share of costs than the other two sites. Figure 19 illustrates changes in capital costs for four lake dam sites.

For lock dam sites, the range of cost reductions is dictated by differences in economies of scale for the smaller matrix vs. the larger bulb turbines. On the one hand, the smaller turbines have a lower power density requiring higher flow (and capacity) thresholds to be competitive with larger turbines. On the other hand, the smaller turbines can operate over a wider range of flow and head relative to the design values compared with the larger turbines. Therefore, differences in per-kilowatt cost for smaller turbines relative to larger turbines are likely to display a nonlinear profile, where costs decline as capacity increases before rising as space to accommodate a large number of smaller turbines becomes binding. These factors are partly illustrated by comparing results for the L\&D \#24, Mississippi L\&D \#14, and Jonesville L\&D sites in Table 8. The data in Table 2 show that the head characteristics of the L\&D \#24 and Jonesville L\&D sites are similar, but median flow for the former is one order of magnitude higher than for the latter. The resulting capacity differences mean that the smaller matrix turbines are more cost effective at the L\&D \#24 site than at the Jonesville L\&D site. Additionally, the design capacity at the 
LD \#24 and Mississippi L\&D \#14 sites are identical and both sites benefit from the use of matrix turbines because of higher design efficiencies relative to the bulb turbine.
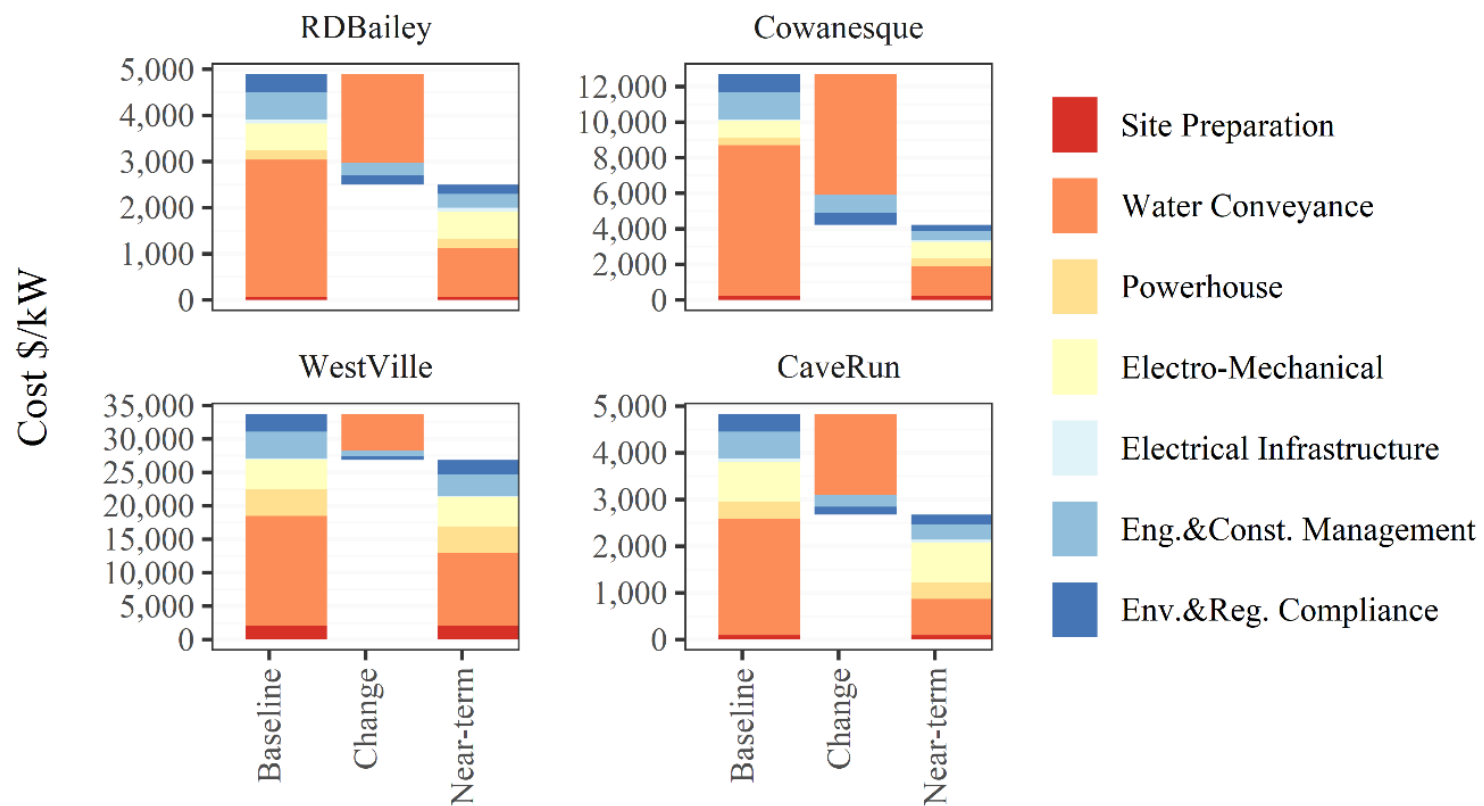

Figure 19. Baseline vs. near-term innovation capital cost changes for lake dams.

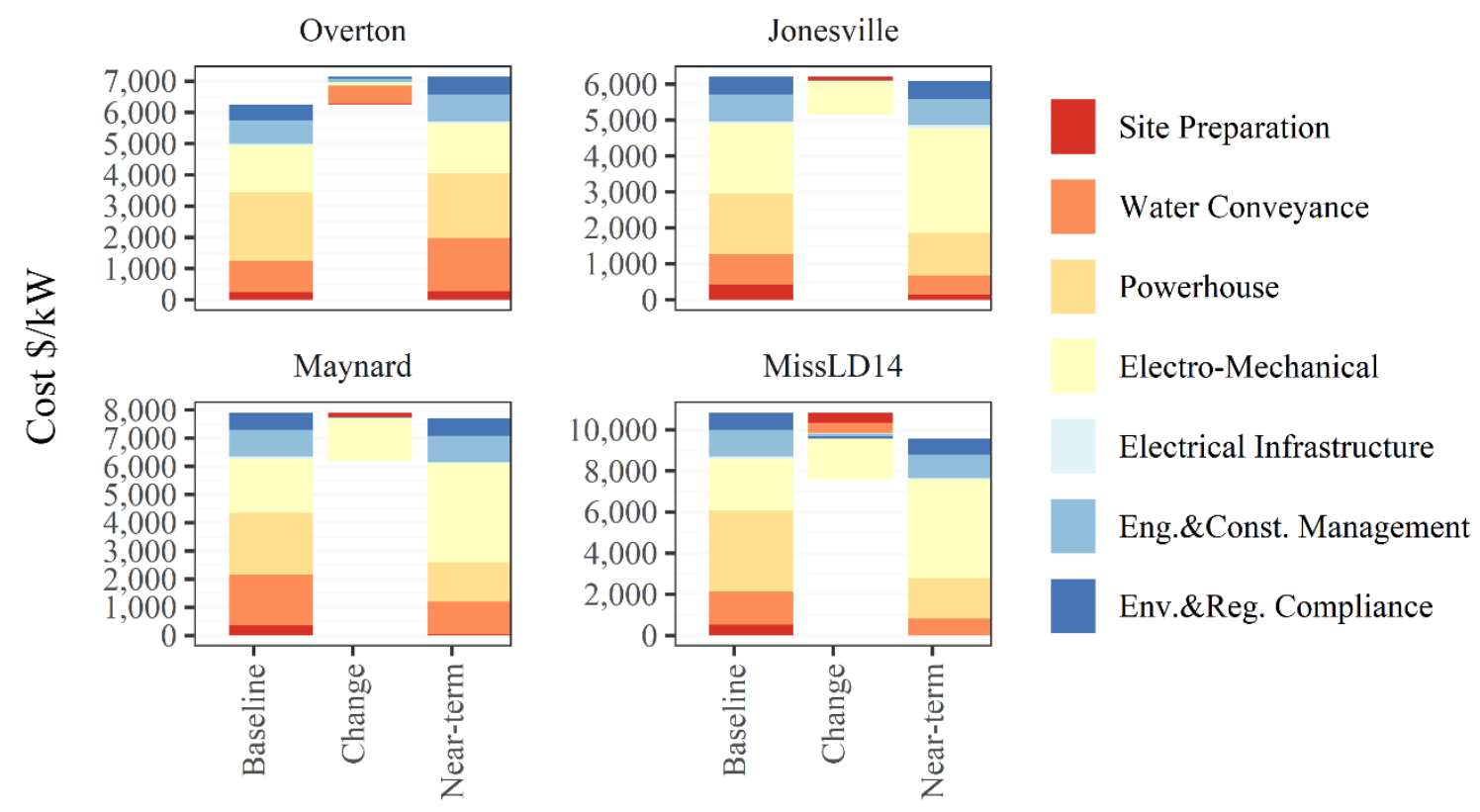

Figure 20. Baseline vs. near-term innovation capital cost changes for lock dams.

Matrix turbines were not evaluated as near-term innovations for the Overton Lock Dam site because of the large capacity potential and space limitations. The baseline capacity of about $70 \mathrm{MW}$ was reduced to about $48 \mathrm{MW}$ in line with recent revisions to the proposal for hydropower by the developer at the Overton site (Steimle, 2019). However, even with a lower capacity of $48 \mathrm{MW}$, more than 100 turbine matrix turbine modules would be required. The reduction in capacity for this site leads to a $14 \%$ increase in the per-kilowatt capital costs. This increase in capital cost per kilowatt must be evaluated along with 
reductions in total capital requirements of about $\$ 100$ million to develop the site, as well as potential increases in the capacity factor and reductions in overall cost of energy as discussed in the next section. Figure 20 illustrates the changes for four lock dam sites.

\subsection{NEAR-TERM VS. BASELINE CAPACITY FACTOR AND LCOE ESTIMATES}

Figure 21 compares the near-term and baseline capacity factor estimates. As expected, capacity factor estimates for lake dam sites are nearly identical for the two cases since the near-term innovations mainly affect the cost of water conveyance. Although the lining and penstock materials evaluated for the nearterm case have the potential to reduce frictions head losses, these were not considered in the current study. Thus, slight differences in capacity factor estimates between the baseline and near-term cases for the lake dams in Figure 21 are due to small variations in the algorithm used for the performance evaluation, as well as rounding. For lock dams, capacity factor differences between the baseline and nearterm cases reflect changes in the performance characteristics of bulb-Kaplan relative to the smaller matrix turbines. For the matrix turbine, a flat efficiency of 0.85 is assumed, but the turbines operate in off or on mode. In essence, the smaller matrix turbines discretize adjustments to flow changes and each unit has a larger range of operating head/flow relative to design values. Thus, for the same plant flow and head, the near-term cases for lock dams generally have slightly higher capacity factors than for the baseline case. The near-term case for Overton is based on a reduced design capacity rather than matrix turbines, resulting in a capacity factor of 0.59 in the near-term, which is higher than its baseline value of 0.44 .

The combined impact of changes in capital costs and capacity factors is reflected in the near-term vs. baseline estimates of the LCOE in Figure 22, with Table 9 providing additional information on these differences. As expected, LCOE estimates for the near-term cases are generally lower than for the baseline cases. The range of changes in the LCOE across all sites is quite wide, from $-\$ 306 / \mathrm{MWh}$ to $-\$ 14 / \mathrm{MWh}$, but only three of the sites have LCOE reduction magnitudes above \$130/MWh. Lake dams, which generally have the largest LCOE estimates in the baseline, also have the largest reductions, spanning from $-\$ 306 / \mathrm{MWh}$ to $-\$ 53 / \mathrm{MWh}$, or $-71 \%$ to $-14 \%$. For lock dams, the range of reductions in LCOE is $-\$ 57 / \mathrm{MWh}$ to $-\$ 14 / \mathrm{MWh}$, or $-21 \%$ to $-14 \%$. These reductions in LCOE are significant with 8 of 18 reference sites in Figure 22 having LCOE values under \$150/MWh in the near-term case compared with only 2 in the baseline case. 

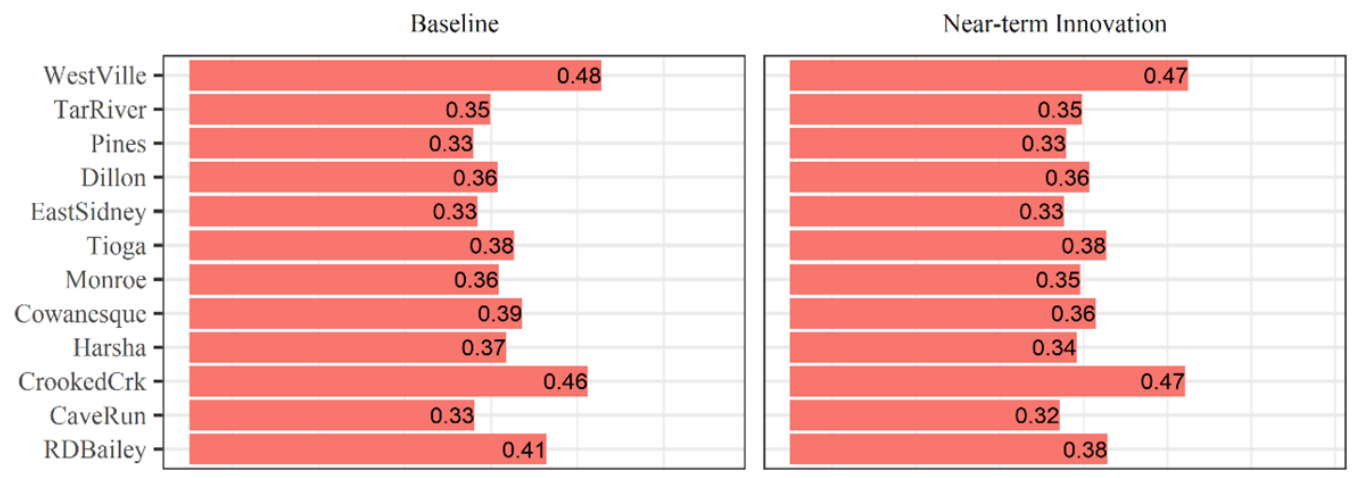

$\overline{\tilde{\hat{\sigma}}}$

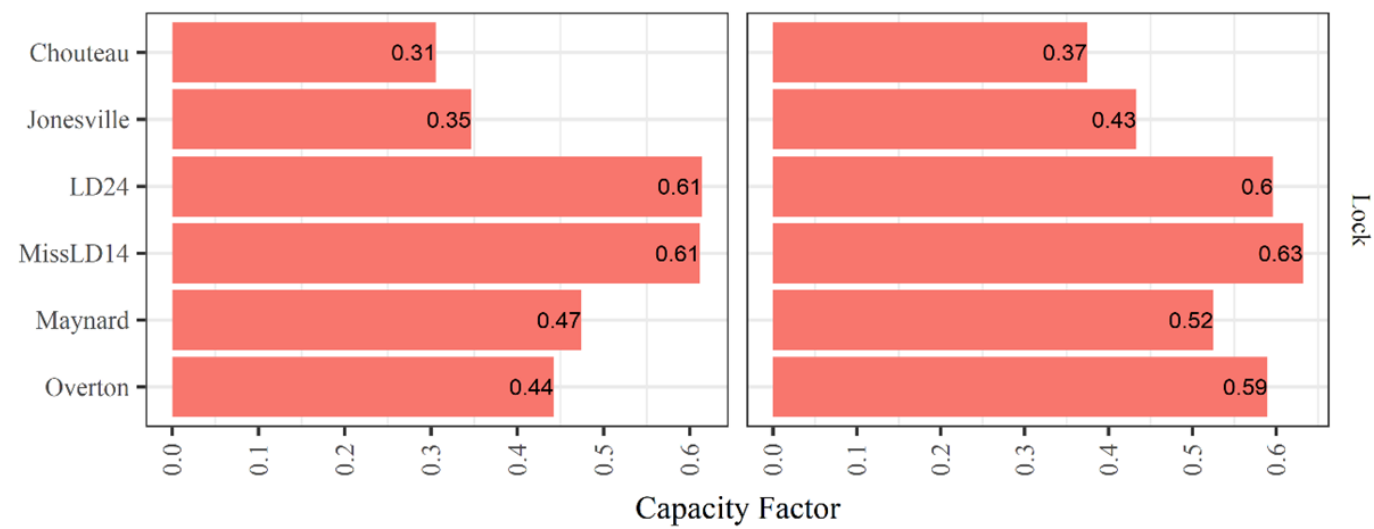

Figure 21. Baseline and innovation capacity factor estimates.

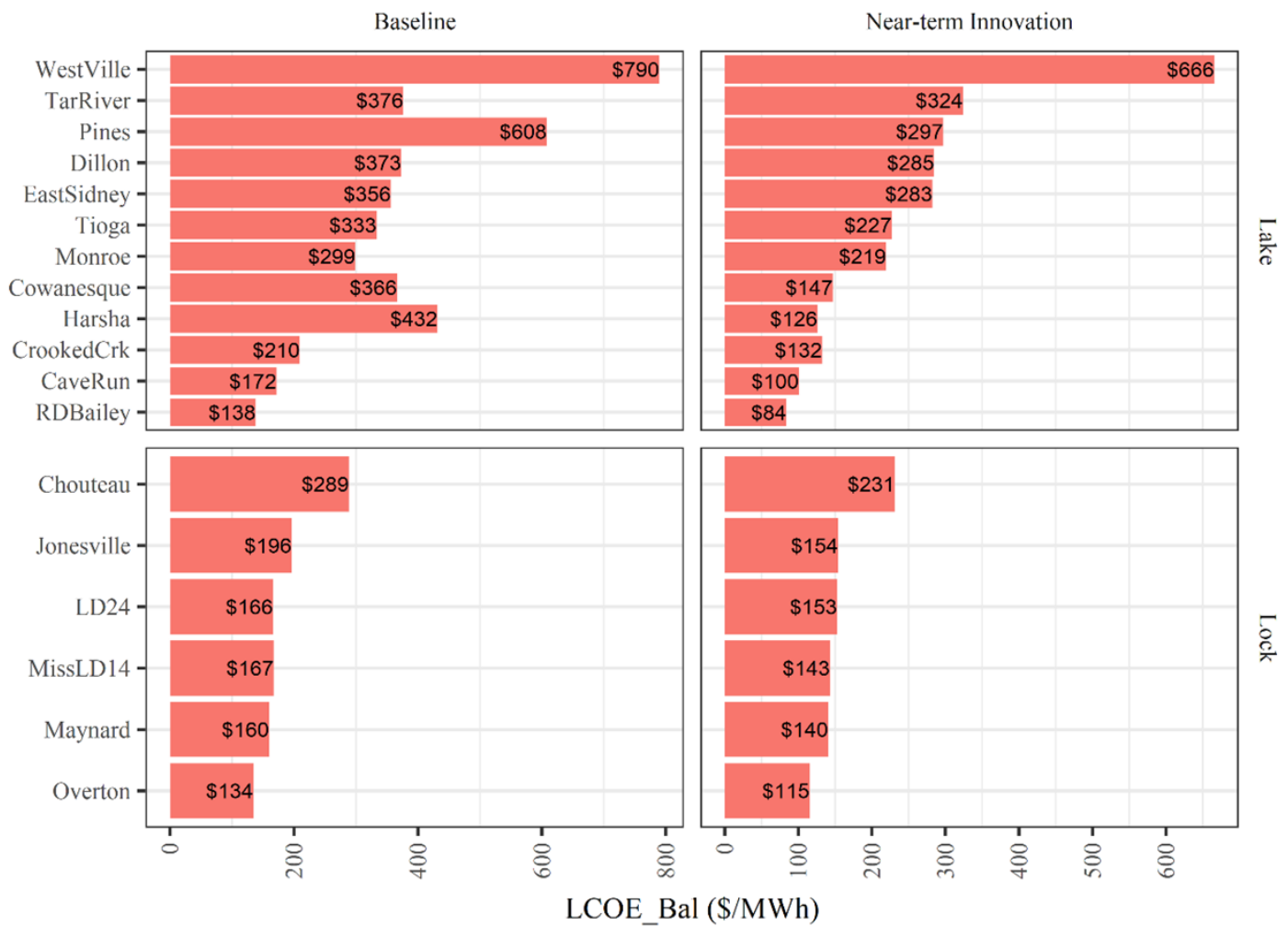

Figure 22. LCOE: baseline and near-term innovation cases. 
Table 9. Near-term vs. baseline LCOE changes.

\begin{tabular}{|c|c|c|c|c|c|}
\hline \multirow{2}{*}{ Reference site } & \multirow{2}{*}{ Lake/lock } & \multicolumn{2}{|c|}{ LCOE (\$/MWh) } & \multicolumn{2}{|c|}{ Change in LCOE } \\
\hline & & Base & Near-term & (\$/MWh) & $(\%)$ \\
\hline Tioga & Lake & 333.3 & 226.6 & -106.7 & -32.0 \\
\hline Dillon & Lake & 372.9 & 285 & -87.9 & -23.6 \\
\hline R. D. Bailey & Lake & 138.3 & 83.9 & -54.4 & -39.3 \\
\hline Monroe & Lake & 299 & 219.3 & -79.7 & -26.7 \\
\hline Cowanesque & Lake & 366.3 & 146.8 & -219.5 & -59.9 \\
\hline Westville & Lake & 789.7 & 665.6 & -124.1 & -15.7 \\
\hline Cave Run & Lake & 171.6 & 100.4 & -71.2 & -41.5 \\
\hline Lake O'The Pines & Lake & 588.4 & 297.2 & -291.2 & -49.5 \\
\hline William H. Harsha & Lake & 431.7 & 126 & -305.7 & -70.8 \\
\hline Chouteau L\&D & Lock & 288.6 & 231.2 & -57.4 & -19.9 \\
\hline Jonesville L\&D & Lock & 196.3 & 154.3 & -42.0 & -21.4 \\
\hline Maynard L\&D & Lock & 161.8 & 140.3 & -21.5 & -13.3 \\
\hline L\&D \#24 & Lock & 166.3 & 152.8 & -13.5 & -8.1 \\
\hline John Overton L\&D * & Lock & 134.1 & 115.4 & -18.7 & -13.9 \\
\hline Mississippi L\&D \#14 & Lock & 167 & 142.8 & -24.2 & -14.5 \\
\hline Crooked Creek & Lake & 209.6 & 132.3 & -77.3 & -36.9 \\
\hline East Sydney & Lake & 356.4 & 282.6 & -73.8 & -20.7 \\
\hline Tar River & Lake & 376.5 & 323.7 & -52.8 & -14.0 \\
\hline
\end{tabular}

*The near-term case for Overton is the same as the baseline but with reduced design capacity.

\section{SUMMARY AND NEXT STEPS}

\subsection{SUMMARY}

Given that less than 3,000 of the more than 90,000 dams in the US currently produce electricity, a considerable potential exists to increase hydropower generation at NPD sites. However, NPD sites have small potential capacities that may not be competitive with other sources of electricity because of the lack of economies of scale and other attributes. Thus, new technologies to reduce the cost and investment uncertainty associated with hydropower at NPD sites require considerable R\&D efforts. Furthermore, R\&D efforts must be guided by a deep understanding of the multidimensional drivers of hydropower construction and operation costs at these sites. This study performed a cost analysis of potential NPD hydropower in the US to understand the drivers of baseline costs and the potential impacts of innovations to reduce these costs. A population of $\sim 3,100$ sites from an ORNL assessment of NPD resources (Hadjerioua 2012) with initial estimated capacities $\geq 100 \mathrm{~kW}$ was selected and grouped into 20 classes based on three dam infrastructure attributes: dam type, primary purpose, and spillway type using a clustering algorithm. Daily flow and head data and the dam infrastructure cluster identifier for a subset of 135 of the $\sim 3,100$ sites were then further grouped into 20 resource clusters. The resource clusters are distinguished by dam infrastructure identifiers, median flow and head levels, and shapes of the flowduration and median-head curves. Representative sites for each of the 20 resource clusters were used as reference sites for the cost analysis in this study.

Hydropower facility configuration, generation performance, and costs were analyzed in detail for most of the reference sites, as well as a few additional sites using the ORNL smHIDEA model. The smHIDEA model is a bottom-up tool under active development for evaluating existing and emerging hydropower technologies and configurations. Capacity, facility design dimensions, capital costs, plant generation and 
efficiency profiles, capacity factor, and LCOE were estimated for the reference sites under a baseline case and a near-term innovation case. The baseline case represents plant designs using widely deployed technologies in the hydropower industry, whereas the near-term case focuses on potential changes that could be widely deployed in the next 5 to 10 years. Potential medium- to long-term innovations for NPD hydropower are also discussed but not analyzed in this study. The cost-reduction potential of near-term innovations relative to the baseline was evaluated.

Overall, the study finds that installed capacities vary from $200 \mathrm{~kW}$ to $70 \mathrm{MW}$, representing two orders of magnitude variation across nearly 20 sites, emphasizing the need for a systematic approach to analyze the cost of hydropower at NPD sites. Capital cost estimates range from $\$ 2,200 / \mathrm{kW}$ to $\$ 34,000 / \mathrm{kW}$ but are below $\$ 12,000 / \mathrm{kW}$ for most sites. Water conveyance components are the major cost drivers for lake dams, while powerhouse and electro-mechanical equipment are the major cost drivers for the lock dams. Baseline LCOE estimates vary from $\$ 79 / \mathrm{MWh}$ to $\$ 790 / \mathrm{MWh}$, with most sites under $\$ 400 / \mathrm{MWh}$. The near-term innovations considered lead to reductions in capital cost per kilowatt of $-77 \%$ to $-2.1 \%$ and LCOE reductions of $-71 \%$ to $-14 \%$ across all sites. Overall, changes in cost and performance lead to 8 of the 18 sites having LCOE values below \$150/MWh under the near-term case compared with only 2 of 18 sites in the baseline case.

\subsection{STUDY LIMITATIONS AND UNCERTAINTIES}

Although the current study used a comprehensive approach to evaluate the potential costs and cost reduction potentials of innovations for hydropower at NPD sites, several limitations exist. Among these are lack of complete information on dam attributes for the reference sites used in the study. These attributes could affect facility design opportunities and challenges under baseline and innovation cases, with potential implications for estimated costs. Another limitation is the lack of detailed resource information for the majority of $\sim 3,100$ sites with initial capacity estimates of $100 \mathrm{~kW}$ or more. This means that only 135 sites could be included in the final cost analysis. The results presented here may be applicable to other sites, but this would require additional information and analysis. Although available aerial photos of the sites were examined for this study, no general method can capture potential staging constraints at each site at this time, so this represents a source of uncertainty in the results.

In terms of the analysis itself, the facility design as a whole is not fully optimized since the LCOE measure used to evaluate costs - while providing a lifetime view of potential hydropower costs - may not capture all sources of costs. The LCOE also depends on several assumed parameters that are inherently uncertain, including assumptions about plant lifetime, development and construction periods, discount rates, and target electricity price in the regional market, among others. These sources of uncertainty may have important implications for NPD hydropower cost.

\subsection{NEXT STEPS}

An obvious next step for this study is to address some of the limitations and uncertainties highlighted above. In particular, a need exists to compile detailed daily flow and head data for as many of the $\sim 3,100$ sites identified in this study as possible. A need also exists to identify and compile available information on NPD dam features that are important to hydropower cost estimation but not available from databases such as the NID. Methods to extend cost estimates for the reference sites to the remainder of the $\sim 3,100$ sites without necessarily performing a large number of detailed bottom analysis of the individual sites are needed. Studies are needed to ascertain the extent of barriers to the near-term innovations evaluated in this study and options for accelerating their deployment. Information on potential breakthrough innovations to improve performance and costs of hydropower at NPD sites in the medium to long term is also an important next step. Finally, the smHIDEA tool would need to be continually enhanced with 
capabilities to evaluate the emerging technology and facility configurations for small hydropower development at NPD and other sites.

\section{REFERENCES}

AECC (Arkansas Electric Coop Corporation). 2002. Board of consultants final report for the Dam \#2 Hydropower Project. FERC Docket \#P-3033.

Aldersey-Williams, J., and Rubert, T. 2019. "Levelised cost of energy-A theoretical justification and critical assessment." Energy Policy 124, 169-179.

Amaral, S. V., Watson, S. M., Schneider, A. D., Rackovan, J., and Baumgartner, A. 2020. Improving survival: injury and mortality of fish struck by blades with slanted, blunt leading edges, Journal of Ecohydraulics. Accessed online at https://doi.org/10.1080/24705357.2020.1768166

AMP (American Municipal Power, Inc.). 2015. Hydropower: Building for the Future.

Andritz. 2020. HYDROMATRIX®: An innovative way to hydropower generation. https://www.andritz.com/resource/blob/33116/4c8a075eb7a93bd0ef8bce5ca90933fd/hyhydromatrix-product-presentation-en-data.pdf

Ardizzon, G., Cavazzini, G., and Pavesi, G. 2014. "A new generation of small hydro and pumped-hydro power plants: Advances and future challenges.” Renewable and Sustainable Energy Reviews, 31, $746-761$.

Beiter, P., et al. 2016. A spatial-economic cost-reduction pathway analysis for US offshore wind energy development from 2015-2030. NREL/TP-6A20-66579. National Renewable Energy Laboratory, Golden, Colorado.

Bishop, N., Linke, D., Alsberg, C., Anders, J., Grovue, A., Hill-Nelson, S., Johnson, K., Smith, B., Youlen, D., and Young, K. 2015. New pathways for hydropower: Getting hydropower built-What does it take. ORNL/TM-2015/48. Oak Ridge National Laboratory, Oak Ridge, Tennessee.

Chen, J., and Engeda, A. 2020. "Standard module hydraulic technology: A novel geometrical design methodology and analysis for a low-head hydraulic turbine system, Part I: General design methodology and basic geometry considerations." Energy 196, 117151.

Corà, E., Fry, J. J., Bachhiesl, M., and Schleiss, A. 2019. Hydropower technologies: The state-of-the-art. WP4-D1Rp-02. https://consultation.hydropowereurope.eu/assets/consultations/2019.08.13\%20HydropowerTechnology_State $\% 20 \mathrm{of} \% 20$ the $\% 20 \mathrm{Art}$ \%20FINAL.pdf

De Rose, A., Buna, M., Strazza, C., Olivieri, N., Stevens, T., Peeters, L., and Tawil-Jamault, D. 2017. Technology readiness level: Guidance principles for renewable energy technologies. European Commission: Petten, The Netherlands.

Drown, P., and French, B. 2017. French Modular Impoundment: Final Cost and Performance Evaluation. DOE-FDE-0007244. French Development Enterprises, LLC, North Billerica, Massachusetts.

Ernst, D., Glavic, M., Stan, G. B., Mannor, S., and Wehenkel, L. 2007. "The cross-entropy method for power system combinatorial optimization problems.” 2007 IEEE Lausanne Power Tech 12901295. 
FERC (Federal Electricity Regulatory Commission). 2012. Order issuing major original license for the Jennings Randolph Hydroelectric Project to Fairlawn Hydroelectric Company, LLC. Project No. 12715-003.

FERC (Federal Energy Regulatory Commission). 2019. Hydroelectric licensing regulations under the America's Water Infrastructure Act of 2018. Final Rule. Docket No. RM19-6-000, Order No. 858. https://www.govinfo.gov/content/pkg/FR-2019-04-24/pdf/2019-08239.pdf

Filippini, M., and Luchsinger, C. 2007. "Economies of scale in the Swiss hydropower sector." Applied Economics Letters 14(15), 1109-1113.

Godinho, F. N., Eira, A., Leitão, M. M. P., Courret, D., Javier, F., Sanz-Ronda, R. B., and Odelberg, A. 2020. Fish-friendly Innovative Technologies for Hydropower. FIThydro. http://www.fithydro.eu/wp-content/uploads/2019/07/D2.1-SYGMA.pdf

H.R. 267. 2013. Hydropower Regulatory Efficiency Act of 2013. 113th Congress of the United States https://www.govtrack.us/congress/bills/113/hr267/text

Hadjerioua, B., Wei, Y., and Kao, S. C. 2012. An assessment of energy potential at non-powered dams in the United States. Oak Ridge National Laboratory, Oak Ridge, Tennessee.

https://www1.eere.energy.gov/water/pdfs/npd report.pdf

IEA (International Energy Agency). 2019. Innovation Gaps. Paris. https://www.iea.org/reports/innovation-gaps

Kougias, I., et al. 2019. "Analysis of emerging technologies in the hydropower sector." Renewable and Sustainable Energy Reviews 113, 109257.

Krouse, W. 2014. Development of new, low-head hydropower turbine-modeling \& laboratory test DE-EE0005426. EE0005426-HGE-1Final. Hydro Green Energy, Westmont, Illinois. https://www.osti.gov/servlets/purl/1329187

Maechler, M., Rousseeuw, P., Struyf, A., Hubert, M., Hornik, K., Struder, M., Roudier, P., Gonzalez, J., Kozlowski, K., Schubert, E., and Murphy, K. 2019. Finding groups in data. CRAN. https://cran.rproject.org/web/packages/cluster/cluster.pdf

Meilă, M. 2007. "Comparing clusterings_-an information based distance." Journal of Multivariate Analysis 98(5), 873-895.

MJ2 Technologies. 2020. "VLH Range.” http://www.vlh-turbine.com/products/vlh-turbine/vlh-range/

Moreels, D., and Leijnen, P. 2018. High Efficiency Axial Flux Machines. MAGNAX White Paper, V 1.9. https://images.engineeringnet.eu/RSS/images/MagnaxAxialFluxMachines-whitepaper.pdf

Natel Energy. 2020. RHT Cut Sheets. https://1hskmz3i2o5bhic6pojfb512-wpengine.netdna-ssl.com/wpcontent/uploads/2019/12/RHT_cutsheets dec 2019.pdf

O'Connor, P. W., Chalise, D. R., and DeNeale, S. T. 2017. The Small Hydropower Integrated Design and Economic Assessment Model: Documentation and Selected Applications. Unpublished draft, Oak Ridge National Laboratory, Oak Ridge, Tennessee.

O'Connor, P., et al. 2016a. Hydropower Vision A New Chapter for America's 1st Renewable Electricity Source. ORNL/TM-2016/688. Oak Ridge National Laboratory, Oak Ridge, Tennessee.

O'Connor, P., Rugani, K., and West, A. 2016. Summary Report of Advanced Hydropower Innovations and Cost Reduction Workshop at Arlington, VA, November 5 and 6, 2015. ORNL/TM-2016/113. Oak Ridge National Laboratory, Oak Ridge, Tennessee. 
Oladosu, G. A., Werble, J., Tingen, W., Witt, A., Mobley, M., and O'Connor, P. In review. "Costs of mitigating the environmental impacts of hydropower projects in the United States." Renewable and Sustainable Energy Reviews 135, 110121.

Parker, D. 2017. "A Fresh power couple is in town - Meet new hydro and existing dams." Presented at HydroVision International 2017.

Patel, S., Yee, D., and Yenter, J. 2017. "Optimizing the value of variable speed systems for low head dams." Presented at HydroVision International 2017.

PE100+ Association. 2019. "PE \& HDPE PE100 pipe: Properties and types." PE technical guidance. https://www.pe100plus.com/PE-Pipes/Technical-guidance/Trenchless/Methods/PE-Pipe-i1341.html

Plastics Insight. 2017. "HDPE Production Capacity, Price and Market." https://www.plasticsinsight.com/resin-intelligence/resin-prices/hdpe/

Rokach, L., and Maimon, O. 2005. "Clustering methods." In Data Mining and Knowledge Discovery Handbook, 321-352. Boston: Springer.

Steimle, E. 2019. Application for non-capacity amendment of license, American Eel Study Plan. Rye Development. https://elibrary.ferc.gov/eLibrary/filedownload?fileid=15311803

Rytwinski, T., Algera, D. A., Taylor, J. J., Smokorowski, K. E., Bennett, J. R., Harrison, P. M., and Cooke, S. J. 2017. "What are the consequences of fish entrainment and impingement associated with hydroelectric dams on fish productivity? A systematic review protocol." Environmental Evidence 6(1), 1-9.

SAF Hydroelectric, LLC. 2011. The Lower Saint Anthony Falls (LSAF) Hydroelectric Project FERC License 12451. https://www.xcelenergy.com/staticfiles/xe/Corporate/Corporate $\% 20 \mathrm{PDFs} /$ LSA_Final_Report Mile stone11.pdf

Sari, M. A., Badruzzaman, M., Cherchi, C., Swindle, M., Ajami, N., and Jacangelo, J. G. 2018. "Recent innovations and trends in in-conduit hydropower technologies and their applications in water distribution systems.” Journal of Environmental Management 228, 416-428.

Schubert, E., and Rousseeuw, P. J. 2019. "Faster k-medoids clustering: improving the PAM, CLARA, and CLARANS algorithms." In International Conference on Similarity Search and Applications 171-187. Cham: Springer.

SHC (Small Hydro Consulting). 2019. Civil cost estimates for five NPD hydropower development sites. Working Report Submitted to Oak Ridge National Laboratory

Smith, B. T., DeNeale, S. T., Witt, A. M., Mobley, M. H. and Fernandez, A. R. 2017. Standard modular hydropower technology acceleration workshop: Summary report. ORNL/TM-2017/328. Oak Ridge National Laboratory, Oak Ridge, Tennessee.

Steinley, D. 2006. "K-means clustering: A half-century synthesis." British Journal of Mathematical and Statistical Psychology 59(1), 1-34.

UNIDO (United Nations Industrial Development Organization). 2019. World small hydropower development report: Case studies. https://www.unido.org/sites/default/files/files/202005/UNIDO $\% 20$ Case $\% 20$ Studies for $\% 20 \mathrm{web} . \mathrm{pdf}$

Uria-Martinez, R., et al. 2018. 2017 Hydropower market report. Oak Ridge National Laboratory, Oak Ridge, Tennessee.

USACE (US Army Corps of Engineers). 2018. 2018 National inventory of dams database. http://nid.usace.army.mil/ 
USACE (US Army Corps of Engineers). 2019. 2019 National inventory of dams database. http://nid.usace.army.mil/

Vimmerstedt, et al. 2019. 2019 Annual Technology Baseline. NREL/PR-6A20-74273. National Renewable Energy Laboratory, Golden, Colorado.

Voith. 2020. StreamDiver ${ }^{\circledR}:$ Utilizing New Hydropower Potential. http://voith.com/caen/t 3390 StreamDiver_screen.pdf

Witt, A. M., Uria-Martinez, R., Johnson, M. M., Werble, J. M., Mobley, M. H., and O’Connor, P. W. 2018. "United States trends in non-powered dam electrification." International Journal on Hydropower \& Dams 25(4).

Zhang, Q. F., Smith, B., and Zhang, W. 2012. Small hydropower cost reference model. ORNL/TM2012/501. Oak Ridge National Laboratory, Oak Ridge, Tennessee.

Zhou, D., and Deng, Z. D. 2017. "Ultra-low-head hydroelectric technology: A review." Renewable and Sustainable Energy Reviews 78, 23-30.

Zhou, D., Gui, J., Deng, Z. D., Chen, H., Yu, Y., Yu, A., and Yang, C. 2019. "Development of an ultralow head siphon hydro turbine using computational fluid dynamics." Energy 181, 43-50. 


\section{APPENDIX A. HYDROPOWER TRL}

\begin{tabular}{|c|c|c|}
\hline & ORNL List & European Union List* \\
\hline TRL1 & Ideas to form R\&D proposals & Basic principles observed \\
\hline TRL2 & Formally funded R\&D proposals & Technology concept formulated \\
\hline TRL3 & $\begin{array}{l}\text { Conceptual design - technical feasibility through } \\
\text { theoretical analysis and computer modeling }\end{array}$ & Experimental proof of concept \\
\hline TRL4 & Physical model validation in laboratory & Technology validated in lab \\
\hline TRL5 & Field validation and demonstration & Technology validated in relevant environment \\
\hline TRL6 & Pilot plant operation & $\begin{array}{l}\text { Technology pilot demonstrated in relevant } \\
\text { environment }\end{array}$ \\
\hline TRL7 & $\begin{array}{l}\text { Verification and validation completed and ready for } \\
\text { commercialization }\end{array}$ & $\begin{array}{l}\text { System prototype demonstration in operational } \\
\text { environment }\end{array}$ \\
\hline TRL8 & $\begin{array}{l}\text { Successfully applied and well performed in some } \\
\text { countries/regions }\end{array}$ & System complete and qualified \\
\hline TRL9 & $\begin{array}{l}\text { Mature technology-good performance has been } \\
\text { proved for decades }\end{array}$ & Actual system proven in operational environment \\
\hline Source & $\begin{array}{l}\text { Zhang, Q. F., Smith, B., and Zhang, W. } 2012 . \\
\text { Small hydropower cost reference model. } \\
\text { ORNL/TM-2012/501. Oak Ridge National } \\
\text { Laboratory, Oak Ridge, Tennessee. }\end{array}$ & $\begin{array}{l}\text { De Rose, A., Buna, M., Strazza, C., Olivieri, N., } \\
\text { Stevens, T., Peeters, L., and Tawil-Jamault, D. } 2017 . \\
\text { Technology readiness level: Guidance principles for } \\
\text { renewable energy technologies. European } \\
\text { Commission: Petten, The Netherlands. }\end{array}$ \\
\hline
\end{tabular}

*The first eight of the European Union TRL are identical to those used by WPTO to guide R\&D projects. 


\section{APPENDIX B. NPD INFRASTRUCTURE AND RESOURCE CLUSTERS}

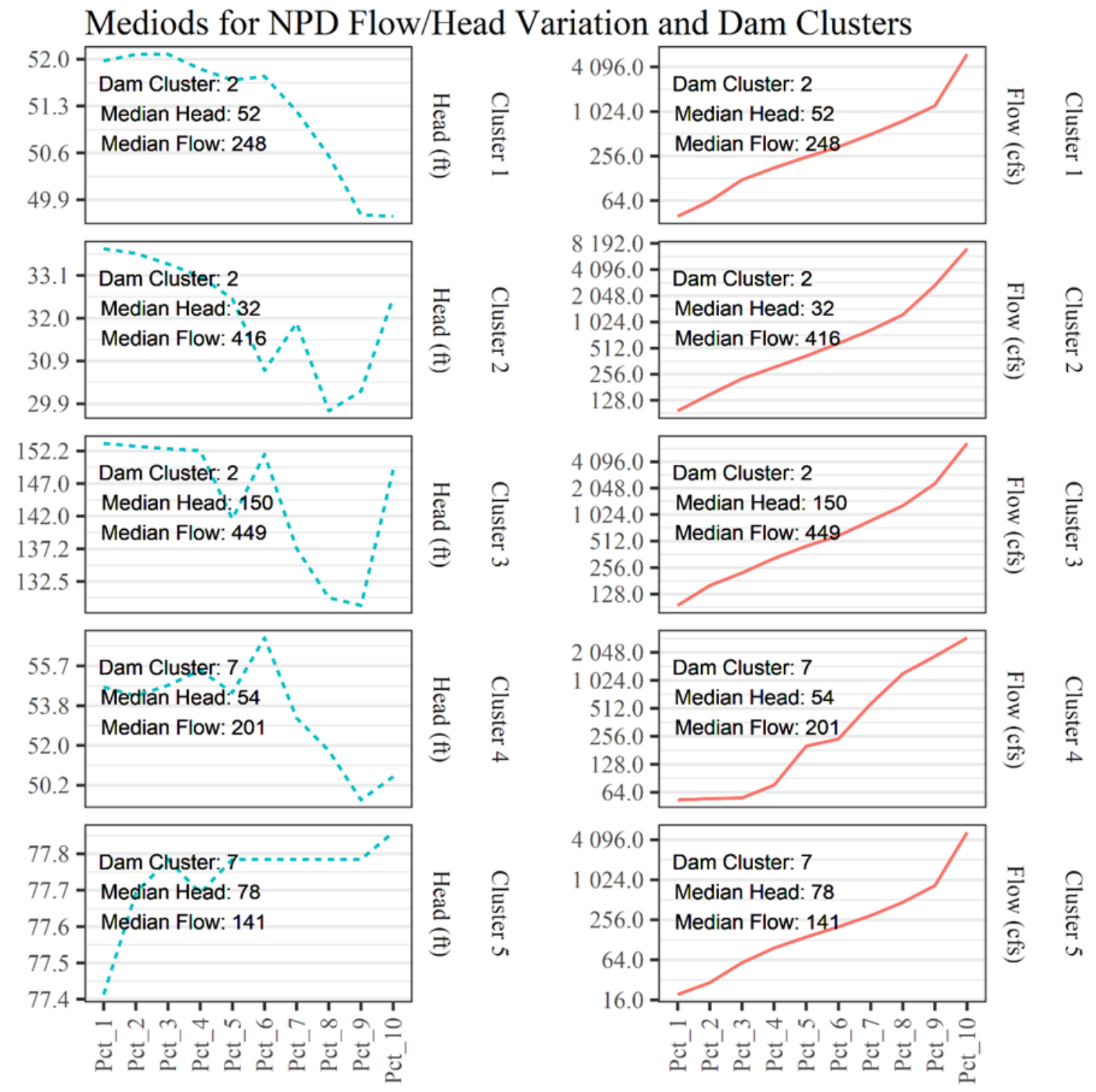

Percentile Increments of 10

Variables — flow -.- head 


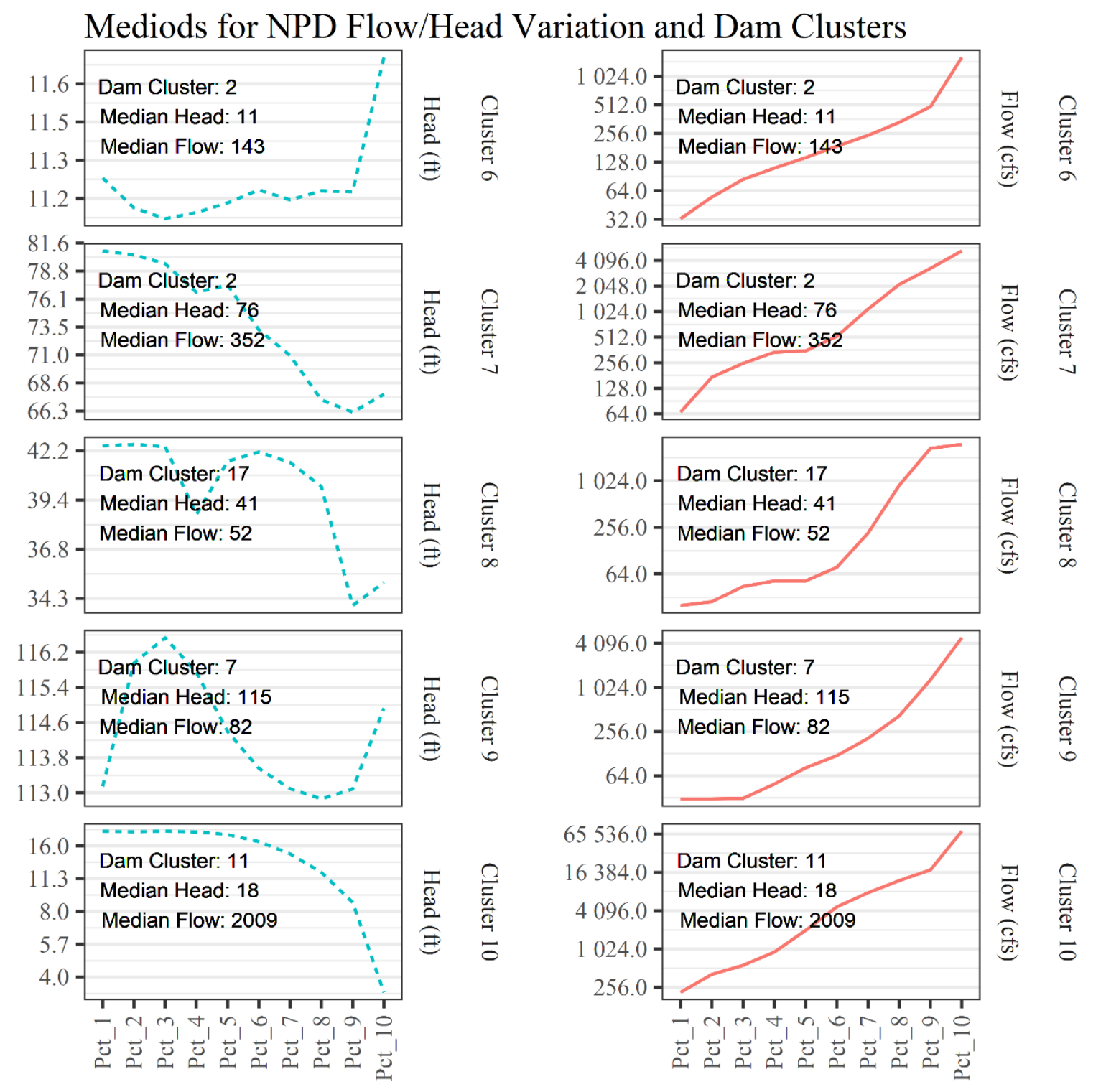

Percentile Increments of 10

Variables _ flow --- head 


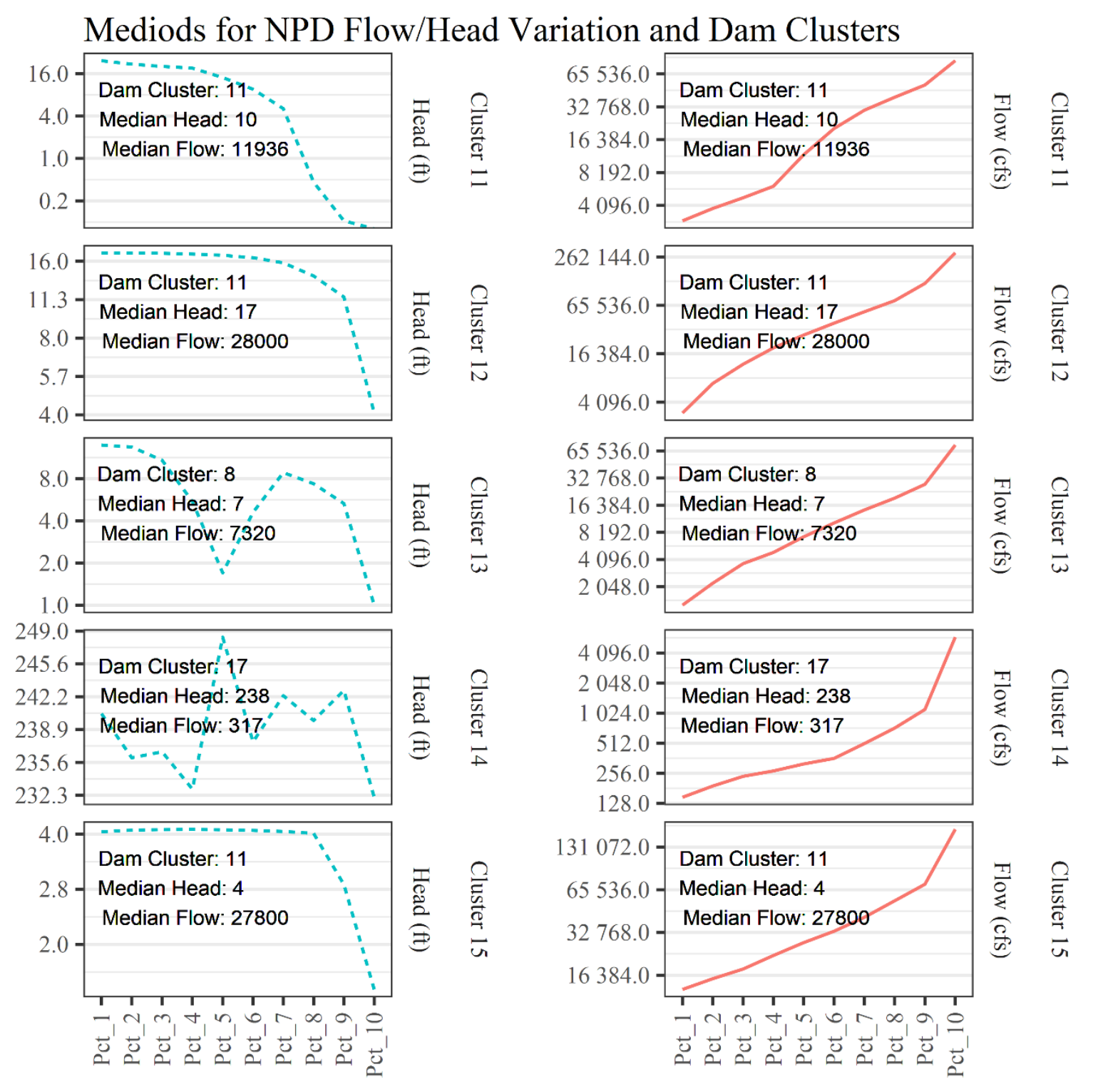

Percentile Increments of 10

Variables _ flow --- head 


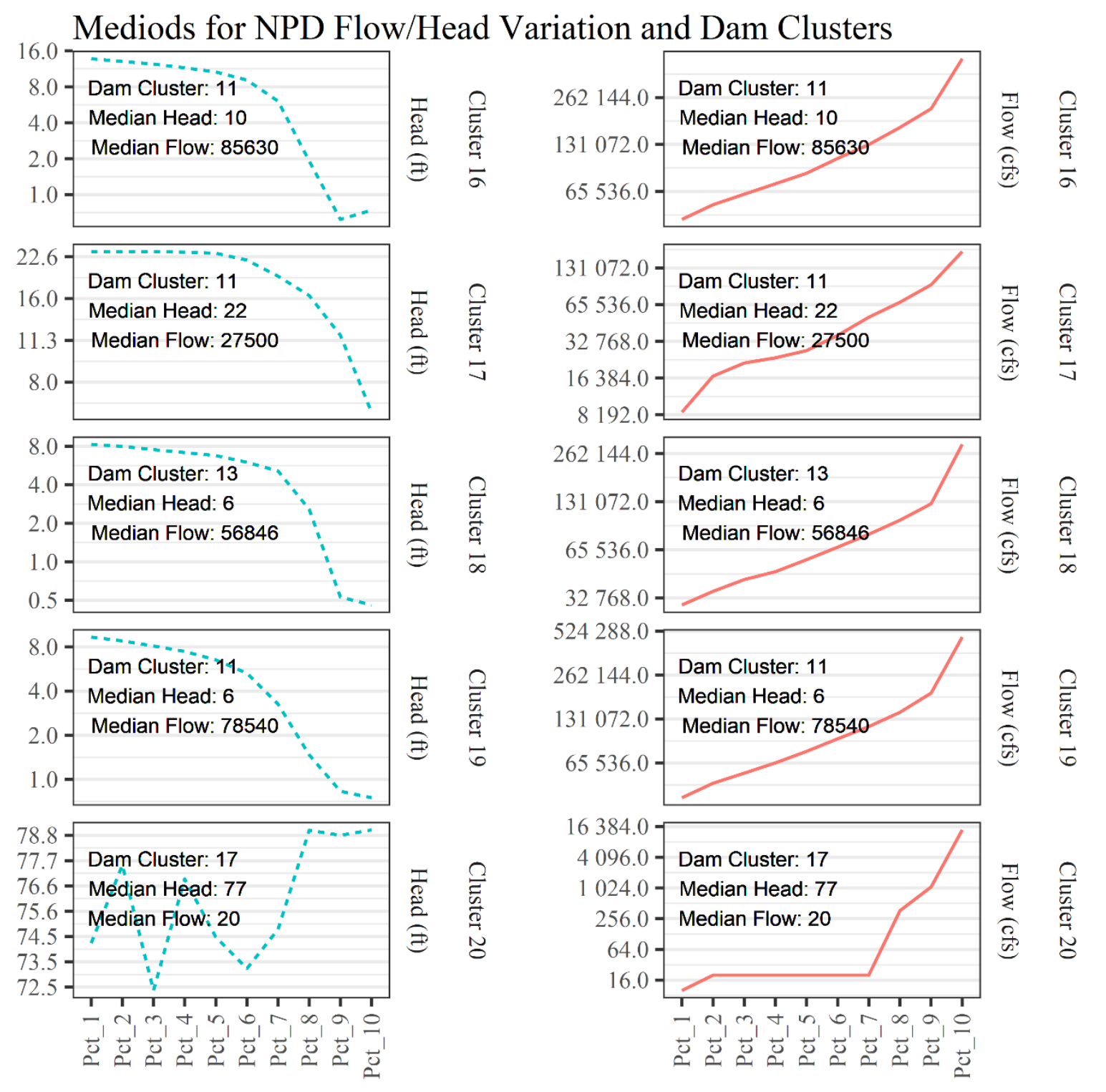

Percentile Increments of 10

Variables — flow --- head 


\section{APPENDIX C. SITES PROFILES}

\section{C.1 TIOGA DAM}

The Tioga-Hammond Lakes project (coordinates $41^{\circ} 53^{\prime} 57.0^{\prime \prime} \mathrm{N} 77^{\circ} 08^{\prime} 21.0^{\prime \prime} \mathrm{W}$ ) consists primarily of two separate dams in Pennsylvania: one on Tioga River and one on Crooked Creek. The two dams are approximately $2 \mathrm{mi}$ upstream of the confluence of the Tioga River and Crooked Creek. The lakes are joined by a gated connecting channel in a saddle of the ridge separating the two streams. An uncontrolled spillway in Hammond Dam serves both reservoirs. A gated outlet conduit is provided in the left abutment of Tioga Dam for the control of flows for both reservoirs. Tioga Dam is of earth and rockfill construction, is 2,710 ft long, and has a maximum height of $140 \mathrm{ft}$ above the streambed. Hammond Dam is of earth and rockfill construction, is $6,450 \mathrm{ft}$ long, and has a maximum height of $122 \mathrm{ft}$ above the streambed. Tioga Dam controls $280 \mathrm{mi}^{2}$ of drainage area in the Tioga River basin, while Hammond Dam controls $122 \mathrm{mi}^{2}$ of drainage area in the Crooked Creek basin. An additional feature of the project is the Mansfield local flood protection project, which consists of channel improvements, levees, and pumping stations that provide flood risk management to the borough of Mansfield, Pennsylvania during high-water events. The project was authorized by the Flood Control Act of July 3, 1958, Public Law 85-500, and was completed in 1979; federal cost was $\$ 186$ million. The project provides flood risk management, recreation, and environmental stewardship to protect habitat and water quality, and expands public access within the Chesapeake Bay watershed (Source: https://usace.contentdm.oclc.org/digital/collection/p16021coll11/id/3542)

\section{C.2 DILLON DAM}

Dillon Dam (coordinates 39 59'30.0"N 82 04'48.0"W) is in Summit County, Colorado, south of I-70 and bordered by the towns of Frisco, Silverthorne, and Dillon. The project was authorized under Section 4 of the Flood Control Act of 1938 and was completed in July 1959 with a drainage area of $748 \mathrm{mi}^{2}$. The lake is impounded by a rolled earth-fill impervious core dam, $118 \mathrm{ft}$ tall and 1,400 ft long, with an uncontrolled, partial concrete lined spillway near the left abutment of the dam. The outlet works include an intake structure with thee sluice gates that discharge through a conduit into a stilling basin. Two conduits located around the gates of the outer sluices are used to maintain minimum pool. Other structures include two earth-fill dikes. Primary project purposes are flood risk reduction, low flow augmentation, and recreation. There are four-day use recreation areas at the project. Dillon Lake State Park comprises most of the recreational facilities on the project (Source: https://www.lrd.usace.army.mil/Portals/73/docs/Civil\%20Works/Ohio\%20River\%20System $\% 20$ Projects/ Flood $\% 20$ Risk $\% 20$ Management $\% 20$ Projects/Final $\% 20$ combined $\% 202020 \% 20$ Ohio $\% 20$ River $\% 20$ Syste m\%20Fact\%20Sheets\%20reduced\%20(22APR2020).pdf).

\section{C.3 R. D. BAILEY DAM}

R. D. Bailey Dam (coordinates $37^{\circ} 36^{\prime} 01.1^{\prime \prime N} 81^{\circ} 49^{\prime} 20.6^{\prime \prime W}$ ) is on the Guyandotte River near Justice, on the Wyoming-Mingo county line in West Virginia. Named in honor of the late Judge R. D. Bailey, the lake provides flood protection for the lower Guyandotte River basin, including the city of Huntington. The project was authorized under the 203 of Flood Control Act of 1962 and was completed in 1980 with a drainage area of $540 \mathrm{mi}^{2}$. The lake is impounded by a rock and random-fill dam with a concrete face and an uncontrolled broad-crested saddle spillway. The project no longer has a marina concessionaire. The dam was the first rock-fill dam developed by the US Army Corps of Engineers with a concrete face, a complex and difficult job. The 310-ft-high dam is the second-highest in West Virginia (Summersville Dam is highest at $390 \mathrm{ft}$ ), and measures 1,400 ft across. The intake structure, a 310-ft concrete tower, has gates at four intervals. The outlet works include an intake structure with two sluices controlled by hydraulically operated slide gates that discharge through a circular tunnel through the left abutment of the dam. Five intake gates at four different elevations discharge into a sluice for selective withdrawal. Water can normally be released from any of the four levels to control water temperature and water quality 
downstream. The primary project purposes of the dam are flood risk management, water quality, and recreation. (Source:

https://www.lrd.usace.army.mil/Portals/73/docs/Civil\%20Works/Ohio\%20River\%20System\%20Projects/ Flood\%20Risk\%20Management\%20Projects/Huntington\%20District/RD\%20Bailey\%20Lake\%20FINAL .pdf).

\section{C.4 MONROE LAKE DAM}

Monroe Lake Dam (coordinates 39 $09^{\circ} 28.7^{\prime \prime} \mathrm{N} 86^{\circ} 30^{\prime} 41.3^{\prime \prime} \mathrm{W}$ ) is in Monroe County and extends into Brown, Jackson, and Lawrence Counties in south central Indiana. The dam is on Salt Creek, $25.9 \mathrm{mi}$ upstream of its juncture with the East Fork of White River, approximately 20 mi southeast of Bloomington. The project was authorized under the Flood Control Act of 1938 and was completed in 1965. Monroe Lake is the largest lake entirely situated in Indiana, with 10,750 acres of water surface area and capacity from 237,000 to 347,000 acre-ft depending on water level. Monroe Lake is managed by the US Army Corps of Engineers and the Indiana Department of Natural Resources. The Monroe Lake Dam comprises an impervious core with a rock shell and mowed turf downstream face, and riprap upstream face. The maximum height of the dam is $93 \mathrm{ft}$ and the crest length is 1,350 ft. The top elevation of the dam is $574 \mathrm{ft}$ above mean sea level (msl). The Monroe Lake Dam structures include a conduit-type outlet works, a spillway (with a dry tower), a public-use road across the top of the dam, and an operations building with a parking area and a gauging station. The outlet works consist of a dry type tower and a 12$\mathrm{ft}$ diameter, elliptical, concrete conduit. The spillway is through an open cut of the left abutment around a natural hillside peninsula known as the Salt Creek lake access. The crest elevation is $556 \mathrm{ft}$ above msl.

The cut is $600 \mathrm{ft}$ wide and $750 \mathrm{ft}$ long. The spillway is designed to accommodate a maximum discharge of $73,760 \mathrm{cfs}$ of flow. Flow is controlled by three service gates - each with $3.75 \mathrm{ft}$ horizontal by $12-\mathrm{ft}$ vertical dimensions. The conduit inlet invert elevation is $497 \mathrm{ft} \mathrm{msl}$. The dam also has two bypass gateseach $30 \mathrm{in}$. in diameter. Primary project purposes are flood damage reduction, water supply, fish and wildlife habitat, and recreation (Source:

https://www.Ird.usace.army.mil/Portals/73/docs/Civil\%20Works/Ohio\%20River\%20System\%20Projects/ Flood\%20Risk\%20Management\%20Projects/Louisville\%20District/Monroe\%20Lake\%20FINAL.pdf)

\section{C.5 COWANESQUE LAKE DAM}

Cowanesque Lake Dam (coordinates $41^{\circ} 59^{\prime} 10.3^{\prime \prime} \mathrm{N} 77^{\circ} 09^{\prime} 07.2^{\prime \prime} \mathrm{W}$ ) is in Tioga County, Pennsylvania, on the Cowanesque River approximately $2 \mathrm{mi}$ upstream of the confluence with the Tioga River at Lawrenceville, Pennsylvania. The embankment is of earth and rockfill, is $3,100 \mathrm{ft}$ long, rises $151 \mathrm{ft}$ above the streambed, and has a 400-ft-long spillway in the right abutment. The outlet works consist of an excavated approach channel, a combined intake and gate structure, a 12 by 14 -ft diameter horseshoeshaped tunnel, and a concrete outlet structure with a stilling basin. A conservation lake is maintained at elevation 1080 National Geodetic Vertical Datum having a surface area of 1,090 acres and a length of $4.2 \mathrm{mi}$. Water supply storage accounts for $79 \%$ of the conservation storage space. The project was completed in 1980. The US Army Corps of Engineers operates and maintains three major recreation areas on Cowanesque Lake. The South Shore Recreation Area provides boat launching, picnicking, a designated swimming area, fishing pier, comfort stations, and concession facilities. The Lawrence Recreation Area provides picnic facilities and a comfort station. The Tompkins Campground provides modern group and primitive campsites, a boat launch, and a designated swimming area (Source: https://usace.contentdm.oclc.org/digital/api/collection/p16021coll11/id/3552/download)

\section{C.6 WESTVILLE DAM}

Westville Dam (coordinates $42^{\circ} 04^{\prime} 54.0^{\prime \prime} \mathrm{N} 72^{\circ} 03^{\prime} 30.0^{\prime \prime} \mathrm{W}$ ) is on the Quinebaug River in the towns of Southbridge and Sturbridge, about $18 \mathrm{mi}$ southwest of Worcester and $25 \mathrm{mi}$ east of Springfield, Massachusetts. The project was completed in 1962 and is part of a network of six dams constructed and maintained by the US Army Corps of Engineers to relieve the effects of flooding along the major rivers of the Thames River Basin. The project consists of an earth-fill dam $560 \mathrm{ft}$ long and $78 \mathrm{ft} \mathrm{high}$; three gated 
rectangular conduits, each measuring $6 \mathrm{ft}$ high, $4 \mathrm{ft}$ wide, and $63 \mathrm{ft}$ long; and a chute spillway founded on bedrock with a 200-ft-long weir. The weir's crest elevation is $15 \mathrm{ft}$ lower than the top of the dam.

Westville Lake contains a 23 -acre recreation pool $1 / 2 \mathrm{mi}$ long, with a depth of $10 \mathrm{ft}$ at the dam. The flood storage area of the project totals 913 acres and extends 6.4 mi upstream into the village of Fiskdale, a part of Sturbridge. This area is normally empty and is used only to store floodwaters. Westville Lake can store up to 3.61 billion gallons of water for flood control purposes. This is equivalent to $6.5 \mathrm{in}$. of water covering its drainage area of $99.5 \mathrm{mi}^{2}$. (Source: https://www.nae.usace.army.mil/Missions/CivilWorks/Flood-Risk-Management/Massachusetts/Westville/)

\section{C.7 CAVE RUN LAKE DAM}

Cave Run Lake Dam (coordinates $38^{\circ} 07^{\prime} 04.2^{\prime \prime} \mathrm{N} 83^{\circ} 31^{\prime} 59.6^{\prime \prime} \mathrm{W}$ ) is in Morehead, Kentucky. The project was authorized by the Flood Control Act of June 22, 1936 and became operational in February 1974. It supports an 8,270-acre reservoir built by the US Army Corps of Engineers in 1974. The dam is an earthen and rock-fill embankment dam; it is $148 \mathrm{ft}$ tall and 2,700 ft long. The Cave Run Lake provides flood protection, water supply, habitat for fish and wildlife, and recreation, and improves flow in the Licking River. Primary project purposes are flood risk reduction, water supply, fish and wildlife habitat, and recreation. (Source:

https://www.Ird.usace.army.mil/Portals/73/docs/Civil\%20Works/Ohio\%20River\%20System\%20Projects/ Flood\%20Risk\%20Management\%20Projects/Louisville\%20District/Cave\%20Run\%20Lake\%20FINAL.p df)

\section{C.8 LAKE O' THE PINES DAM}

Lake O' the Pines Dam (coordinates 32 $45^{\prime} 04.2^{\prime \prime} \mathrm{N} 94^{\circ} 29^{\prime} 59.5^{\prime \prime} \mathrm{W}$ ) is in the Red River Basin, which is under supervision of the District Engineer, US Army Corps of Engineers District, Fort Worth, Texas. The project was authorized by the Flood Control Act approved July 24, 1946, Public Law No. 526, 79th congress, 2nd session, and was operational in December 1959 with a drainage area of $850 \mathrm{mi}^{2}$. The earthfill dam is $10,600 \mathrm{ft}$ long and rises $97 \mathrm{ft}$ above the streambed. Water intake structures are located at various points on the lake and one downstream of the lake. Discharges from the two gates in the control structure on the southeast end vary from 5 to $3,000 \mathrm{cfs}$. In addition to the primary purpose of flood control, the land and water areas of the reservoir bring other public benefits, including the development of public use facilities, the conservation of fish and wildlife, and the provision of domestic and industrial water supply. (Source: https://www.swf-wc.usace.army.mil/lakeopines/Information/index.asp)

\section{C.9 WILLIAM H. HARSHA DAM}

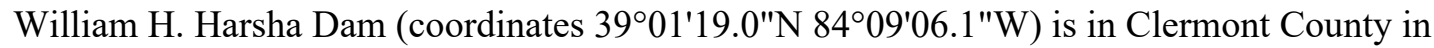
southwestern Ohio, about $25 \mathrm{mi}$ east of Cincinnati on the East Fork of the Little Miami River. The project was authorized under the Flood Control Act of 1938. The Louisville District of the US Army Corps of Engineers designed, built, and operates the project to reduce flood damages downstream from the dam. The dam is earth-fill with outlet works, a separate saddle dam, and a spillway. The dam is $200 \mathrm{ft}$ high and $1,450 \mathrm{ft}$ long. The saddle dam is $100 \mathrm{ft}$ high and 2,600 ft long. The project was authorized as a multipurpose flood control project with additional authorized responsibilities for recreation management, environmental stewardship, water supply, and water quality. Originally called East Fork Lake, the dam and lake were renamed in 1981 to honor retired congressman William H. Harsha, who was elected to Congress in 1960 and served until his retirement in 1981. (Source: https://www.lrl.usace.army.mil/Missions/Civil-Works/Recreation/Lakes/William-H-Harsha-Lake/)

\section{C.10 CHOUTEAU LOCK \& DAM}

Chouteau Lock \& Dam (coordinates $42^{\circ} 04^{\prime} 54.0^{\prime \prime} \mathrm{N} 72^{\circ} 03^{\prime} 30.0^{\prime \prime} \mathrm{W}$ ) is on the Verdigris River in Oklahoma. The lock is at McClellan-Kerr navigation mile 401.4, about 4 mi northwest of Okay in Wagoner County, Oklahoma, and the dam is in the old river channel at navigation mile 403.0. The project is part of the McClellan-Kerr Arkansas River Navigation System in the River and Harbor Act approved July 24, 1946, 
Project Document HD 758, 79th Congress, 2nd Session, and became operational for navigation on December 26, 1970. The structure is a combined earth-filled and concrete gravity dam. The dam is 11,690 $\mathrm{ft}$ long. The spillway is a gated, concrete, ogee weir with a crest elevation of 485.0, with left and right uncontrolled overflow sections. The spillway is $386 \mathrm{ft}$ wide, with a net flow width of $346 \mathrm{ft}$. The left and right uncontrolled overflow sections of the spillway are separated by three 60 by $27-\mathrm{ft}$ Tainter gates with 10 -ft-wide concrete piers. Additionally, the left and right embankments are designed to overflow with lengths of 280 and $2,700 \mathrm{ft}$, respectively. A 24 -ft-wide service bridge was constructed on the piers for access to the lock. The lock has a 110 by $600-\mathrm{ft}$ chamber of the single-lift type with miter gates, a $21-\mathrm{ft}$ normal lift, and a 24-ft maximum lift. (Source: https://www.swt.usace.army.mil/Locations/Tulsa-DistrictLakes/Oklahoma/Chouteau-Lock-and-Dam/Pertinent-

Data/https://www.nae.usace.army.mil/Missions/Civil-Works/Flood-RiskManagement/Massachusetts/Westville/)

\section{C.11 JONESVILLE LOCK \& DAM}

Jonesville Lock \& Dam (coordinates 31 ${ }^{\circ} 28^{\prime} 60.0^{\prime \prime} \mathrm{N} 91^{\circ} 51^{\prime} 42.0^{\prime \prime} \mathrm{W}$ ) is in Catahoula Parish on highway 124 south of Jonesville, Louisiana. The project was authorized under the River and Harbor Act of July 14, 1960 and was completed in 1972 with lock chambers $84 \mathrm{ft}$ wide and $600 \mathrm{ft}$ long having five Tainter gates. This lock and dam is part of the Ouachita-Black Rivers Navigation Project, which began in 1902 and covers $337 \mathrm{mi}$ of waterway from Camden, Arkansas to Jonesville, Louisiana. A lift from 12-30 ft allows a minimum 9-ft deep and 100-ft wide navigation channel needed by barge traffic to travel from the Red River to Camden, Arkansas. (Source: http://wwwsp.dotd.la.gov/Inside LaDOTD/Divisions/Multimodal/Port Priority/Waterway\%20Document s/OMC\%20Navigation\%20Fact\%20Booklet.pdf)

\section{C.12 COL. CHARLES D. MAYNARD LOCK \& DAM}

Col. Charles D. Maynard Lock \& Dam No. 5 (coordinates $34^{\circ} 24^{\prime} 42.0^{\prime \prime} \mathrm{N} 92^{\circ} 06^{\prime} 12.0^{\prime \prime} \mathrm{W}$ ) is on the Arkansas River. Lock \& Dam No. 5 was authorized by the Rivers and Harbors Act Approved July 24, 1946 as part of the McClellan-Kerr Arkansas River Navigation System. Construction began in 1965 and began operating in December 1968. Lock \&Dam No. 5 was renamed the Colonel Charles D. Maynard Lock \&Dam in 2008 by Public Law 110-263. The navigation lock and dam consists of a lock, a gated spillway, and overflow embankments. The spillway is a concrete gravity-type structure about $1,040 \mathrm{ft}$ long. The spillway is controlled by 1531 -ft-high by 60 -ft-wide conventional Tainter gates. Between the spillway gates are 1610 -ft wide piers, which support the Tainter gates. The embankment on the south side extends about $500 \mathrm{ft}$ parallel to the dam and ties into high ground at Elev. 223. The embankment on the left side abuts the lock wall and extends radially about $1,300 \mathrm{ft}$ to high ground. The embankment is designed to overflow when the Pool No. 5 water surface elevation reaches a height greater than Elev. 223. (Source: https://www.govinfo.gov/content/pkg/CRPT-110hrpt229/html/CRPT-110hrpt229.htm)

\section{C.13 GREEN RIVER LOCK \& DAM \#2}

Green River Lock \& Dam (coordinates $37^{\circ} 31^{\prime} 54.0^{\prime \prime} \mathrm{N} 87^{\circ} 15^{\prime} 54.0^{\prime \prime} \mathrm{W}$ ) is $31 \mathrm{mi}$ above the mouth of the Ohio River. Lock \&Dam \#2 were built from 1836 to 1842 and support an 11-mi-long pool of water. The original dam was a timber crib structure, consisting of an outside frame of timbers filled with dirt and rock, and the original lock was stone masonry. The lock was shut down in 2007 because of structural and mechanical problems. (Source: https://finance.ky.gov/offices/kra/Pages/Lock-Dam-2.aspx)

\section{C.14 JENNINGS RANDOLPH LAKE DAM}

Jennings Randolph Lake Dam (coordinates 39²5'58.7"N 7907'18.2"W ) (previously known as Bloomington Lake Dam) is on the North Branch of the Potomac River near the towns of Barnum, West Virginia and Swanton, Maryland. It was completed in 1985 by the US Army Corps of Engineers. The dam consists of a rolled-earth rock-fill embankment about 2,130 ft long, with a crest elevation of 1,514 ft above mean sea level (ft msl). The dam crest width is $25 \mathrm{ft}$ and approximately $296 \mathrm{ft}$ above the former 
streambed. The outlet works consist of a 16.33-ft-diameter, 1,920-ft-long concrete-lined tunnel under the dam's south embankment that discharges into a stilling basin. A 332-ft-high intake tower at the upstream end of the tunnel and 1,080 ft upstream of the dam includes ports at five different elevations. Water drawn from various depths is mixed in the intake tower and then passed through the two low-flow gates into the tunnel. An emergency spillway consisting of a chute about $210 \mathrm{ft}$ long with a crest elevation of 1,468 ft $\mathrm{msl}$ is near the east end of the dam's north embankment. The spillway is equipped with five Tainter gates and discharges to the North Branch downstream from the stilling basin. At the typical summer pool elevation of 1,466 ft msl, the reservoir extends about $3 \mathrm{mi}$ up the North Branch and covers an area of 918 acres with a normal storage of about 88,226 acre-ft. It is a multipurpose project and provides water quality control, flood control, water supply, and recreation. (Source:

http://www.advancedhydrosolutions.com/Jennings.html)

\section{C.15 MISSISSIPPI RIVER LOCK \& DAM \#7}

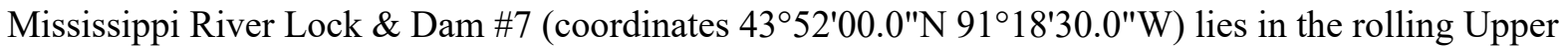
Mississippi River Valley near the communities of La Crescent, Minnesota, and La Crosse, Wisconsin. The dam consists of a concrete structure $940 \mathrm{ft}$ long, 5 roller gates, and 11 Tainter gates, with two segments of earth embankment 8,100 ft long from the dam to French Island with a 1,000 $\mathrm{ft}$ long and 2,400 ft long from French Island to Onalaska, Wisconsin, with a $670 \mathrm{ft}$ long concrete spillway. . The lock is $110 \mathrm{ft}$ wide by $600 \mathrm{ft}$ long. The US Army Corps of Engineers completed the facility in 1935 as part of the overall 9-foot channel project. In 1989, after more than 60 years of service, the US Army Corps of Engineers undertook a major rehabilitation effort to replace much of the operating equipment and to construct a new control building to provide reliable service to navigation customers. (Source: https://www.mvp.usace.army.mil/Missions/Navigation/Locks-Dams/Lock-Dam-7/)

\section{C.16 MISSISSIPPI RIVER LOCK \& DAM \#24}

Mississippi River Lock \& Dam \#24 (coordinates 39²2'44.6"N 9054'03.9"W) is on the Mississippi River, near Clarksville in Pike County, Missouri and Calhoun County, Illinois. Lock and Dam 24 was the first dam on the Upper Mississippi River 9-ft Channel Project constructed without roller gates. It was designed with the highest level of Tainter gate technology available and incorporated 1580 -ft-long, fully submersible Tainter gates into the 1,340-ft-long dam. These Tainter gates were innovative in that they rendered roller gate technology - the principle engineering feature in dam construction at the timeobsolete. Having opened on May 12, 1940, Lock and Dam \#24 has well exceeded its 50-year design life and is currently undergoing major rehabilitation. (Source:

https://www.mvs.usace.army.mil/Missions/Navigation/Locks-and-Dams/Lock-Dam-24/)

\section{C.17 JOHN OVERTON LOCK \& DAM}

John Overton Lock \& Dam (coordinates $31^{\circ} 11^{\prime} 13.1^{\prime \prime N} 92^{\circ} 17^{\prime} 34.4^{\prime \prime} \mathrm{W}$ ) in Louisiana is one of five locks and dams on the Red River that are part of the J. Bennett Johnston Waterway, which was authorized by Congress in 1968 to stabilize river banks, straighten river bends, and maintain a 9-ft-deep, 200-ft-wide channel for boat traffic. Overton Lock and Dam consists of a 104-ft-high by 914-ft-long concrete gravity dam with five 60 -foot-wide Tainter gates and an 84 -ft-wide by 685 -ft-long navigation lock. The reservoir above the dam is commonly referred to as "Pool 2" and is maintained by the US Army Corps of Engineers at an elevation of $64 \mathrm{ft}$ NGVD, with a surface area of approximately 3,750 acres and a storage capacity of about 67,500 acre-ft. Two main recreation sites exist within close proximity to Overton Lock and Dam. These are the Poland Recreation Area, which is less than $1 \mathrm{mi}$ west of the dam, and the John H. Overton Lock and Dam West Recreation Area, which is directly adjacent to the area where the proposed project would be constructed. (Source: https://www.transmissionhub.com/articles/2013/06/ferc-seekscomment-on-78-mw-red-river-hydro-project-in-la.html)

\section{C.18 MISSISSIPPI RIVER LOCK \& DAM \#16}


Mississippi River Lock \& Dam \#16 (coordinates $41^{\circ} 25^{\prime} 30.0^{\prime \prime} \mathrm{N} 91^{\circ} 00^{\prime} 36.7^{\prime \prime} \mathrm{W}$ ) is about 1 mi upstream from Muscatine, Iowa, and $457.2 \mathrm{mi}$ above the confluence of the Mississippi and Ohio Rivers. The complex stretches across the river at a point where the valley is wide. The earthen embankment section of the dam straddles portions of Hog Island in the main channel. The lock dimensions are $110 \mathrm{ft}$ wide by 600 $\mathrm{ft}$ long with additional provisions for an auxiliary lock. The maximum lift is $9 \mathrm{ft}$ with an average lift of $6.5 \mathrm{ft}$. Filling or emptying the lock chamber takes approximately $7 \mathrm{~min}$. The movable dam has 12 nonsubmersible Tainter gates ( $20 \mathrm{ft}$ high and $40 \mathrm{ft}$ long), three submersible Tainter gates of the same dimensions, and four non-submersible roller gates (20 ft high and $80 \mathrm{ft}$ long). The dam system also includes a linear, concrete-capped, ogee spillway, and a submersible earth- and sand-filled dike. Water takes 8 hours to travel from Lock \& Dam \#15 in Davenport, Iowa, to Lock \& Dam \#16. (Source: https:/usace.contentdm.oclc.org/utils/getfile/collection/p16021coll11/id/2992)

\section{C.19 MISSISSIPPI RIVER LOCK \& DAM \#21}

Mississippi River Lock \& Dam \#21 (coordinates 39 $54^{\prime} 10.8^{\prime \prime} \mathrm{N} 91^{\circ} 25^{\prime} 43.7^{\prime \prime} \mathrm{W}$ ) is $324.9 \mathrm{mi}$ above the confluence of the Mississippi and Ohio Rivers. The complex stretches across the river at a point where the valley is wide with flat bottom land on either side of the river. The city of Quincy, Illinois lies on the low bluffs along the river just upstream from the complex. Lock dimensions are $110 \mathrm{ft}$ wide by $600 \mathrm{ft}$ long with provisions for an auxiliary lock. The maximum lift is $10.5 \mathrm{ft}$ with an average lift of $6.55 \mathrm{ft}$. Filling or emptying the lock chamber takes approximately $7 \mathrm{~min}$. The movable dam has 10 submersible, elliptical Tainter gates ( $20 \mathrm{ft}$ high by $64 \mathrm{ft}$ long) and three submersible roller gates ( $20 \mathrm{ft}$ high by $100 \mathrm{ft}$ long). The dam system also includes two earth- and sand-filled transitional dikes, and a submersible earth dike. Water takes 5 hours to travel from Lock and Dam \#20 in Canton, Missouri, to Lock and Dam \#21. (Source: https://usace.contentdm.oclc.org/utils/getfile/collection/p16021coll11/id/2972)

\section{C.20 WACO LAKE DAM}

Waco Lake Dam \#21 (coordinates 31 $35^{\prime} 32.7^{\prime \prime} \mathrm{N} 97^{\circ} 12^{\prime} 41.0^{\prime \prime} \mathrm{W}$ ) is in the southeastern portion of the Bosque River Watershed, Brazos River Basin, entirely within McLennan County, Texas and to the north and west of the city of Waco, Texas. The project was authorized for construction under the Flood Control Act approved September 3, 1954. The Waco Lake project was constructed by the US Army Corps of Engineers and is operated under the immediate supervision of the District Engineer, Fort Worth District. Construction of the lake began in June 1958, and deliberate impoundment of water began February 1965. The dam is an earth-fill embankment, with a concrete outlet works in the upstream side and a concrete gate-controlled spillway in the left abutment. The overall length of the dam, including the spillway, is $24,618 \mathrm{ft}$. Its maximum height is $140 \mathrm{ft}$ above the streambed. The dam is constructed of selected soils, carefully placed and compacted. It is protected from wave action by $24 \mathrm{in}$. of riprap placed on the upstream face. (Source: https://www.swf-wc.usace.army.mil/waco/information/index.asp) 


\section{APPENDIX D. BASELINE GENERATION AND EFFICIENCY PROFILES}

\section{D.1 JENNINGS RANDOLPH LAKE DAM}

JenningsRandolph Site
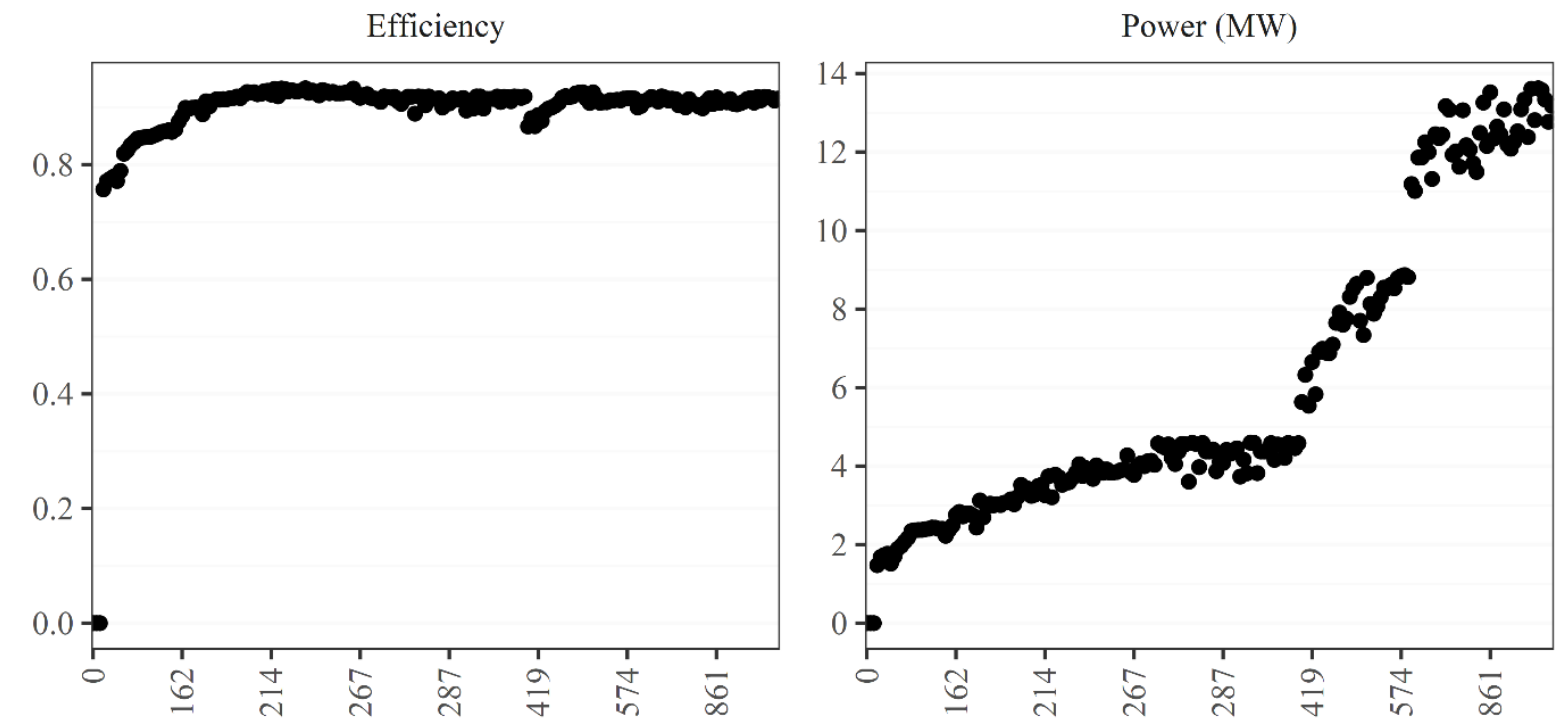

Plant Operating Flow (cfs)

\section{D.2 CAVE RUN LAKE DAM}

CaveRun Site
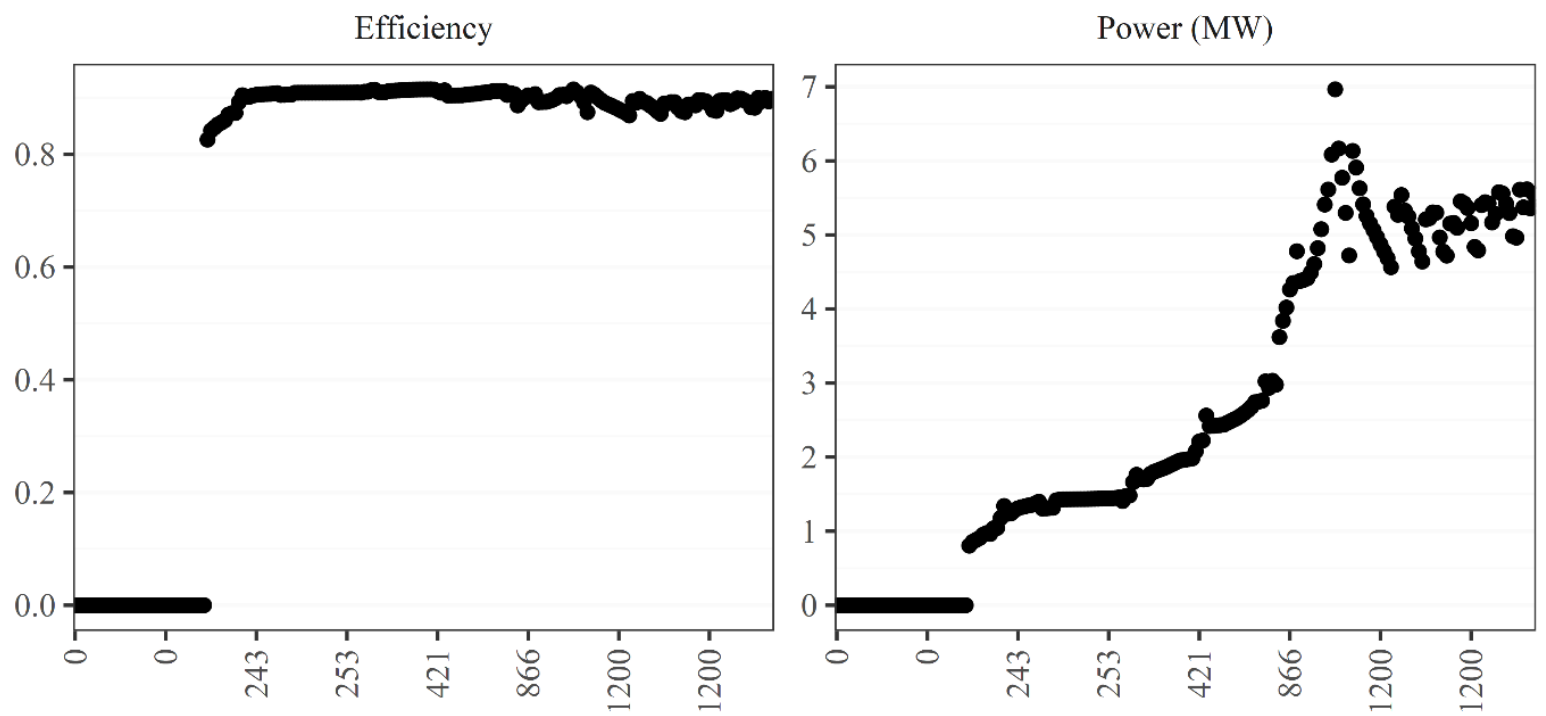

Plant Operating Flow (cfs) 


\section{D.3 TIOGA LAKE DAM}

Tioga Site
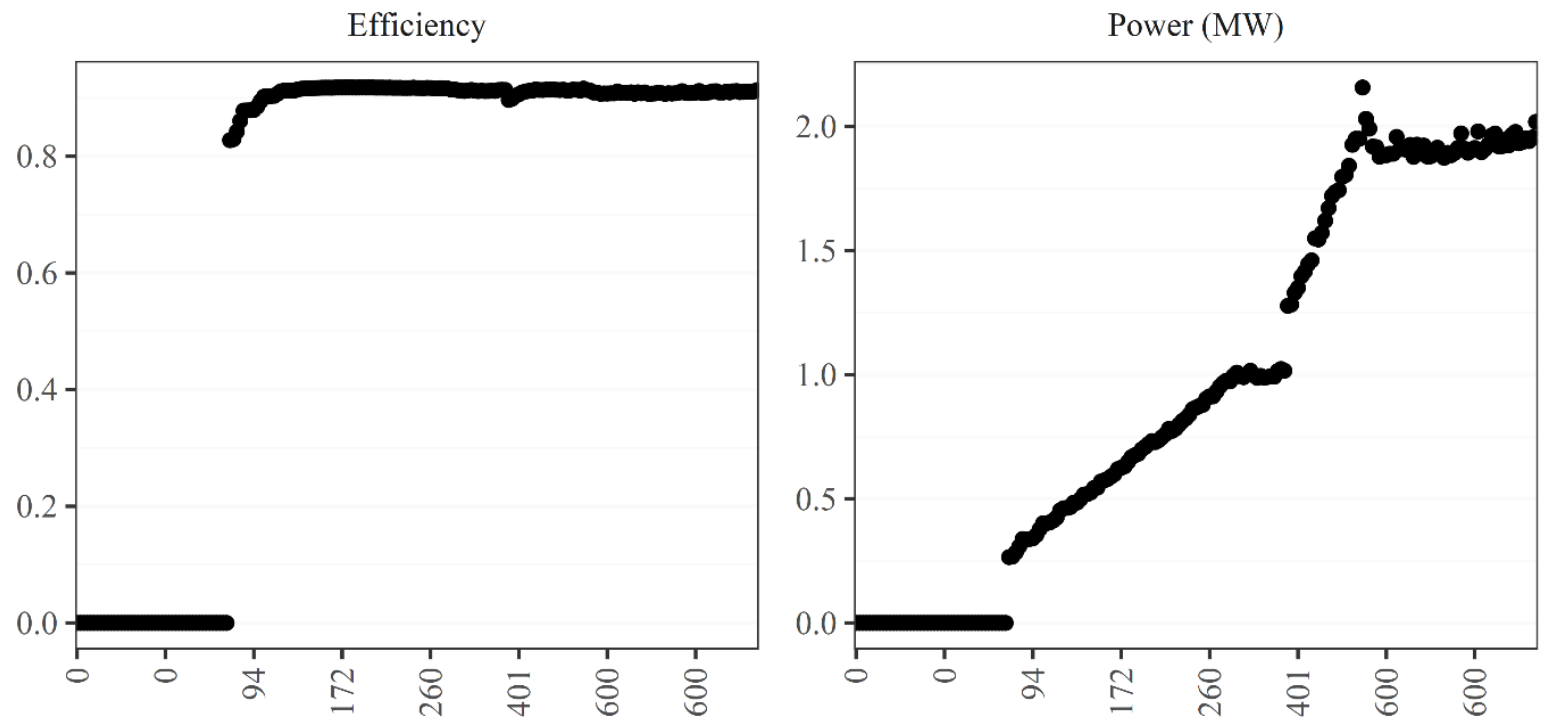

Plant Operating Flow (cfs)

\section{D.4 R. D. BAILEY LAKE DAM}

RDBailey Site
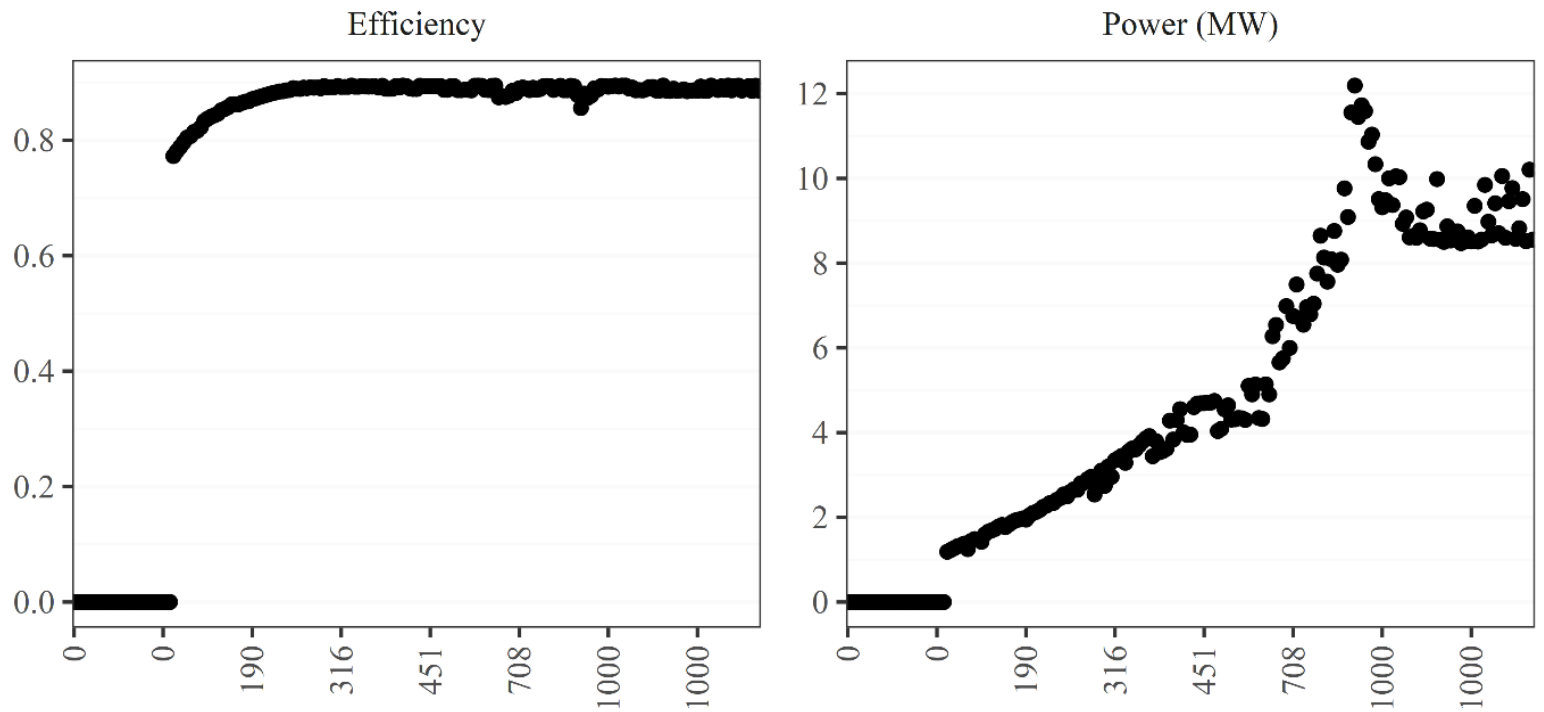

Plant Operating Flow (cfs) 


\section{D.5 DILLON LAKE DAM}

Dillon Site
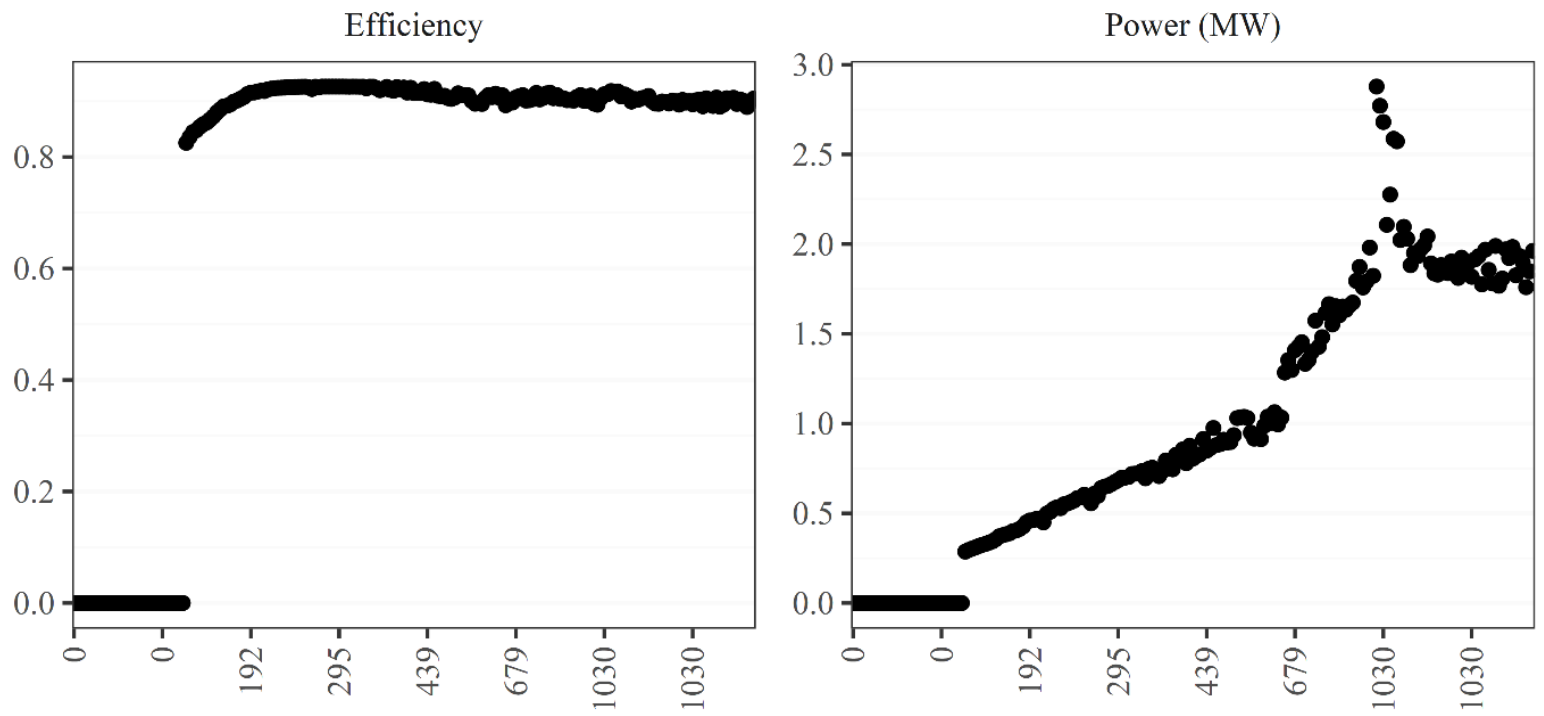

Plant Operating Flow (cfs)

\section{D.6 TAR RIVER LAKE DAM}

TarRiver Site
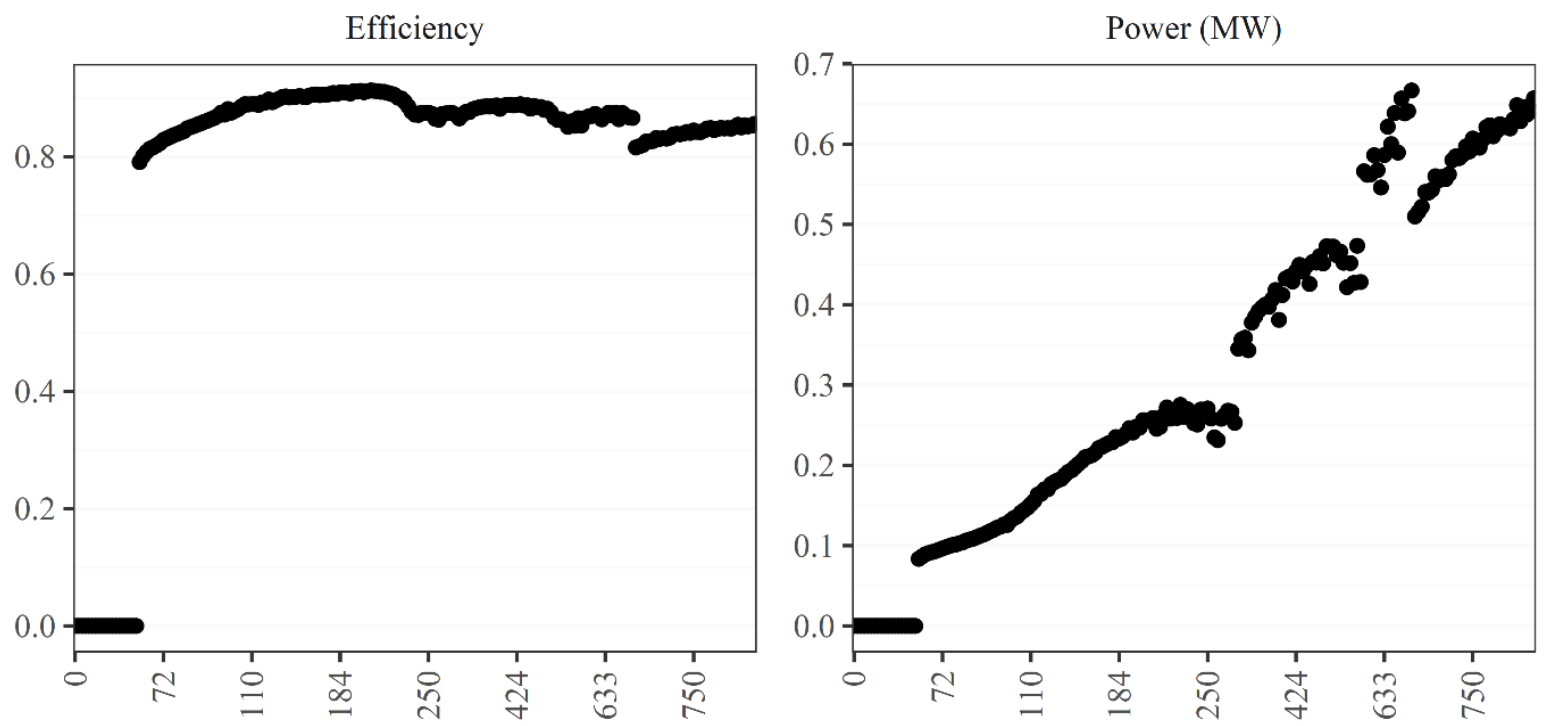

Plant Operating Flow (cfs) 


\section{D.7 EAST SIDNEY LAKE DAM}

EastSidney Site
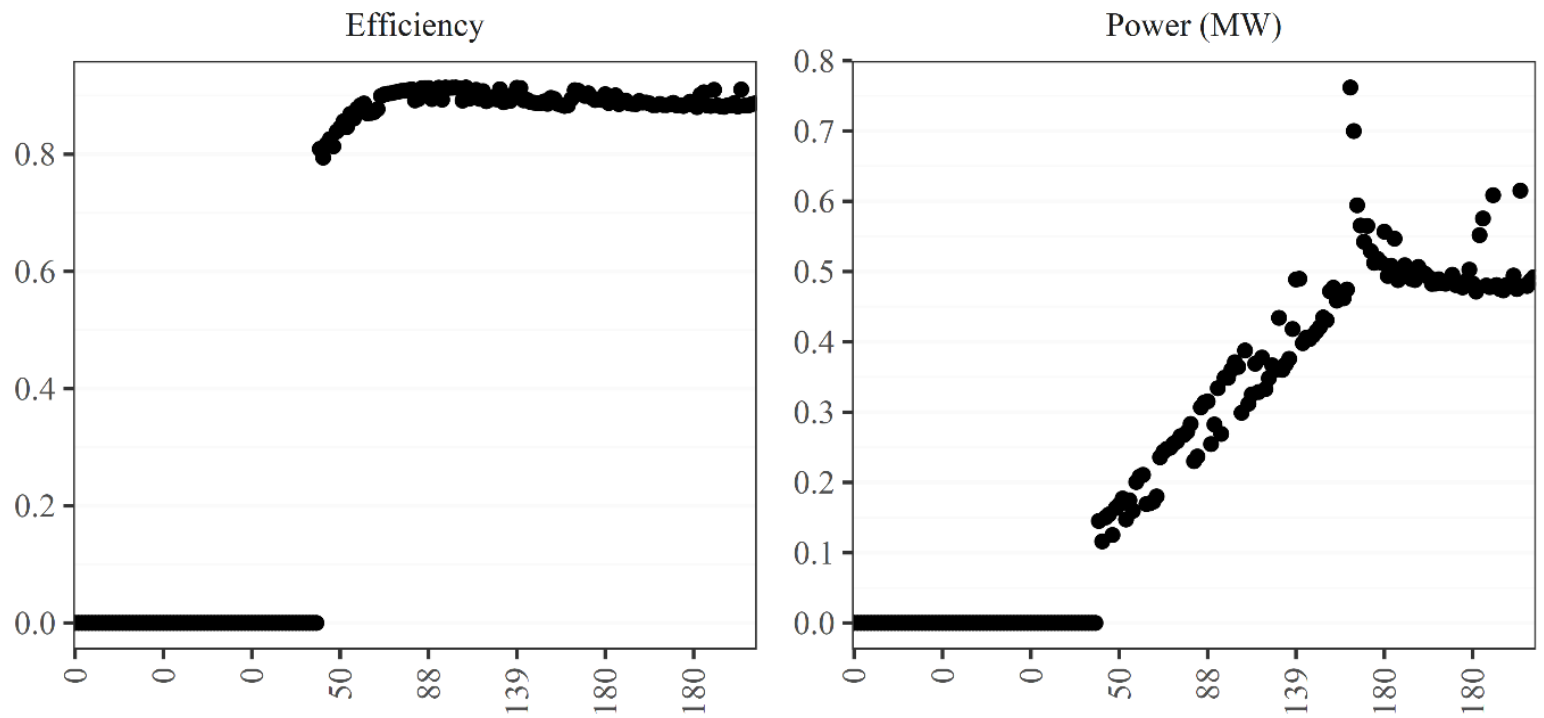

Plant Operating Flow (cfs)

\section{D.8 CROOKED CREEK LAKE DAM}

CrookedCrk Site
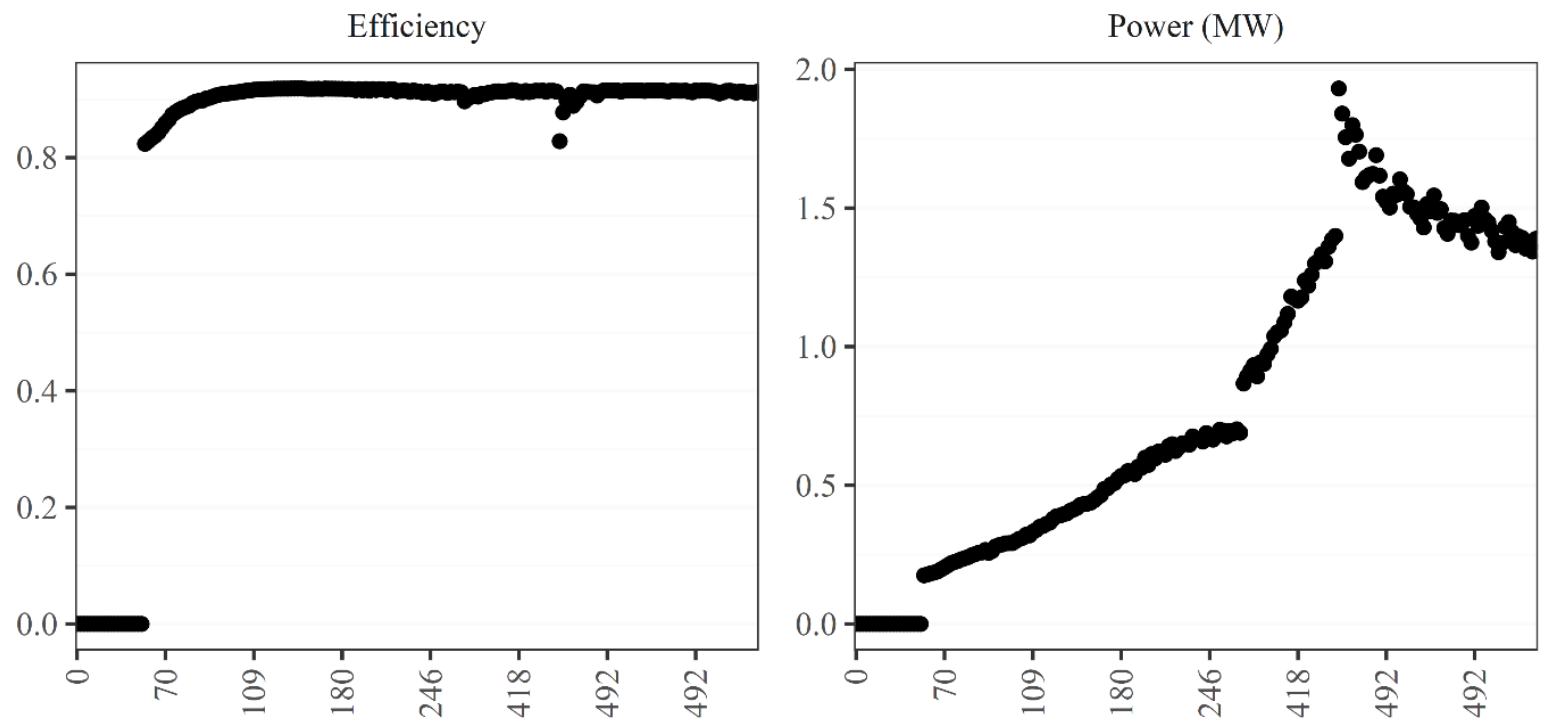

Plant Operating Flow (cfs) 


\section{D.9 COWANESQUE LAKE DAM}

Cowanesque Site
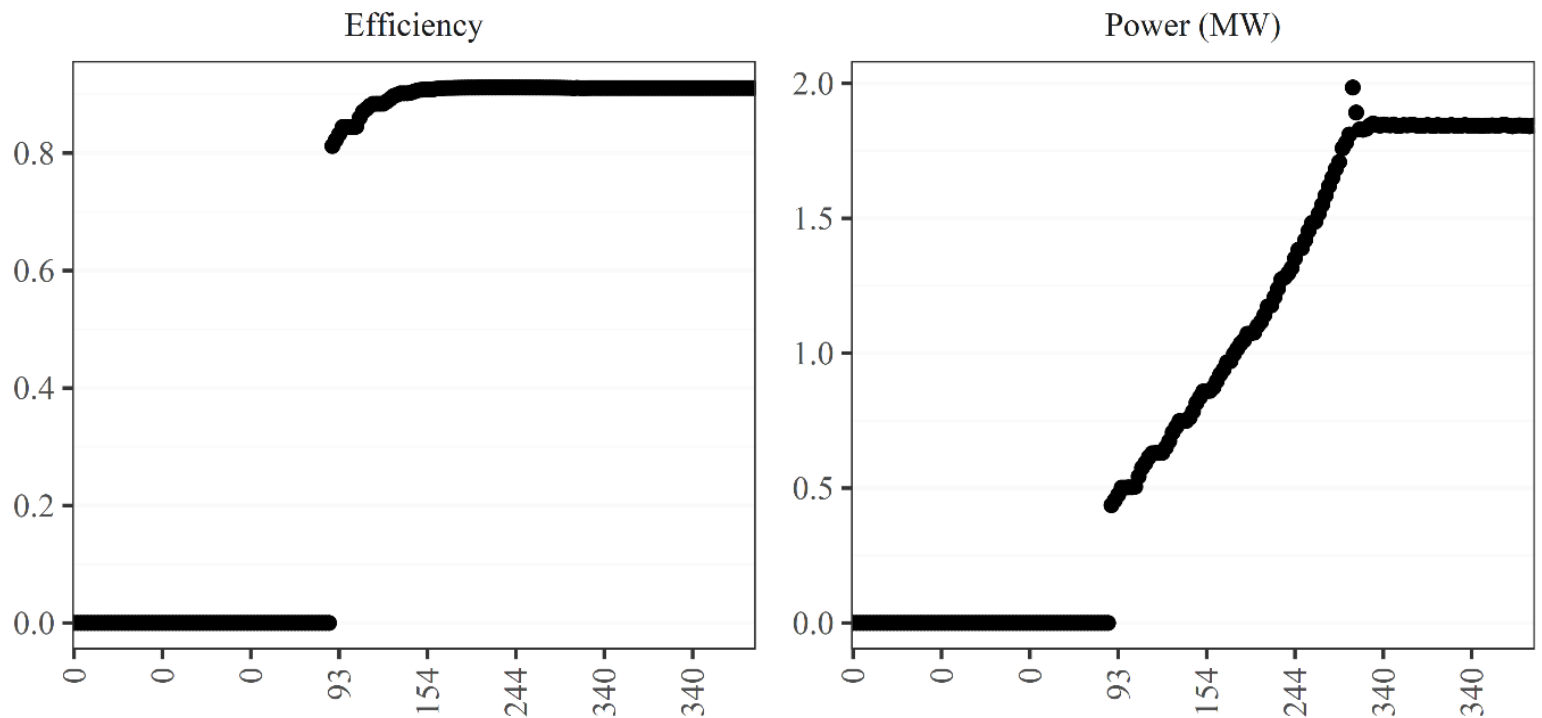

Plant Operating Flow (cfs)

\section{D.10 WILLIAM HARSHA LAKE DAM}

Harsha Site
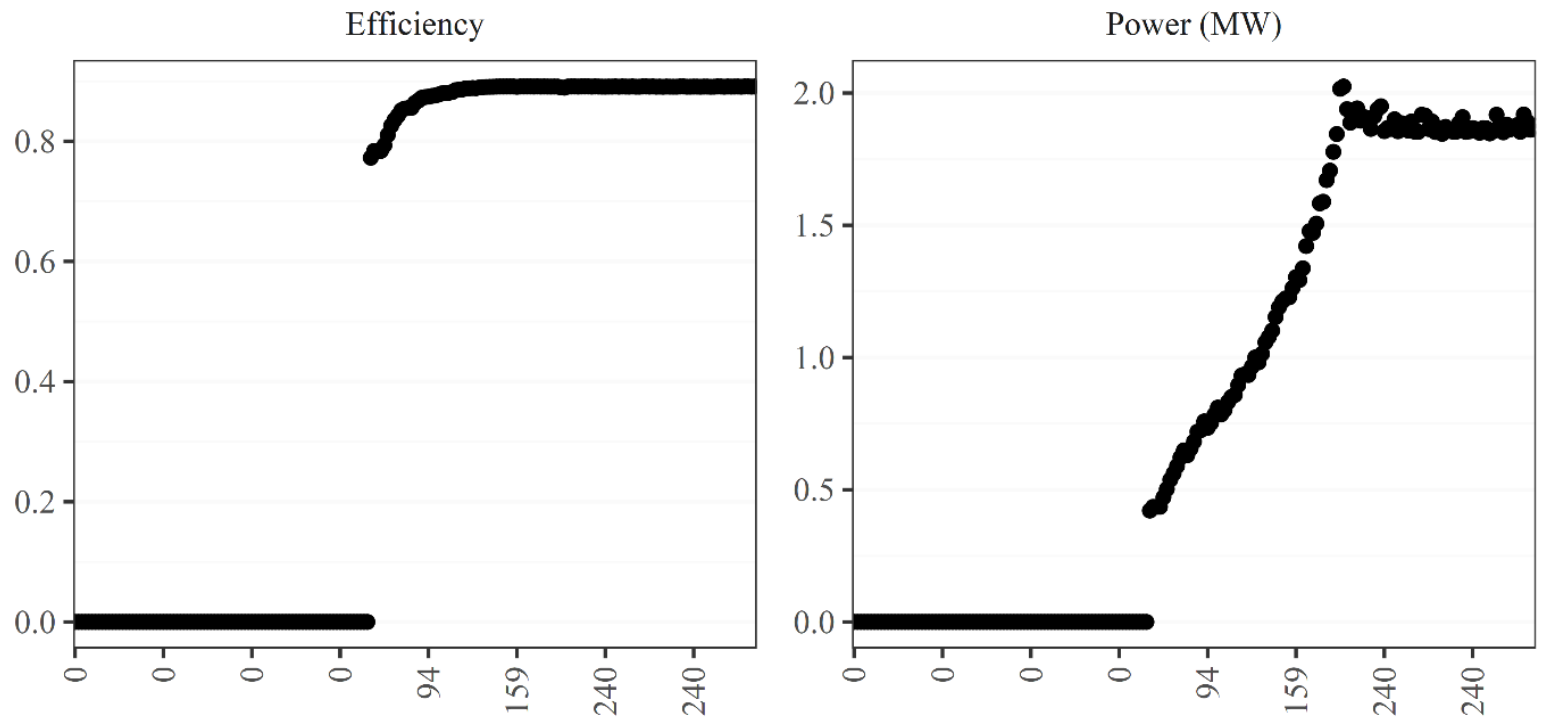

Plant Operating Flow (cfs) 


\section{D.11 MONROE LAKE DAM}

Monroe Site
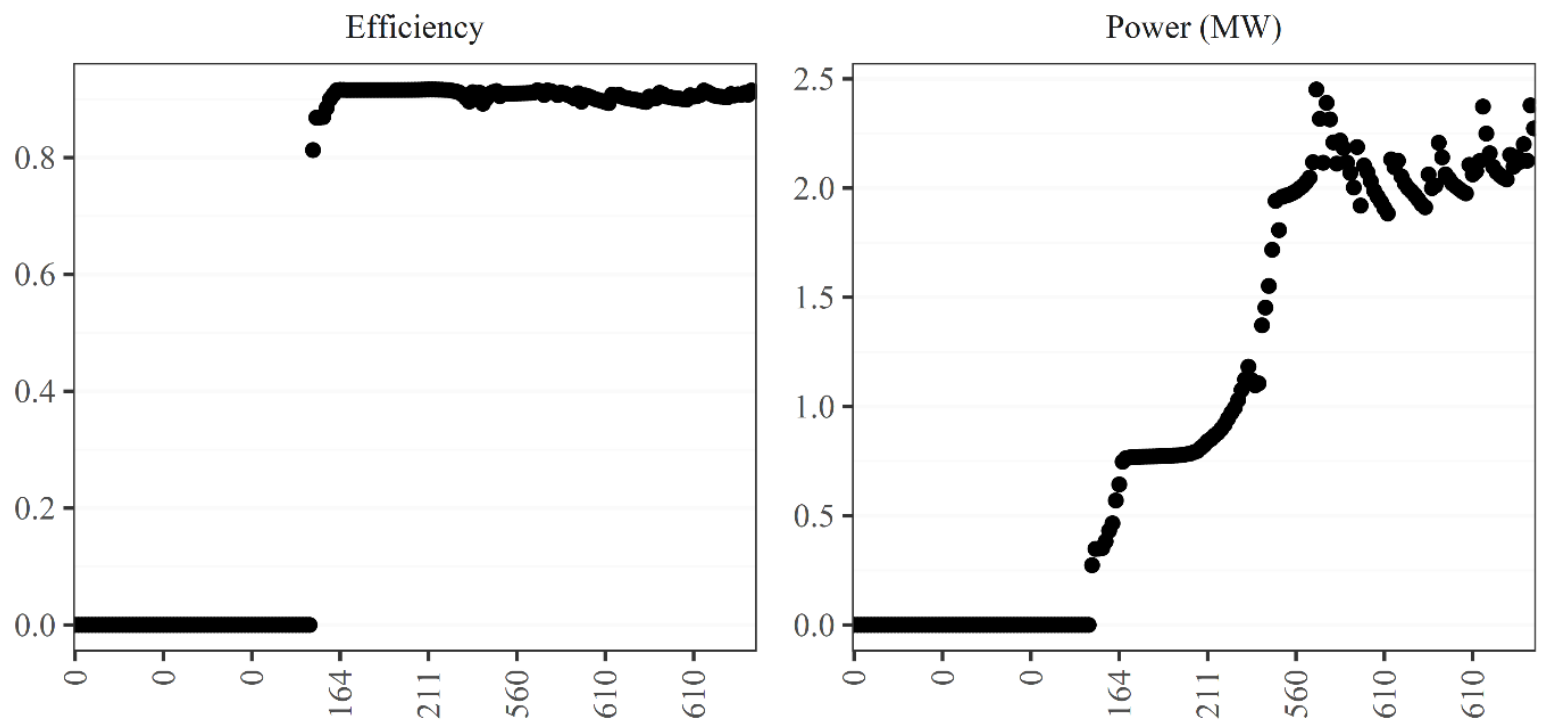

Plant Operating Flow (cfs)

\section{D.12 LAKE O' THE PINES DAM}

Pines Site
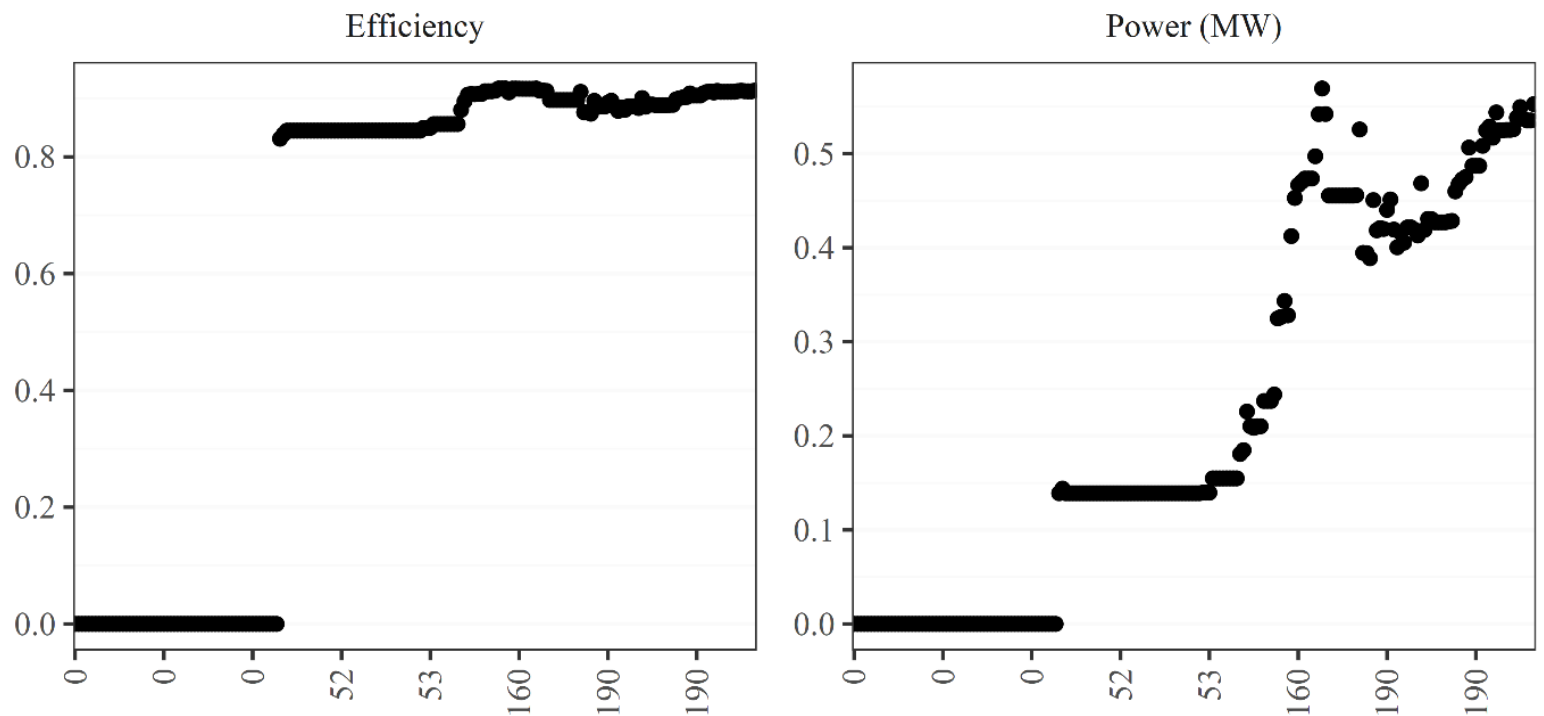

Plant Operating Flow (cfs) 


\section{D.13 WESTVILLE LAKE DAM}

WestVille Site
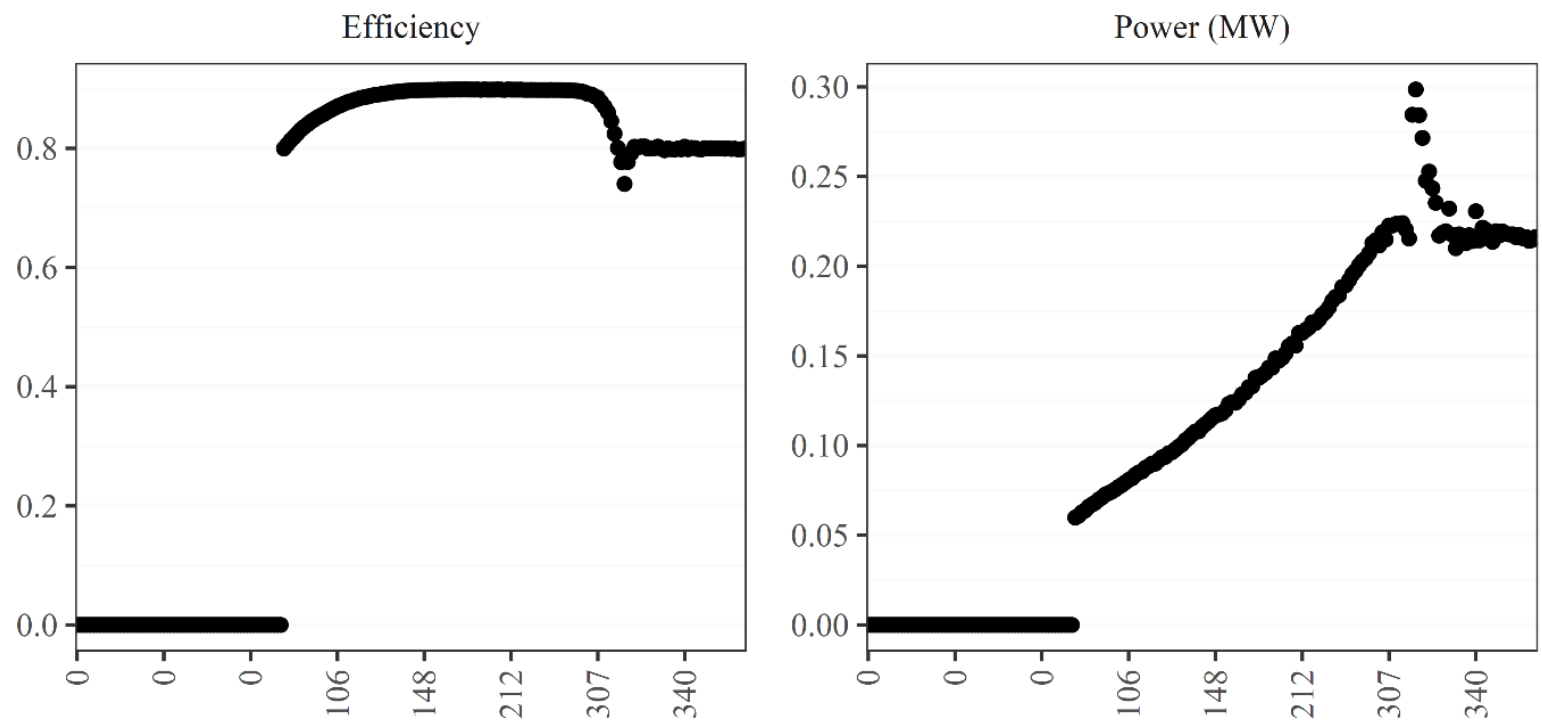

Plant Operating Flow (cfs)

\section{D.14 MISSISSIPPI LOCK DAM \#14}

MissLD14 Site
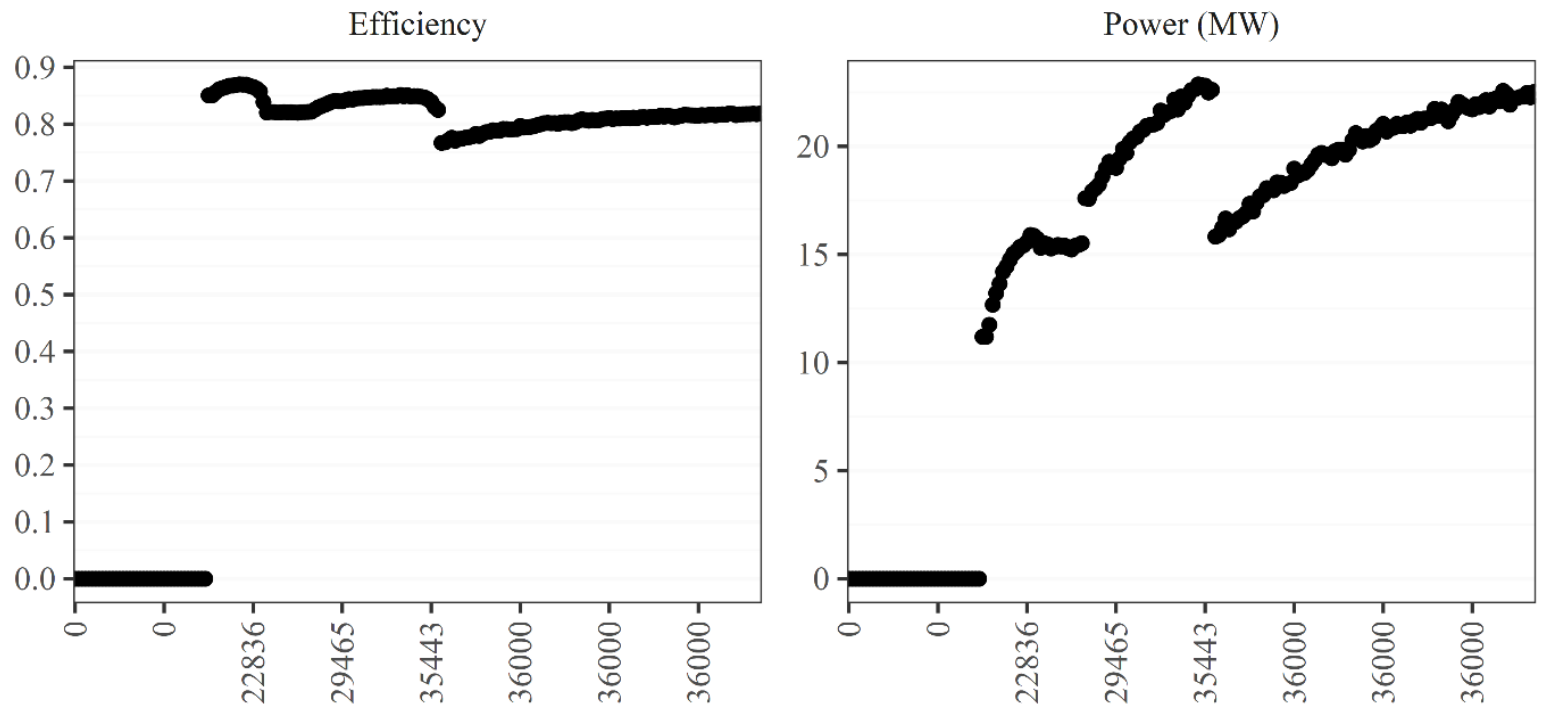

Plant Operating Flow (cfs) 


\section{D.15 MISSISSIPPI LOCK DAM \#24}

LD24 Site
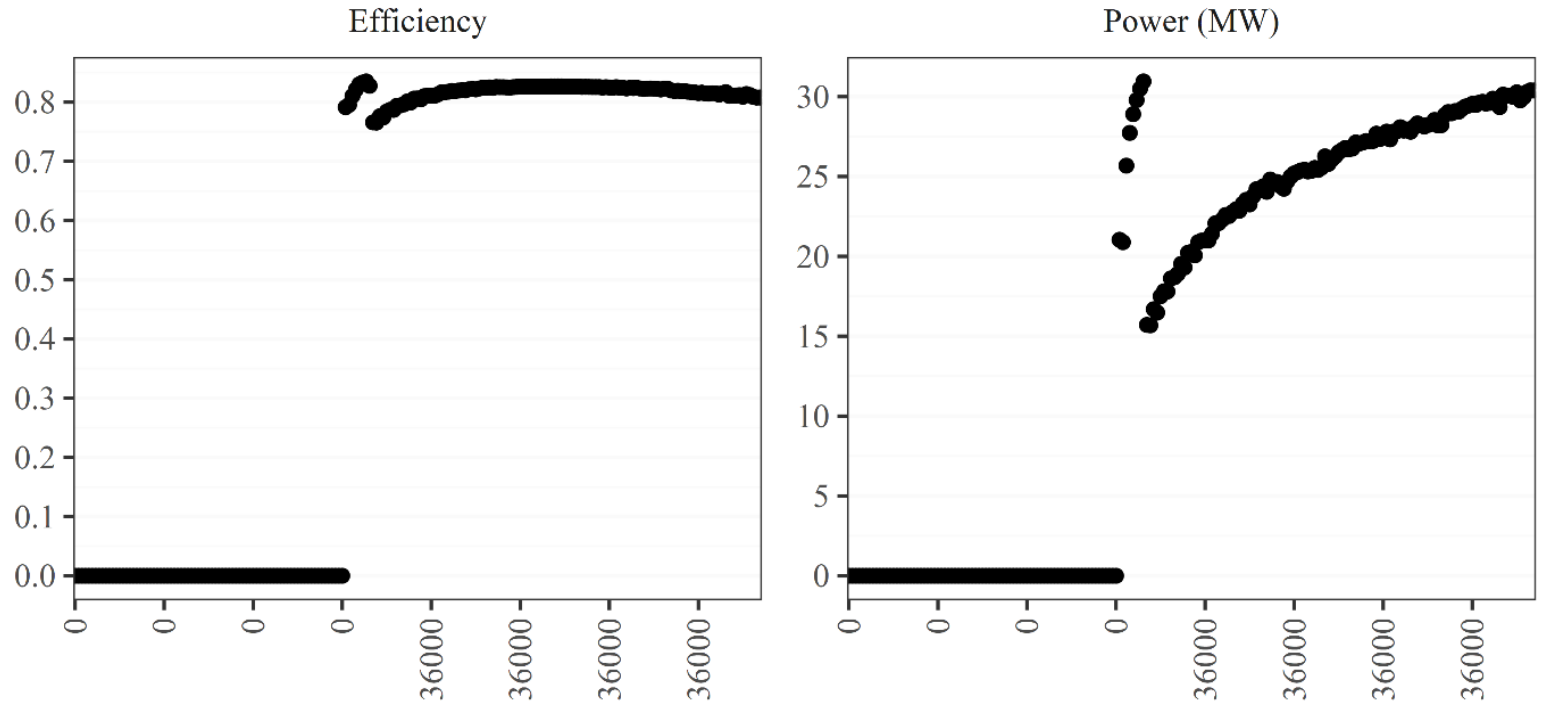

Plant Operating Flow (cfs)

\section{D.16 JOHN OVERTON LOCK DAM}

Overton Site
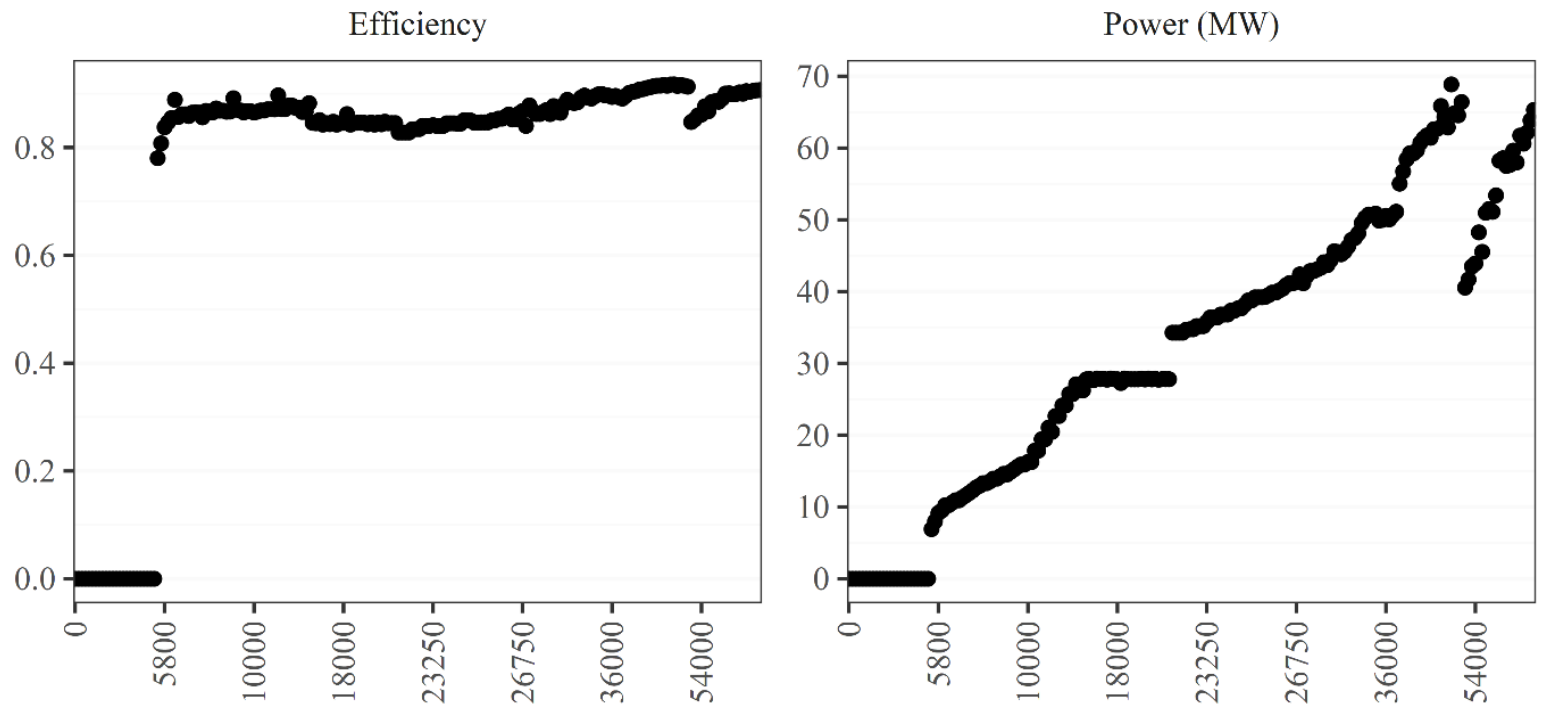

Plant Operating Flow (cfs) 


\section{D.17 CHOUTEAU LOCK DAM}

Chouteau Site
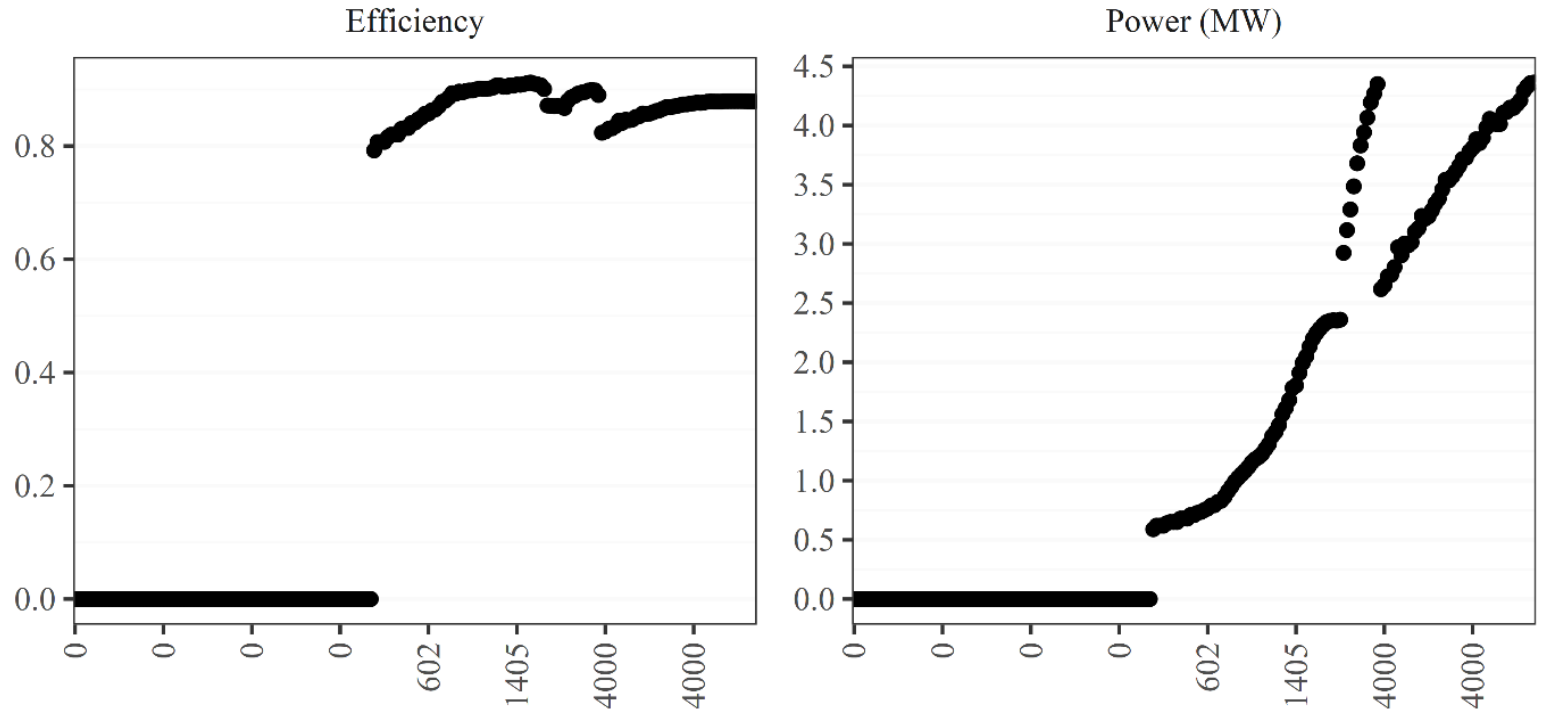

Plant Operating Flow (cfs)

\section{D.18 MAYNARD LOCK DAM}

Maynard Site
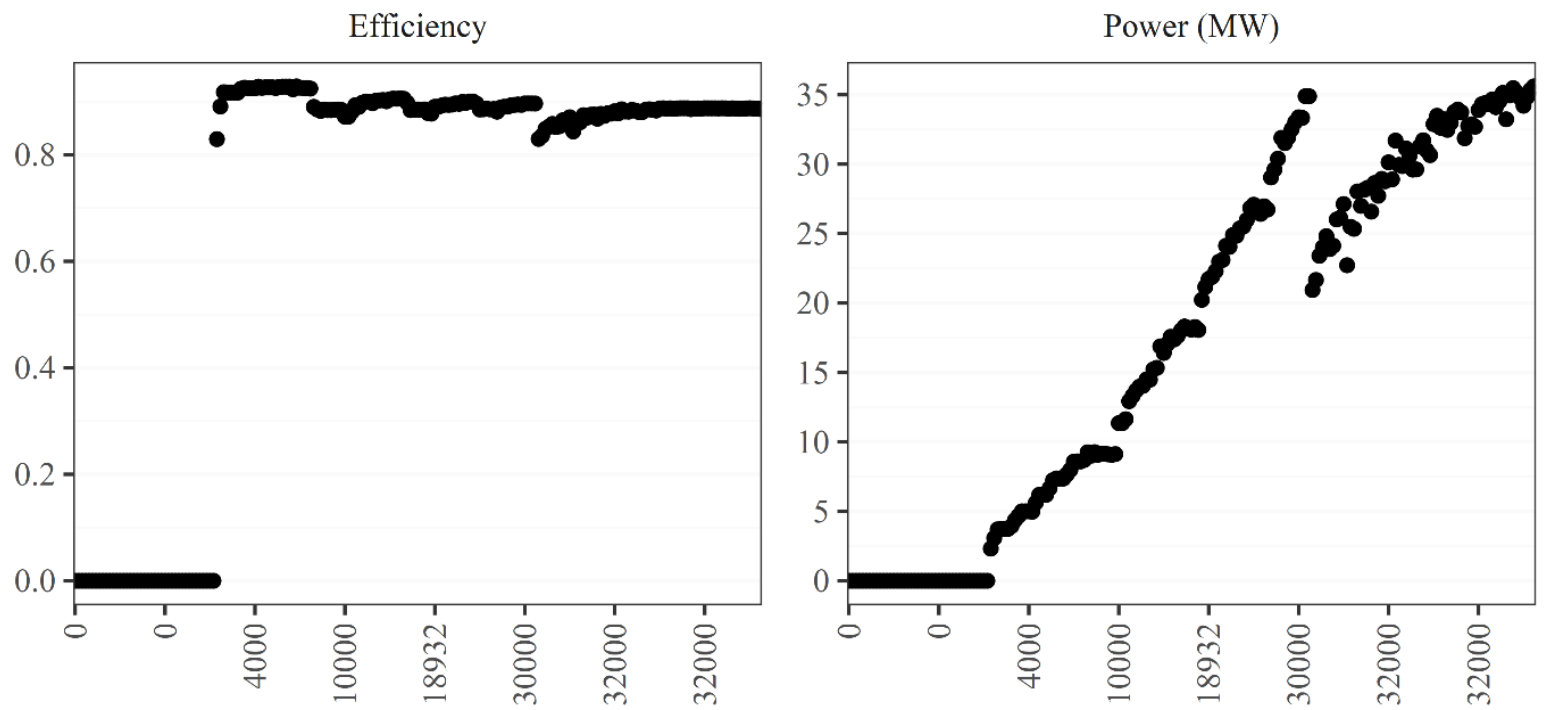

Plant Operating Flow (cfs) 


\section{D.19 JONESVILLE LOCK DAM}

Jonesville Site
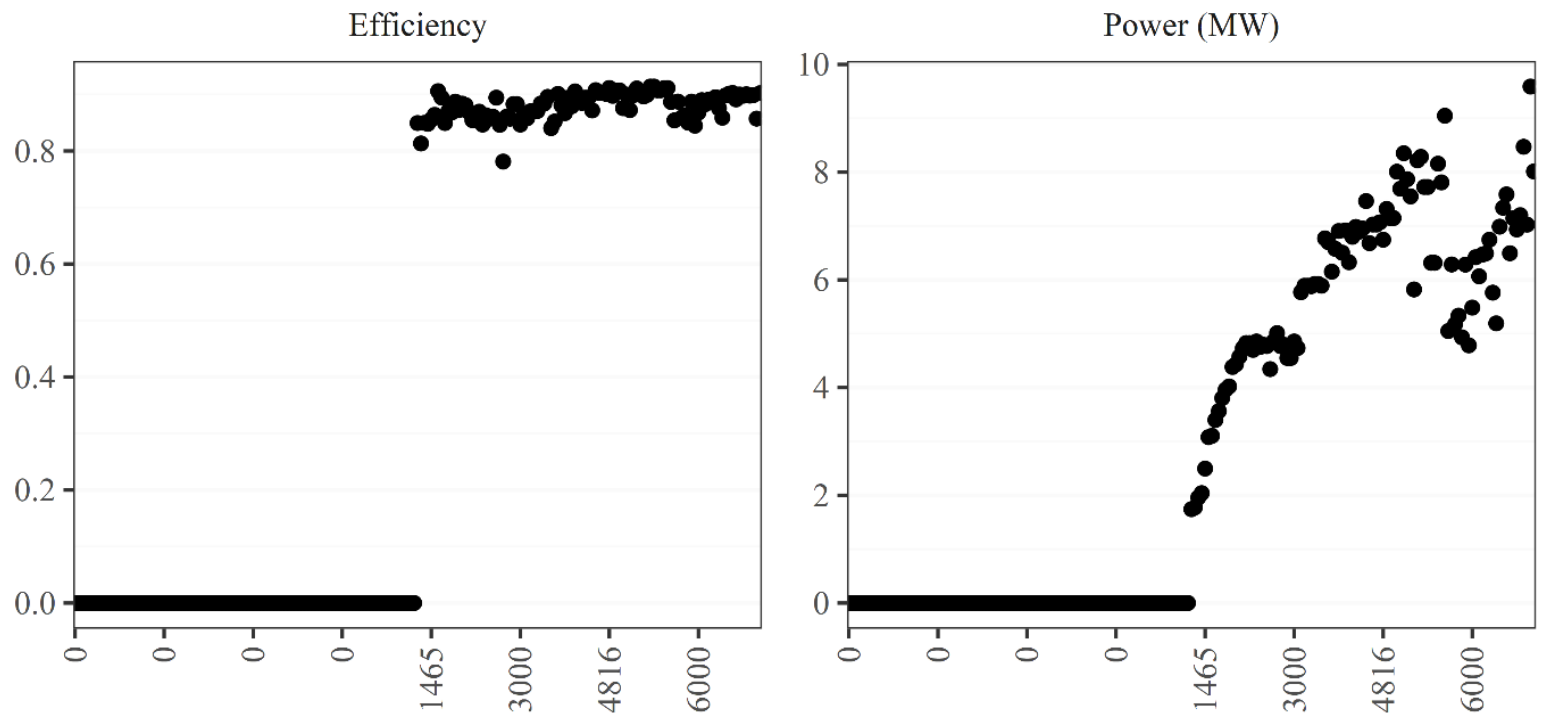

Plant Operating Flow (cfs) 